Universidade De São Paulo

Faculdade de Filosofia, Ciências e Letras de Ribeirão Preto Pós-Graduação em Física Aplicada à Medicina e Biologia

\title{
Atividade, transição de fase e efeito de mídia em um modelo sociocultural
}

Sandro Martinelli Reia

Ribeirão Preto - SP

2015 


\section{SANDRO MARTINELLI REIA}

\section{Atividade, transição de fase e efeito de mídia em um modelo sociocultural}

Versão corrigida

Tese apresentada à Faculdade de Filosofia, Ciências e Letras de Ribeirão Preto da Universidade de São Paulo, como parte das exigências para a obtenção do título de Doutor em Ciências.

Área de Concentração:

Física Aplicada à Medicina e Biologia.

Orientador:

Ubiraci Pereira da Costa Neves

Ribeirão Preto - SP

2015 
AUTORIZO A REPRODUÇÃO E DIVULGAÇÃO TOTAL OU PARCIAL DESTE TRABALHO, POR QUALQUER MEIO CONVENCIONAL OU ELETRÔNICO, PARA FINS DE ESTUDO E PESQUISA, DESDE QUE CITADA A FONTE.

Reia, Sandro Martinelli.

Atividade, transição de fase e efeito de mídia em um modelo sociocultural/ Sandro Martinelli Reia; orientador Ubiraci Pereira da Costa Neves. Ribeirão Preto, 2015. 131 p.

Tese (Doutorado - Programa de Pós-Graduação em Física Aplicada à Medicina e Biologia) - Faculdade de Filosofia, Ciências e Letras de Ribeirão Preto da Universidade de São Paulo.

1. Modelo de Axelrod 2. Dinâmica Social 3. Sistemas Complexos

4. Transição de Fase 


\section{Agradecimentos}

Esta tese é resultado de 4 anos de trabalho no Departamento de Física da Faculdade de Filosofia, Ciências e Letras de Ribeirão Preto que pertence à Universidade de São Paulo. Neste período, as interações com docentes, funcionários e alunos do Programa de Pós-Graduação em Física Aplicada à Medicina e Biologia foram essenciais para a minha formação.

Nesse sentido, agradeço aos professores Alexandre Souto Martinez, Antônio Caliri, Antonio Carlos Roque da Silva Filho, Eder Rezende Moraes, Marco Antonio Alves da Silva, Nelson Augusto Alves, Osame Kinouchi Filho, Oswaldo Baffa Filho e Ubiraci Pereira da Costa Neves pelos cursos ministrados.

Agradeço aos funcionários do departamento André Luiz Girol, José Luiz Aziani, Julio Cezar, Nilza Marina Leone Marino e Ricardo Gastaldi Ferreira dos Santos por todos os tipos de apoio e suporte oferecidos.

Agradeço o apoio financeiro da CAPES.

Agradeço ao prof. Nelson A. Alves pelo uso do cluster de computadores e ao prof. Osame Kinouchi pela disponibilização do computador em seu laboratório.

Faço um agradecimento especial ao prof. Ubiraci P. C. Neves pela orientação, pelas supervisões nos dois estágios realizados através do programa PAE na disciplina de Física Matemática e pela colaboração em todo o trabalho realizado.

Agradeço a todos os meus amigos, em especial Márcio Fernando Cobo, Mairon Marques dos Santos e Tiago Bueno de Moraes, pelas conversas ocasionais.

Agradeço também a Ariadne de Andrade Costa pela convivência, ajuda e influência positiva na determinação para resolver problemas. Agradeço a Sra. Célia e ao Sr. Jorge pela hospitalidade de sempre.

Por fim, agradeço ao meu pai, a minha mãe, ao meu irmão, a minha avó e as pests pelo convívio e por tudo mais ao longo desses anos. 


\title{
Resumo
}

\author{
REIA, S. M. Atividade, transição de fase e efeito de mídia em um modelo
} sociocultural. 131 p. Tese (Doutorado) - Faculdade de Filosofia, Ciências e Letras de Ribeirão Preto, Universidade de São Paulo, Ribeirão Preto, 2015.

A existência de opiniões distintas em uma sociedade na qual indivíduos interagem constantemente atraiu o interesse de cientistas sociais e físicos estatísticos. Em 1997, Robert Axelrod propôs um modelo vetorial para o estudo da formação de domínios culturais diferentes em uma rede de agentes interagentes. Nesse modelo, os agentes são representados por um vetor de $F$ componentes em que cada componente assume um dentre $Q$ estados inteiros. O modelo apresenta uma transição de um estado monocultural (ordenado) para um estado multicultural (desordenado) que tem sido estudada na literatura através de parâmetros de ordem tais como o tamanho relativo do maior domínio cultural $(S)$ e a fração de domínios culturais diferentes $(g)$. Desde então, propriedades como robustez à introdução de ruídos, à variação de topologia e à introdução de campos local, global e externo foram investigadas. Nosso trabalho está organizado em três partes principais. Na primeira, apresentamos a proposta de novas medidas baseadas no conceito de atividade por agente para o estudo do modelo de Axelrod na rede quadrada. Mostramos que a variância da atividade do sistema $(A)$ pode ser usada para indicar os pontos de transição e que sua distribuição de frequência pode indicar a ordem da transição. Na segunda, estimamos o diagrama de fases no plano $(F, Q)$ e comparamos resultados obtidos em redes com condição de contorno aberta e fechada. Para isso, utilizamos as susceptibilidades dos parâmetros de ordem $S$ e $A$ para determinar os valores críticos $Q_{c}(F)$ para alguns valores de $F$. $\mathrm{Na}$ terceira, analisamos a formação de domínios culturais com a introdução de agentes persistentes para modelar efeitos de mídia interna. Nossos resultados revelam 
uma dependência de $Q_{c}$ com a probabilidade de ocupação $p$ de agentes persistentes que nos permite obter o diagrama de fases no plano $(p, Q)$. Interpretamos a linha crítica como resultado da competição de duas forças opostas (denominadas efeito de barreira e efeito de ligação) causadas por agentes não-persistentes que aderem aos persistentes.

Palavras-chave: 1. Modelo de Axelrod 2. Dinâmica Social 3. Sistemas Complexos 4. Transição de Fase 


\section{Abstract}

REIA, S. M. Activity, phase transition and media effect in a sociocultural model. 131 p. Thesis (Ph.D.) - Faculdade de Filosofia, Ciências e Letras de Ribeirão Preto, Universidade de São Paulo, Ribeirão Preto, 2015.

The existence of different opinions in a society where individuals constantly interact has attracted the interest of social scientists and statistical physicists. In 1997, Robert Axelrod proposed a vectorial model to study the formation of cultural domains in a network of interacting agents. In this model, the agents are represented by a $F$ components vector in which one from $Q$ integer states is assigned to each component. The model presents a transition from a monocultural state (ordered) to a multicultural one (disordered) that has been studied by using order parameters such as the relative size of the biggest cultural domain $(S)$ and the fraction of different domains $(g)$. Since then, some properties as the robustness to the introduction of noise, to the variation of topology and to the introduction of local, global and external fields were studied. Our work is organized in three main parts. In the first part we present the proposal of new measurements based on the concept of activity per agent to study the Axelrod's model in a square lattice. We show the variance of system's activity $(A)$ can be used to indicate the transition points and that the system's activity frequency distribution can be used to indicate the order of the transition. In the second part we estimate the phase diagram in the $(F, Q)$ plane and compare the results obtained from simulations performed in lattices with open and closed boundary conditions. For this purpose, we use the susceptibility of order parameters $S$ and $A$ to determine the critical values $Q_{c}(F)$ for some values of $F$. In the third part we analyze the formation of cultural domains by introducing persistent agents to model effects of internal media. Our results reveal a dependence of 
$Q_{c}$ on the occupation probability $p$ of persistent agents that allows us to obtain the phase diagram in the $(p, Q)$ plane. We interpret the critical locus as a result of two opposite forces (called barrier effect and bonding effect) caused by non-persistent agents which adhere the persistent ones.

Key-words: 1. Axelrod's model 2. Social Dynamics 3. Complex systems 4. Phase Transition 


\section{Lista de Figuras}

1.1 Esboço qualitativo da variação da magnetização $m$ do modelo de Ising em um sistema de tamanho finito em função do campo magnético $H$. A magnetização em equilíbrio (linha contínua) é a média calculada sobre os valores da magnetização em estados metaestáveis que ocorrem em simulações de Monte Carlo (linhas tracejadas). A magnetização $\pm m_{s p}$ é a magnetização espontânea em um sistema infinito. Extraído e adaptado de [19]. . . . . . . . . . . . . . . . . . . 9

1.2 Esboço qualitativo da susceptibilidade $\chi$ de um sistema que sofre transição de fase de segunda ordem. No esboço, é representado o comportamento da susceptibilidade para uma rede hipercúbica $d$ dimensional. Extraído de [20]. . . . . . . . . . . . . . . . . . 10

2.1 Configurações inicial e final de uma rede quadrada de lado $L=4$, com $F=3$ e $Q=2$. Cada sítio da rede abriga um agente representado por seu vetor cultural de $F=3$ componentes, onde cada componente é representada pelos tons de cinza $(q=1)$ e preto $(q=2)$. Em (a), configuração inicial na qual os agentes têm os estados das $F$ componentes sorteados aleatoriamente. Em (b), o sistema atingiu uma configuração final monocultural. 
2.2 Configurações inicial e final de uma rede quadrada de lado $L=4$, com $F=3$ e $Q=15$. Cada sítio da rede abriga um agente representado por seu vetor cultural de $F=3$ componentes, onde cada componente é representada por um de $Q=15$ diferentes tons de cinza. Em (a), configuração inicial na qual os agentes têm os estados das $F$ componentes sorteados aleatoriamente. Em (b), o sistema atingiu uma configuração final multicultural.

2.3 Relação do valor do parâmetro de ordem $\langle S\rangle$ com o número de estados $Q$ do modelo de Axelrod para $F=3$. Médias realizadas sobre 30 simulações com condições iniciais diferentes em uma rede $L=150$. . . 24

2.4 Relação do valor do parâmetro de ordem $\langle g\rangle$ com o número de estados $Q$ do modelo de Axelrod para $F=3$. Médias realizadas sobre 30 simulações com condições inciais diferentes em uma rede $L=150$. . . 25

2.5 Relação do valor do parâmetro de ordem $\langle S\rangle$ em (a) e do parâmetro $\langle g\rangle$ em (b) com o número de estados $Q$ do modelo de Axelrod para $F=3,4,5,7,10$. Médias realizadas sobre 30 simulações com condições iniciais diferentes em uma rede $L=150 \ldots$. . . . . . . . . 27

2.6 Relação do valor do parâmetro de ordem $\langle S\rangle$ em (a) e do parâmetro $\langle g\rangle$ em (b) com o número de estados $Q$ do modelo de Axelrod para $F=2$. Médias realizadas sobre 30 simulações com condições iniciais diferentes em uma rede $L=150 \ldots \ldots$. . . . . . . . . . . . . . . 28

2.7 Em (a) e (b), dependência dos parâmetros de ordem $\langle S\rangle$ e $\langle g\rangle$, respectivamente, com o número de estados $Q$ para $F=3$ nos tamanhos de rede $L=50,100,150$. Em (c) e (d), dependência dos parâmetros de ordem $\langle S\rangle$ e $\langle g\rangle$, respectivamente, com o número de estados $Q$ para $F=2$ nos tamanhos de rede $L=50,100,150$. As médias foram realizadas sobre $M=30$ simulações independentes com condições iniciais diferentes. . . . . . . . . . . . . . . . . 30

3.1 Parâmetro de ordem $\langle A\rangle$ em função de $Q$ para diferentes tamanhos de rede $L$ e $F=3$. A média $\langle A\rangle$ foi obtida de $M=30$ simulações independentes. 
3.2 Comparação entre as susceptibilidades $\chi_{S}$ (quadrados) e $\chi_{A}$ (círculos) dos parâmetros de ordem $S$ e $A$, respectivamente. Em (a), temos $\chi_{S}$ no eixo da esquerda e $\chi_{A}$ no eixo da direita. As duas curvas apresentam um pico em $Q_{c}=14$ para $F=3, L=150$ e $M=30$. Em (b), $Q_{c}$ é determinado a partir dos parâmetros $A\left(Q_{c}\left(\max \chi_{A}\right)\right)$ e $S\left(Q_{c}\left(\max \chi_{S}\right)\right)$ para vários tamanhos de rede $L$. . . . . . . . . . 40

3.3 Parâmetro $\langle A\rangle / F$ versus $Q$ para $F=3,4,5,7$ e $L=150$. Os dados foram obtidos de $M=30$ simulações.

3.4 Parâmetro $\langle A\rangle / F$ em função de $Q$ em (a) e $\langle S\rangle$ em função de $Q$ em (b), para $F=2$ e $L=50,100,150$. Os dados foram obtidos de $M=30$ simulações.

3.5 Estado estacionário (a) e mapa da atividade (b) obtidos de uma simulação com $L=100, F=3$ e $Q=14$. Na figura (a), cada vetor cultural $\psi_{i}$ é representado por uma tonalidade diferente. Na figura (b), a intensidade da cor representa a atividade do aglomerado, partindo de $A_{C}=0$ (preto) até $A_{C}=0.024$ (branco) . . . . . . . . . . .

3.6 Atividade do cluster $\left\langle A_{C}\right\rangle$ como função do tamanho do cluster $N_{C}$. Dados obtidos de uma única simulação em uma rede $L=100 \mathrm{com}$ $F=3$ e $Q=14$.

3.7 Número de clusters de tamanhos diferentes em função de $r^{2}$ em uma rede quadrada com $L=100, F=3$ e $Q=14$. Cada ponto corresponde à contagem de clusters diferentes e ao ajuste linear (com coeficiente de determinação $r^{2}$ ) de uma das $M=1000$ simulações independentes.

3.8 Distribuição de frequência da atividade do sistema $A$ para $M=1000$ simulações com $L=100, F=3$ e $Q=14$.

3.9 Distribuição de frequência da atividade do sistema $A$ para $F=2$ e $Q$ aumentando de um valor abaixo $(Q=6)$ para um valor acima $(Q=8)$ do ponto de transição. Dados obtidos de $M=1000$ simulações usando uma rede $L=100$. . . . . . . . . . . . . . . . . . . 48

3.10 Distribuições acumuladas $U$ da atividade do cluster $A_{C}$ para valores diferentes de $F$ no ponto $Q=Q_{c}$ em uma rede $L=100 . \quad$. . . . . . 49 
4.1 Medidas de $\langle S\rangle$ em (a) e $\chi_{S}$ em (b) como função de $Q$ para $F=3$ nas redes $L=8,16,32,64,128$. Cada medida corresponde a médias sobre $M=1000$ simulações nas redes $L=8,16,32$ e $M=100$ nas redes $L=64,128 \ldots \ldots \ldots \ldots$. . . . . . . . . . . 53

4.2 Medidas de $\langle A\rangle$ em (a) e $\chi_{A}$ em (b) como função de $Q$ para $F=3$ nas redes $L=8,16,32,64,128$. Cada medida corresponde a médias sobre $M=1000$ simulações nas redes $L=8,16,32$ e $M=100$ nas redes $L=64,128 \ldots \ldots \ldots \ldots \ldots$. . . . . . . . . . . 54

4.3 Distribuição de probabilidade de $P(S)$ em função de $S$ (coluna a esquerda) e de $P(A)$ em função de $A$ (coluna à direita) para $F=3$ e $Q=12$ (regime monocultural), $Q=13$ (ponto de transição em $L=64), Q=14$ (regime multicultural). Os dados correspondem à $M=10000$ simulações em uma rede $L=64$. . . . . . . . . . . 56

4.4 Tabela de extrapolantes do algoritmo BST. Extraído de [42]. . . . . . 59

4.5 Extrapolação de $Q_{c}^{\chi_{S}}$ para $F=3$. Os valores $Q_{c}^{\chi_{S}}(F, L)$ foram extraídos da tabela 4.1. . . . . . . . . . . . . . . . . . . . 6 60

4.6 Em (a), pontos $Q_{c}^{\chi_{S}}(F)$ indicados pelos símbolos $(\square)$ ajustados linearmente pela função $Q_{c}^{S}(F)$ dada pela equação 4.3 (representada pela reta). Em (b), pontos $Q_{c}^{\chi_{A}}(F)$ indicados pelos símbolos $(\times)$ ajustados linearmente pela função $Q_{c}^{A}(F)$ dada pela equação 4.4 (representada

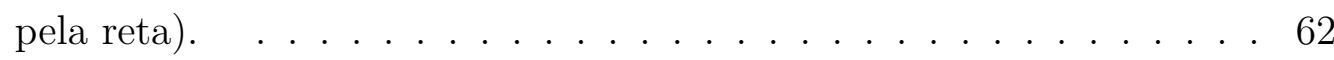

4.7 Probabilidade $P_{0}$ de não interação entre um par agente-vizinho qualquer em uma configuração inicial aleatória. Os valores de $P_{0}^{\chi_{S}}$ são indicado pelos símbolos $(\square)$, e os valores de $P_{0}^{\chi_{A}}$ pelos símbolos $(\times)$. A linha contínua representa o valor $P_{c}=0.84 \ldots \ldots$. . . . . . 65

4.8 Estimativas do diagrama de fases. Linhas de transição determinadas pelas expressões $Q_{c}^{S}(F), Q_{c}^{A}(F)$ e $Q_{c}(F) \ldots \ldots$. . . . . . 66

4.9 Comportamento de $P_{0}$ (dado pela equação (4.9)) em função de $F$ para o caso unidimensional. A linha contínua representa o valor limite $e^{-1}$. 67 
4.10 Medidas de $\langle S\rangle$ em (a) e $\chi_{S}$ em (b) como função de $Q$ para $F=3$ nas redes $L=8,16,32,64,128$. Cada medida corresponde a médias sobre $M=1000$ simulações nas redes $L=8,16,32$ e $M=100$ nas redes $L=64,128$ com condição de contorno aberta. . . . . . . . . . . 68

4.11 Medidas de $\langle A\rangle$ em (a) e $\chi_{A}$ em (b) como função de $Q$ para $F=3$ nas redes $L=8,16,32,64,128$. Cada medida corresponde a médias sobre $M=1000$ simulações nas redes $L=8,16,32$ e $M=100$ nas redes $L=64,128$ com condição de contorno aberta. . . . . . . . . . .

4.12 Estimativas do diagrama de fases. Linhas de transição determinadas pelas expressões $Q_{c}^{S}(F)$ e $Q_{c}^{A}(F)$ (condições de contorno periódicas), $Q_{c}^{S *}(F)$ e $Q_{c}^{A *}(F)$ (condição de contorno aberta) e $Q_{c}(F) \ldots . .72$

5.1 Parâmetro de ordem $\langle S\rangle$ em função de $Q$ para $p=0,0.1,0.5$ e 0.9 , obtido de $M=100$ simulações com $F=5$ e $L=100$. . . . . . . . . 76

5.2 Diagrama de fases no plano $(p, Q)$ para $F=5$ (obtido a partir de $M=100$ simulações e $L=100)$. O caminho crítico $Q_{c}(p)$ é representado pelos pontos quadrados e pela linha contínua separando a fase multicultural da fase monocultural. Os pontos circulares e a linha tracejada em cinza apenas indicam a existência de picos da susceptibilidade dentro do regime monocultural. . . . . . . . . . . . . . 78

5.3 Diagrama de fases no plano $(p, Q)$ para $F=5$ (obtido a partir de $M=$ 100 simulações nas redes $L=50,75,100$ e 150). A linha contínua representa a extrapolação dos pontos $Q_{c}$ no limite termodinâmico. . . 79

5.4 Configurações no estado estacionário para $F=5$ e $Q=21$ (com $L=100)$ ilustrando o "efeito barreira". As configurações da coluna da esquerda são representadas por agentes persistentes (em branco), agentes aderentes (em cinza) e os demais agentes (em preto). $\mathrm{Na}$ coluna da direta, as configurações são representadas por agentes persistentes e aderentes que pertencem ao cluster dominante (em branco) e os demais agentes (em preto). A primeira, a segunda e a terceira linha correspondem aos valores $p=0.02,0.03$ e 0.24 , respectivamente. 80 
5.5 Configurações no estado estacionário para $F=5$ e $Q=21$ (com $L=100$ ) ilustrando o "efeito de ligação". As configurações da coluna da esquerda são representadas por agentes persistentes (em branco), agentes aderentes (em cinza) e os demais agentes (em preto). $\mathrm{Na}$ coluna da direta, as configurações são representadas por agentes persistentes e aderentes que pertencem ao cluster dominante (em branco) e os demais agentes (em preto). A primeira e a segunda linha correspondem aos valores $p=0.44$ and 0.64 , respectivamente. . . . . . . . .

5.6 $\operatorname{Em}(\mathrm{a}),\langle\tilde{A}\rangle$ (triângulos), $\left\langle\tilde{A}_{D}\right\rangle$ (círculos) e $\langle S\rangle$ (quadrados) em função de $p$ para $Q=21$. Em (b), gráfico log-log de $\langle\tilde{A}\rangle$ (triângulos) e $\left\langle\tilde{A}_{D}\right\rangle$ (círculos) em função de $Q$ para $p=0.44$. Ambos os gráficos resultam de $M=100$ simulações com $F=5$ e $L=100$

5.7 Gráfico log-log de $\langle\tilde{A}\rangle$ (triângulos) e $\left\langle\tilde{A}_{D}\right\rangle$ (círculos) versus $Q$ para um fixo $p=0.04$ em (a), $p=0.24$ em (b) e $p=0.64$ em (c). Os gráficos resultam de $M=100$ simulações com $F=5, Q=21$ e $L=100$. . . 86

$5.8 \operatorname{Em}(\mathrm{a}),\langle\tilde{A}\rangle$ (triângulos) e $\left\langle\tilde{A}_{D}\right\rangle$ (círculos) versus $p$ sobre a linha crítica. Em (b), gráfico log-log de $\langle\tilde{A}\rangle$ (triângulos) e $\left\langle\tilde{A}_{D}\right\rangle$ (círculos) versus $Q$ sobre a linha crítica. Resultados obtidos de $M=100$ simulações com $F=5, M=100$ e $L=100$. . . . . . . . . . . . . . . 87

5.9 Diagrama de fases no plano $(p, Q)$ para $F=3,5,7(L=100$ e $M=100) .88$

6.1 Figuras da rede quadrada de lado $L=100$ no modelo de percolação por sítio. Um sítio ocupado é representado pela cor preta, e um sítio vazio é representado pela cor branca. A cor cinza representa o maior aglomerado formado por sítios ocupados. As probabilidades de ocupação $\tilde{p}$ são: $\tilde{p}=0.2$ (a), $\tilde{p}=0.4$ (b), $\tilde{p}=0.6$ (c) e $\tilde{p}=0.8$ (d). . . 93

6.2 Probabilidade $\tilde{P}$ de um sítio pertencer ao cluster infinito em função da probabilidade de ocupação $\tilde{p}$ para uma rede quadrada com $L=100$ no modelo de percolação por sítio. . . . . . . . . . . . . . . . . . 94 
6.3 Relação entre $P(p)$ e $p$ para o modelo de Axelrod com $F=5$ (em uma rede $L=100$ e $M=100$ simulações). Os valores de $Q<Q_{c}$ (regime monocultural) são: $Q=5 \mathrm{em}$ (a), $Q=10 \mathrm{em}$ (b), $Q=15$ em $(\mathrm{c})$ e $Q=20 \mathrm{em}(\mathrm{d}) \ldots \ldots \ldots 6$

6.4 Relação entre $P(p)$ e $p$ para o modelo de Axelrod com $F=5$ (em uma rede $L=100$ e $M=100$ simulações). Os valores de $Q>Q_{c}$ (regime multicultural) são: $Q=30$ (quadrado), $Q=40$ (círculo), $Q=50$ (triângulo) e $Q=100$ (triângulo invertido) . . . . . . . . . 97

6.5 Probabilidade de ocupação de agentes persistentes $p_{c}$, representada pelos pontos circulares e com escala no eixo da esquerda, e $P_{0}$, representada pelos pontos $(\times)$ e com escala no eixo da direita, em função de $Q$ para $F=5$. Os resultados de $p_{c}$ foram obtidos em uma rede quadrada com $L=100$ e $M=100 \ldots \ldots 7$

6.6 Relação entre o grau de separação $\left(G_{s}\right)$ entre duas subespécies e a probabilidade de se encontrar um par com dado $G_{s}$ nas $M=1000$ simulações realizadas. Os dados correspondem à situações sem (Zero) e com $(\mathbf{U m})$ propagação de marcação genética. . . . . . . . . . . . . 101

6.7 Atividade média $\langle a(t)\rangle$ em função de $Q$ para cinco instantes de tempo $t$ diferentes. Os resultados foram obtidos em uma rede quadrada com $L=100$ e $M=30 \ldots \ldots \ldots$. . . . . . . . . . . . . . . . . . . . . . 


\section{Lista de Tabelas}

4.1 Pontos $\left(Q_{c}^{\chi_{S}}(F, L), Q_{c}^{\chi_{A}}(F, L)\right)$ determinados pelos valores máximo de $\chi_{S}$ e $\chi_{A}$, respectivamente, para vários valores de $F$ e $L$. . . . . . . 57

4.2 Determinação dos pontos de transição $Q_{c}^{\chi_{S}}$ e $Q_{c}^{\chi_{A}}$ através da aplicação do algoritmo de extrapolação BST nos pontos $Q_{c}^{\chi_{S}}(F, L)$ e $Q_{c}^{\chi_{A}}(F, L)$, respectivamente, apresentados na tabela $4.1 \ldots \ldots 60$

4.3 Cálculo de $P_{0}^{\chi_{S}}$ e $P_{0}^{\chi_{A}}$ a partir de dados $Q_{c}^{\chi_{S}}$ e $Q_{c}^{\chi_{A}}$ apresentados na tabela 4.2. Denominamos BST- $S$ os dados resultantes da extrapolação das medidas de $S$, e BST- $A$ os dados resultantes da extrapolação das medidas de $A$. . . . . . . . . . . . . . . . . . 64

4.4 Pontos $\left(Q_{c}^{\chi_{S}}(F, L), Q_{c}^{\chi_{A}}(F, L)\right)$ determinados pelos valores máximo de $\chi_{S}$ e $\chi_{A}$, respectivamente, para vários valores de $F$ e $L$ em redes com condição de contorno aberta. . . . . . . . . . . . . . . . 70

4.5 Determinação dos pontos de transição $Q_{c}^{\chi_{S}}$ e $Q_{c}^{\chi_{A}}$ através do algoritmo de extrapolação BST. Os pontos $Q_{c}^{\chi_{S}}(F, L)$ e $Q_{c}^{\chi_{A}}(F, L)$ foram obtidos através dos pontos de máximo das susceptibilidades $\chi(S)$ e $\chi(A)$ apresentados na tabela $4.4 \ldots \ldots . \ldots 71$ 


\section{Lista de Símbolos}

$i \quad$ Índice de um agente da rede.

j Índice de um agente da rede.

$N \quad$ Número total de agentes na rede.

$s_{i} \quad$ Estado do agente $i$.

$s_{j} \quad$ Estado do agente $j$.

$H \quad$ Energia total.

$p \quad$ Probabilidade de ocupação.

$p_{c} \quad$ Probabilidade de ocupação crítica.

L Tamanho do lado da rede quadrada.

$m$ Soma dos estados dos agentes.

$T$ Temperatura.

$T_{c} \quad$ Temperatura crítica.

F Número de características culturais.

Q Número de estados culturais.

$Q_{c} \quad$ Número crítico de estados culturais.

$\psi_{i} \quad$ Vetor cultural do agente $i$. 
$\sigma_{i, k} \quad k$-ésima característica cultural do agente $i$.

$P_{i, j} \quad$ Probabilidade de interação entre os agentes $i$ e $j$.

$k_{m} \quad$ Índice da característica cultural tal que $\sigma_{i, k_{m}} \neq \sigma_{j, k_{m}}$.

$S \quad$ Tamanho do maior aglomerado.

$N_{D} \quad$ Número de agentes que pertencem ao maior aglomerado.

M Número de simulações independentes realizadas.

$\langle S\rangle \quad$ Média de $S$ sobre $M$ simulações.

$g \quad$ Fração de domínios culturais diferentes na rede.

$N_{g} \quad$ Número de domínios culturais diferentes na rede.

$\langle g\rangle \quad$ Média de $g$ sobre $M$ simulações.

$t \quad$ Intervalo de tempo.

$a_{i}(t) \quad$ Atividade por agente no instante $t$.

$N_{\psi_{i}(t)} \quad$ Número de mudanças no vetor cultural $\psi_{i}$ em $t$ passos de tempo.

$A_{i} \quad$ Atividade por agente no estado final.

A Atividade da rede.

$\chi_{A} \quad$ Susceptibilidade da atividade.

$\chi_{S} \quad$ Susceptibilidade do tamanho do maior aglomerado.

$A_{C} \quad$ Atividade de um dado aglomerado.

$N_{C} \quad$ Número de agentes de um dado aglomerado.

U Distribuição acumulada.

$P(S) \quad$ Probabilidade de uma configuração ter um cluster dominante de tamanho $S$.

$P(A)$ Probabilidade de uma configuração ter uma atividade da rede $A$. 
$Q_{c}^{\chi_{S}} \quad$ Ponto crítico extrapolado com os valores de $Q$ nos quais $\chi_{S}$ é máximo.

$Q_{c}^{\chi_{A}} \quad$ Ponto crítico extrapolado com os valores de $Q$ nos quais $\chi_{A}$ é máximo.

$\omega \quad$ Expoente de extrapolação do algoritmo BST.

$Q_{c}^{S}(F) \quad$ Função de ajuste dos pontos extrapolados $Q_{c}^{\chi_{S}}$.

$Q_{c}^{A}(F) \quad$ Função de ajuste dos pontos extrapolados $Q_{c}^{\chi_{A}}$.

$P_{k} \quad$ Probabilidade de um par de sítios possuírem $k$ características iguais.

$P_{0} \quad$ Probabilidade de não interação no instante inicial.

$P_{c} \quad$ Probabilidade de não interação característica.

$Q_{c}^{S *}(F) \quad$ Função de ajuste dos pontos extrapolados $Q_{c}^{\chi_{S}}$ na rede aberta.

$Q_{c}^{A *}(F) \quad$ Função de ajuste dos pontos extrapolados $Q_{c}^{\chi_{A}}$ na rede aberta.

$\psi_{p} \quad$ Vetor cultural dos agentes persistentes.

$\tilde{A} \quad$ Aderência da rede.

$\tilde{N} \quad$ Número de agentes aderentes na rede.

$\tilde{A}_{D} \quad$ Aderência do aglomerado dominante. 


\section{Sumário}

Lista de Figuras viii

$\begin{array}{ll}\text { Lista de Tabelas } & \text { xv }\end{array}$

Lista de Símbolos $\quad$ xvi

1 Introdução 3

1.1 Dinâmica de opinião . . . . . . . . . . . . . . . . . . . 5

1.2 Modelagem computacional . . . . . . . . . . . . . . 6

1.3 Efeitos de tamanho finito . . . . . . . . . . . . . . . . 8

1.4 Criticalidade e leis de potência . . . . . . . . . . . . . . 11

1.5 Modelo de dinâmica cultural . . . . . . . . . . . . . . . . . . . 13

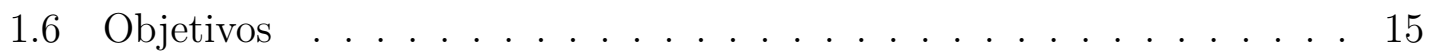

2 Propriedades do modelo de Axelrod 18

2.1 Parâmetro de ordem . . . . . . . . . . . . . . . . . . . . . 23

2.1.1 Comentários sobre $F=2$ e $F=1 \ldots$. . . . . . . . . 29

2.2 Extensões do modelo . . . . . . . . . . . . . . . . . . . . . . 31

3 Atividade de um modelo de dinâmica social 36

3.1 Atividade . . . . . . . . . . . . . . . . . . 36

3.2 Estados de equilíbrio . . . . . . . . . . . . . . . . . . . 38

3.3 Mapa da atividade . . . . . . . . . . . . . . . . . . . . . . . . . 41

3.4 Tamanho do cluster . . . . . . . . . . . . . . . . . . . . 44

3.5 Conclusão . . . . . . . . . . . . . . . . . . . . . . 47 
4 Transição de fase $\quad 51$

4.1 Determinação dos pontos de transição . . . . . . . . . . . . . . . . . . 51

4.2 Algoritmo BST . . . . . . . . . . . . . . . . . . 58

4.3 Diagrama de fases . . . . . . . . . . . . . . . . . . . . 60

4.3.1 Configuração inicial e ponto de transição . . . . . . . . . . . . 61

4.3.2 Comentário sobre caso unidimensional . . . . . . . . . . 64

4.4 Condição de contorno . . . . . . . . . . . . . . . . . . . . . 66

4.5 Conclusão . . . . . . . . . . . . . . . . . . . . . . 72

5 Efeitos de mídia interna $\quad 74$

5.1 Agentes persistentes como mídia interna . . . . . . . . . . . . 75

5.2 Diagrama de fases . . . . . . . . . . . . . . . . . . 77

5.3 Conclusão . . . . . . . . . . . . . . . . . . . . . . . . 88

6 Perspectivas e conclusões gerais $\quad 91$

6.1 Perspectivas . . . . . . . . . . . . . . . . . . . . . . 91

6.1 .1 Percolação . . . . . . . . . . . . . . . . . . . . 91

6.1.2 Diferenciação de espécies . . . . . . . . . . . . . . . . . . 98

6.1.3 Evolução dinâmica da atividade . . . . . . . . . . . . . . 103

6.2 Conclusões gerais . . . . . . . . . . . . . . . . . . 104

$\begin{array}{ll}\text { Referências Bibliográficas } & 106\end{array}$ 


\section{Capítulo}

\section{Introdução}

"If people tend to become more alike in their beliefs, attitudes, and behavior when they interact, why do not all such differences eventually disappear?"

- Robert Axelrod

O processo de formação de opinião sempre despertou o interesse de economistas e cientistas políticos. Em uma sociedade democrática, onde os indivíduos têm a possibilidade de opinar a favor ou contra determinada medida, o consenso para a tomada de decisão é crucial para a manutenção da estabilidade política.

Um consenso é atingido quando a maioria dos indivíduos tem a mesma opinião sobre dado assunto ou, em particular, votam em uma mesma proposta. Em um dos primeiros estudos sobre o mecanismo de decisão pela maioria votante, L. S. Penrose [1] abordou algumas questões relacionadas à representação de opiniões políticas diferentes em uma sociedade. Nesse estudo, são discutidas várias formas de decisão, como o poder de um voto individual na sociedade, o poder de voto em bloco (no qual um aglomerado de indivíduos votam juntos na mesma proposta) e o controle social através da hierarquia. Considera-se também que os indivíduos podem ser resolutos ou indiferentes. Indivíduos resolutos possuem uma preferência sobre determinado assunto, enquanto que os indiferentes não possuem uma posição bem definida. Assim, estuda-se como grupos de indivíduos resolutos induzem grupos de indivíduos indiferentes ao apoio de dada proposta mostrando, portanto, que indivíduos resolutos podem controlar as decisões coletivas em uma sociedade. O autor ainda propõe 
uma grandeza, chamada poder do voto, para determinar o "peso" do voto de cada nação em uma assembleia mundial de nações.

Alguns problemas políticos da decisão pela maioria votante são discutidos por G. Tullock em [2]. Nesse trabalho, Tullock discorre sobre as consequências da legalização (ou não) da troca de votos ${ }^{1}$ em uma sociedade. De acordo com o autor, a troca de votos poderia permitir uma votação mais justa ao considerar, na negociação de votos entre os indivíduos, as diferentes intensidades individuais de apoio a determinada causa. A introdução das "intensidades de desejos individuais" seria benéfica ao processo eleitoral porque "o voto de um homem que se opõe apaixonadamente a uma medida e o de um homem que não se importa muito mas é levemente a favor dela são pesados igualmente" ${ }^{2}$. Na discussão de seus resultados, o autor sugere que o sistema de decisão pela maioria não é o melhor mecanismo para alocar recursos e, portanto, uma análise cuidadosa desse processo deveria estimular o desenvolvimento de novas técnicas para aumentar a eficiência governamental.

Questionamentos das implicações políticas e econômicas do modelo de decisão pela maioria também são apresentados por J. M. Buchanan em [3]. Em seu trabalho, Buchanan aplica as ferramentas da teoria de jogos no mecanismo de maioria votante para analisar a utilização de recursos nos setores públicos e coletivos da economia. Na discussão de seus resultados, Buchanan diz que indivíduos de uma sociedade podem exercer um tipo de controle externo uns nos outros ao limitar e participar das decisões coletivas atuando em favor de seus próprios interesses. Além disso, é ressaltado que deve-se realizar investimentos nos processos de decisão para que as aprovações de projetos públicos inúteis ${ }^{3}$, eventos frequentes em sociedades democráticas, sejam evitadas.

\footnotetext{
${ }^{1}$ A troca de votos, chamada de logrolling ou vote-trandig por G. Tullock em [2], é o processo de negociação entre indivíduos para a aprovação de determinada proposta. Nesse processo, um indivíduo $A$ se compromete a votar em uma proposta apoiada por um indivíduo $B$ se, em contrapartida, o indivíduo $B$ votar em uma proposta apoiada pelo indivíduo $A$.

${ }^{2}$ Extraído de traduzido de [2].

${ }^{3}$ Do original wasteful public projects.
} 


\subsection{Dinâmica de opinião}

Não demorou muito para o mecanismo de influência social atrair o interesse de físicos estatísticos. Em um dos primeiros estudos de dinâmica de opinião desenvolvido por um físico, Weidlich em [4] analisa a estrutura de grupos sociais de indivíduos cujas decisões pessoais podem ser influenciadas pelos seus pares. Para isso, é realizada uma descrição das características gerais de modelos baseados em leis de probabilidade para, então, relacioná-los com fenômenos de polarização de opiniões em uma sociedade. O termo modelo votante ${ }^{4}$ foi cunhado por Holley e Liggett em [5]. Nesse trabalho, os autores demonstram uma dualidade entre sistemas estocásticos interagentes e um tipo de processo de ramificação para estudar as propriedades ergódicas do modelo votante.

De acordo com Dornic et al. [6] e Castellano et al. [7], no modelo votante cada indivíduo da rede pode ter duas opiniões diferentes: $s_{i}= \pm 1$. A cada instante de tempo, um indivíduo $i$, sorteado aleatoriamente, adota a opinião de um agente vizinho $j$ sorteado aleatoriamente entre seus primeiros vizinhos. Nesse modelo, a pressão exercida pela maioria dos vizinhos em um indivíduo é indireta e ocorre por meio da frequência de opiniões iguais presente na vizinhança. O modelo apresenta duas configurações homogêneas que correspondem a dois estados absorventes: um no qual todos os indivíduos tem o estado +1 e outro no qual o estado comum é -1. Partindo de uma configuração inicial aleatória e desordenada, a dinâmica do sistema tende a aumentar a ordem do sistema.

As características semelhantes entre o modelo votante e o modelo de Ising [8] fez com que alguns conceitos do último fossem aplicados no primeiro. O modelo de Ising é um modelo para ferromagnetos que apresenta transição do tipo ordem-desordem [9]. Nesse modelo, os spins de uma rede com $N$ spins podem assumir um valor inteiro $s_{i}= \pm 1$. Cada spin procura se orientar para cima $(+1)$ ou para baixo $(-1)$ de acordo com a orientação de seus vizinhos, de modo que a energia total, dada por $E=-\frac{1}{2} \sum_{\langle i, j\rangle} s_{i} s_{j}$, seja minimizada. Em [10], por exemplo, Galam e Moscovici utilizam acoplamentos baseados no modelo de Ising para alterar o modelo votante. Esse acoplamento visa estudar o fenômeno de polarização na rede quando há algum

\footnotetext{
${ }^{4}$ Do inglês voter model.
} 
tipo de pressão social exercida pela maioria, por meios de comunicação ou por meios políticos, e quando os indivíduos têm preferência por certas opiniões.

Em [11], Ligget propõe um novo modelo, chamado de modelo de maioria votante $^{5}$, para o estudo da dinâmica de opiniões em uma sociedade. Esse modelo é definido em uma rede regular na qual cada sítio $i$ é ocupado por uma variável $s_{i}= \pm 1$. Em cada passo de tempo discreto, um sítio da rede é escolhido aleatoriamente. Esse sítio, então, adota a opinião da maioria dos seus vizinhos com probabilidade $p$ e a opinião da minoria com probabilidade $1-p$. O estudo da formação de consenso nesse modelo revela que há um valor crítico $p_{c}$ acima do qual o sistema sempre se encontra ordenado [12].

\subsection{Modelagem computacional}

A massificação do uso de computadores fez com que modelagens computacionais fossem cada vez mais utilizadas por físicos estatísticos no estudo de fenômenos sociais. Os modelos de maioria votante e o modelo de Ising, por exemplo, são implementados computacionalmente com modelagem baseada em agentes. Esse tipo de modelagem tem sua origem na criação dos autômatos celulares em 1948 por John von Neumann $[7,13]$. Nesse ano, von Neumann estava estudando o problema da criação de robôs auto-replicantes. Após enfrentar as dificuldades e os altos custos envolvidos no desenvolvimento de tais robôs, ele segue sugestão de Stanislaw Ulam para utilizar modelos discretos no estudo de estruturas que se copiam sozinhas. O resultado foi a criação do autômato chamado copiador e construtor universal ${ }^{6}$, no qual cada célula (de uma rede celular bidimensional) pode ter um de 29 estados discretos.

Um autômato celular é representado por uma rede de células $d$-dimensional. Esse espaço discreto abriga, em cada célula, um agente caracterizado por estados discretos dados por números inteiros. Cada agente interage localmente com as células vizinhas. A vizinhança é formada pelos agentes adjacentes mais próximos, sendo as mais famosas a vizinhança de von Neumann, formada pelos quatro vizinhos mais próximos (acima, abaixo, à esquerda, à direita), e a vizinhança de Moore, formada pela vizinhança de von Neumann mais os quatro vizinhos nas diagonais. A interação

\footnotetext{
${ }^{5}$ Do inglês Majority vote model.

${ }^{6}$ Do inglês universal copier and constructor.
} 
é determinada por um conjunto de regras simples que relaciona o estado de uma célula no próximo instante de tempo com o seu estado atual e o estado atual das células vizinhas. Nesse tipo de modelagem o tempo também é discreto. Em cada passo de tempo, a atualização dos sítios da rede pode ser síncrona ou assíncrona [14]. $\mathrm{Na}$ atualização síncrona todos os sítios são atualizados simultaneamente, enquanto que na assíncrona os sítios são atualizados assim que a interação ocorre.

A modelagem baseada em autômatos celulares ganhou destaque com a proposta do Game of Life por Jonh Conway em 1970. O Game of Life é um autômato bidimensional em que cada sítio da rede pode se encontrar vivo (representado pelo estado 1) ou morto (representado pelo estado 0). A cada instante de tempo, a rede é percorrida sequencialmente (a atualização é síncrona) e cada agente tem seu estado alterado de acordo com as seguintes regras: se um agente está vivo e tem dois ou três vizinhos vivos, ele permanece vivo; se um agente está morto e tem três vizinhos vivos, ele se torna vivo. A vizinhança considerada é a vizinhança de Moore. Nesse conjunto de regras simples, a morte por solidão (se tem até um vizinho vivo) e por superpopulação (se tem mais de três vizinhos vivos) evitam que o número de agentes vivos cresça indefinidamente. Esse autômato exemplifica uma das principais características da modelagem baseada em agentes: simulação da atividade de um conjunto de indivíduos autônomos interagindo entre si de acordo com regras específicas simples que resultam em um comportamento global não-trivial. O Life, por exemplo, apresenta um decaimento da densidade temporal de células vivas em forma de lei de potência e a formação de estruturas complexas.

No contexto da dinâmica de opiniões, Oliveira em [15] estuda o modelo de maioria votante em uma rede quadrada. Utilizando a modelagem baseada em agentes, simulações computacionais são realizadas em redes que vão de $L=5$ até $L=80$, onde $L$ é o tamanho do lado da rede quadrada. Para implementar o modelo, ele se baseia no modelo de Ising para definir os estados dos sítios $s_{i}= \pm 1$ e para definir o parâmetro de ordem $M=|m|$, onde $m$ é a soma dos estados de todos os agentes da rede. A análise de seus resultados para os diferentes tamanhos de rede faz uso da teoria de escala de tamanho finito ${ }^{7}$ para estudar a transição do estado ordenado para o estado desordenado.

\footnotetext{
${ }^{7}$ Do inglês Finite-size scaling.
} 


\subsection{Efeitos de tamanho finito}

De acordo com o trabalho de K. Binder em [16], a mecânica estatística nos mostra que o fenômeno de transição de fase ocorre apenas no limite termodinâmico, ou seja, quando $N \rightarrow \infty$, em que $N$ é o número de agentes do sistema. Nas palavras de Peter Nightingale [17]: "Of course, finite systems themselves do not display any critical behavior, but temperature, ordering field and finite-size deviations from criticality are all described by one and the same set of critical exponents". Quando realizamos simulações computacionais, o número de agentes $(N)$ do sistema é sempre finito. Neste sentido, a teoria de "finite-size scaling" estuda os efeitos que o tamanho finito de um sistema causam no comportamento das grandezas de interesse. Segundo M. E. Fisher e M. N. Barber em [18], uma rede de tamanho finito $N$ provoca um deslocamento $\epsilon(N)$ do ponto de transição. Se o parâmetro de controle é a temperatura, para usar o exemplo dado por Fisher e Barber em [18], o deslocamento $\epsilon(N)$ é dado pela expressão

$$
\epsilon(N)=\frac{T_{c}-T_{c}(N)}{T_{c}} \propto N^{-\lambda},
$$

em que $T_{c}(N)$ é a temperatura na qual ocorre a mudança de fase em um sistema com $N$ agentes e $T_{c}$ é valor da temperatura de transição no limite termodinâmico $\left(T_{c}=T_{c}(N \rightarrow \infty)\right)$. O expoente $\lambda$ é chamado de expoente de deslocamento ${ }^{8}$.

Outro efeito de tamanho finito que se observa é o arredondamento da curva de transição. Binder e Landau, em [19], destacam que sistemas em redes finitas não apresentam singularidades e que o comportamento do parâmetro de ordem (para transição de primeira ordem) ou da susceptibilidade (para transição de segunda ordem) é suave. Um exemplo do efeito do arrendondamento para uma transição de primeira ordem é o surgimento de uma região crítica na qual há estados metaestáveis $^{9}$ e coexistência de fases, como ilustrado na figura 1.1 adaptada de [19]. No limite termodinâmico, espera-se que a magnetização seja alterada abruptamente de

\footnotetext{
${ }^{8}$ Do inglês shift exponent.

${ }^{9}$ Estados metaestáveis correspondem às configurações exibidas por um sistema localizado nos mínimos locais de uma função de energia potencial. Nesse contexto, uma perturbação poderia alterar a configuração ao deslocar o sistema de um ponto de mínimo local para outro ponto de menor (ou igual) energia. Tais estados também podem depender da condição inicial. Para um conjunto de parâmetros, por exemplo, o sistema pode ser encontrado em uma ou em outra fase apenas por flutuações nas condições iniciais.
} 
$-m_{s p}$ quando $H \rightarrow 0^{-}$para $m_{s p}$ quando $H \rightarrow 0^{+}$. No sistema finito, nenhuma singularidade ocorre e os estados metaestáveis promovem a suavização da curva de transição (linha contínua). A figura 1.2, extraída e adaptada do trabalho de U. P. da Costa Neves [20], mostra o arredondamento que ocorre na curva da susceptibilidade $\chi$ em uma transição de segunda ordem.

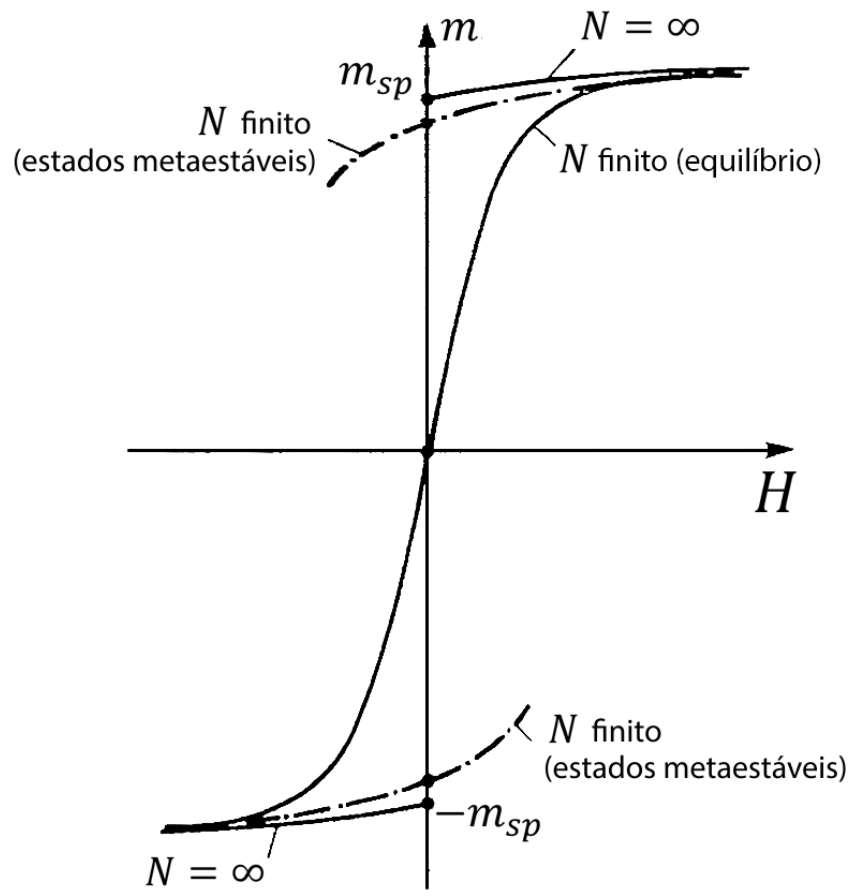

Figura 1.1: Esboço qualitativo da variação da magnetização $m$ do modelo de Ising em um sistema de tamanho finito em função do campo magnético $H$. A magnetização em equilíbrio (linha contínua) é a média calculada sobre os valores da magnetização em estados metaestáveis que ocorrem em simulações de Monte Carlo (linhas tracejadas). A magnetização $\pm m_{s p}$ é a magnetização espontânea em um sistema infinito. Extraído e adaptado de [19].

Assim como o deslocamento $\epsilon(N)$, o arredondamento $\delta(N)$ também se relaciona com o tamanho da rede $N$, através da expressão

$$
\delta(N) \propto \Delta T_{a r} \propto N^{-\theta}
$$

em que o intervalo $\Delta T_{a r}$ ocorre em torno do ponto $T_{c}(N)$ no qual a curva de susceptibilidade apresenta um pico. O expoente $\theta$ é chamado de expoente de arredondamento (em inglês, "rounding exponent"). 


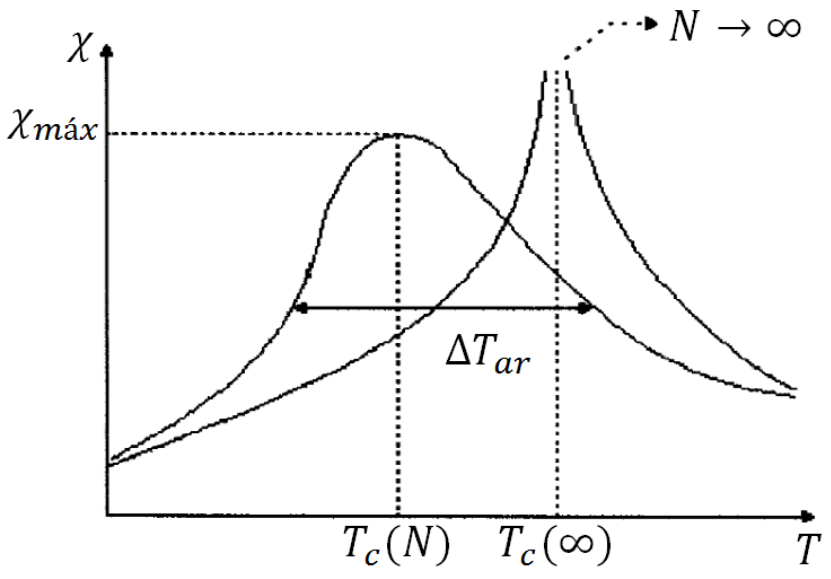

Figura 1.2: Esboço qualitativo da susceptibilidade $\chi$ de um sistema que sofre transição de fase de segunda ordem. No esboço, é representado o comportamento da susceptibilidade para uma rede hipercúbica $d$ dimensional. Extraído de [20].

Os efeitos de tamanho finito (como o deslocamento $\epsilon(N)$ e o arredondamento $\delta(N)$ ) dificultam a determinação do ponto crítico (valor do parâmetro de controle no qual a transição ocorre) e da ordem de transição. Um método que auxilia nessa determinação é a inspeção da distribuição dos parâmetros de ordem. Em seus trabalhos, S. Tsai e S. R. Salinas em [21], K. Binder e D. P. Landau em [19], e D. P. Landau et al. em [22], argumentam que a distribuição do parâmetro de ordem é bimodal em torno do ponto crítico quando a transição é de primeira ordem: a presença de dois picos (correspondendo aos valores do parâmetro de ordem em duas fases distintas) indicaria a coexistência de fases na região crítica. Nos casos de transições de segunda ordem, a distribuição do parâmetro de ordem apresenta um único pico, e este pico se desloca de acordo com o valor do parâmetro de controle do sistema.

Devemos mencionar que, rigorosamente falando, o conceito de transição de fase está relacionado com a regularidade dos potenciais termodinâmicos energia livre de Helmholtz $F$ e energia livre de Gibbs $G$. Nesse sentido, uma transição de fase de primeira ordem é definida como sendo uma transição que apresenta descontinuidade na primeira derivada dos potenciais termodinâmicos, e uma transição de fase de segunda ordem é definida como sendo uma transição que apresenta descontinuidade na segunda derivada desses potenciais. Como exemplo, considere a função de partição 
$Z$ do modelo de Ising com campo externo $H$ :

$$
Z=\sum_{s_{i}= \pm 1} \exp \left[-\beta\left(-J \sum_{<i, j>} s_{i} s_{j}-H \sum_{i} s_{i}\right)\right]
$$

onde o primeiro somatório é realizado sobre os possíveis estados do sítio $i$, o segundo sobre sua vizinhança local e o terceiro sobre todos os sítios da rede. A constante $J$ representa uma constante de acoplamento entre os spins. Lembrando que o potencial de Helmoltz é dado por $F=-k T \log (Z)$, onde $k$ é a constante de Boltzmann, o parâmetro de ordem magnetização $M$ e a susceptibilidade $\chi$ são expressos pelas primeira e segunda derivadas de $F$ com respeito a $H$ :

$$
\begin{aligned}
M & =\frac{1}{N} \frac{\mathrm{d} F}{\mathrm{~d} H}, \\
\chi & =\frac{1}{N} \frac{\mathrm{d}^{2} F}{\mathrm{~d} H^{2}}=N\left(\left\langle M^{2}\right\rangle-\langle M\rangle^{2}\right) .
\end{aligned}
$$

Essa relação da regularidade do parâmetro de ordem e da susceptibilidade com a ordem da transição (para mais informações, consultar o livro de J. J. Binney et al. [23]) faz com que sistemas que não possuem um potencial termodinâmico bem definido, como o que estudamos nesta tese (e para sistemas fora do equilíbrio, em geral), possam ter a transição investigada através da análise cuidadosa dessas grandezas (como ressaltado por G. Ódor em [24]).

Desse modo, a modelagem computacional e a teoria de escala de tamanho finito foram incorporados ao conjunto de ferramentas dos físicos estatísticos. Como ressaltado em [14], os autômatos celulares podem ser utilizados para se estudar fenômenos naturais e sociais. Geralmente, os autômatos podem ser aplicados onde há interesse na evolução dinâmica, na formação de padrões globais e nas propriedades estatísticas de sistemas com muitos agentes interagindo. Essa modelagem baseada em agentes se difundiu para diversos ramos das ciências e é muito importante para simulações computacionais de sistemas complexos. Os modelos de dinâmica de opinião, em particular, se beneficiaram bastante dessas novas ferramentas [25, 26, 27, 28, 29].

\subsection{Criticalidade e leis de potência}

Alguns sistemas físicos apresentam um ponto distinto, como a temperatura crítica $T_{c}$ no modelo de Ising, no qual fenômenos singulares são observados. Nesse caso, 
o parâmetro de ordem magnetização $M$ apresenta uma queda acentuada quando a temperatura é elevada até $T_{c}$. De acordo com Stanley em [30], esse comportamento singular é um exemplo de fenômeno crítico. Nesse artigo, os autores mencionam algumas propriedades encontradas no ponto crítico (e ao redor dele) como leis de escala, universalidade e renormalização.

Em [31], Bak e Tang propõem um modelo baseado em autômatos celulares para o estudo de terremotos em redes bi e tridimensionais. Os resultados revelam que a distribuição de energia liberada em terremotos segue uma lei de potência na forma $D(E) \approx E^{\tau}$ (em que $\tau \approx 1.0$ para o modelo em duas dimensões e $\tau \approx 1.35 \mathrm{em}$ três dimensões). Nesse caso, a lei de potência seria um indicativo das propriedades críticas do modelo proposto. Em [32], os autores fazem a associação entre as propriedades exibidas pelo Game of Life, que é considerado um autômato celular complexo [33, 34, 35], e distribuições do tamanho e do tempo de duração de avalanches em forma de lei potência. Também encontramos a associação entre sistemas na criticalidade e distribuições na forma de leis de potência em [36, 37, 38].

Uma função na forma de lei de potência $f(x)=a x^{k}$ apresenta ausência de escala característica e invariância de escala. Fenômenos físicos na forma exponencial, por exemplo, podem ser caracterizados por uma escala característica, como o tempo de meia-vida de um elemento radioativo [39]. Essa escala não é encontrada em fenômenos descritos por uma lei de potência. A invariância de escala pode ser visualizada ao reescalar a variável $x$ por uma constante $\lambda$ tal que $f(\lambda x)=a(\lambda x)^{k}$. Nesse caso, teremos $f(\lambda x)=a \lambda^{k} x^{k}=\lambda^{k} f(x)$.

No contexto da física dos fenômenos sociais, a relação entre modelos ajustados no ponto crítico e distribuições em forma de lei de potência aparece em [40], onde há a relação entre a distribuição acumulada dos tamanhos de domínios culturais $(U)$ encontrados no modelo cultural de Axelrod e o tamanho desses domínios $s$ na forma $U \propto s^{1-\tau}(\tau \approx 1.6$ para $F=2$ e $\tau \approx 2.6$ para $F \geq 3)$; em [41], onde a densidade de links ativos $n_{A}$ no modelo votante em redes de mundo pequeno é estudada em função do tempo na forma $n_{A} \propto t^{-1 / 2}$; em [42], onde é determinada uma relação de escala entre a altura $h$ e a largura $w$ de uma função que descreve as intensidades máximas de eventos sociais, na forma $h \propto w^{2 / 3}$; em [43], onde a fração de domínios diferentes $g$ se relaciona com a intensidade de um campo externo $B$ aplicado no modelo de Axelrod 
na forma $g \propto B^{0.13}$; entre outros. Em [44], é mencionado que uma distribuição em forma de lei de potência pode ser considerada uma assinatura de complexidade e criticalidade. Essa consideração também é encontrada em [45, 46, 47].

\subsection{Modelo de dinâmica cultural}

A emergência de fenômenos coletivos não-triviais a partir da interação simples entre elementos individuais fez com que a modelagem baseada em agentes adquirisse um papel importante para a física dos sistemas complexos e, quando a modelagem está relacionada ao estudo de fenômenos sociais, tem-se a sociofísica. Uma descrição abrangente dos vários tipos de modelos de dinâmica social estudados pela comunidade de físicos, como, por exemplo, modelos de dinâmica de opinião, de dinâmica cultural, de dinâmica de linguagem, de comportamento coletivo, entre outros, é encontrada no trabalho de revisão de Castellano et al. [7].

Um dos modelos descritos nesse trabalho é o modelo de dinâmica cultural ${ }^{10}$ proposto por Robert Axelrod em 1997 [48]. Em seu artigo seminal "The dissemination of culture" (A disseminação da cultura), Axelrod levanta a seguinte questão: "Se as pessoas tendem a ficar mais parecidas em suas crenças, atitudes e comportamento quando elas interagem, por que todas as diferenças entre elas não desaparecem?".

O mecanismo proposto por Axelrod para responder a esta pergunta é baseado em três princípios (extraído e adaptado de [48]):

- Modelagem baseada em agentes;

- Ausência de autoridade central;

- Agentes adaptativos.

Estes princípios especificam, respectivamente, que a interação é local e se dá entre agentes individuais; que não há nada equivalente a uma "força externa" (ou, em

\footnotetext{
${ }^{10}$ De acordo com Castellano et al. em [7], não há uma distinção clara entre modelos de dinâmica de opinião, como o modelo de maioria votante, e modelos de dinâmica cultural. Contudo, considerase que modelos de dinâmica de opinião são modelos em que apenas uma variável representa o estado de cada indivíduo, chamados de modelos escalares, enquanto que modelos de dinâmica cultural são modelos em que o estado de um indivíduo é determinado por um conjunto de variáveis, chamados de modelos vetoriais
} 
analogia ao modelo de Ising, um campo externo) para induzir e orientar as interações entre os agentes; e que os agentes seguem regras de interação simples e se adaptam ao seu ambiente local.

O modelo foi originalmente definido em uma rede quadrada de lado $L$. Cada indivíduo (agente) da rede é representado por um conjunto de $F$ variáveis inteiras independentes, chamadas de características culturais. A cada característica cultural $f(f=1,2, \ldots, F)$ é atribuído um número inteiro $q(q=1,2,3, \ldots, Q)$ que representa o valor que a característica pode assumir (estado cultural) ${ }^{11}$. Como descrito em [48], o modelo assume que a cultura de um indivíduo é dada por um conjunto de características que estão sujeitas à influência social. Entre essas características temos a linguagem, a religião, a tecnologia, o estilo de se vestir, entre outros. Como exemplo, Axelrod menciona que uma característica de uma cultura poderia ser a preferência pela cor de um cinto. Nesse caso, os estados representariam as cores de cinto disponíveis naquela sociedade.

Um indivíduo da rede pode interagir apenas com um dos quatro vizinhos mais próximos. A probabilidade de interação de um agente com seu vizinho é maior quanto mais características iguais forem compartilhadas pelo par agente-vizinho. Ao ocorrer, a interação entre esse par agente-vizinho promove o aumento das semelhanças entre eles e, consequentemente, o aumento da probabilidade de uma nova interação. Nesse sentido, espera-se que todos os indivíduos da rede alcancem um consenso no qual todos os agentes da rede possuem o mesmo vetor cultural no estado estacionário (configuração final do tipo monocultural).

Na discussão de seus resultados, Axelrod ressalta que, contra-intuitivamente, a convergência local dos estados dos indivíduos não implica necessariamente em convergência global. De fato, observa-se que a configuração final pode ser homogênea, onde todos os agentes apresentam o mesmo vetor cultural, ou heterogênea, onde vários vetores culturais são encontrados na rede. A determinação do tipo de configuração encontrada no estado estacionário depende dos parâmetros $F$ e $Q$ do modelo.

\footnotetext{
${ }^{11}$ O termo "estado" se refere tanto aos valores dos atributos de um indivíduo da rede celular como também à configuração da rede que contém todos os indivíduos. Aqui, a expressão "estado cultural" refere-se aos atributos de um indivíduo específico, enquanto que os termos "estado ordenado" e "estado desordenado" referem-se às configurações da rede, por exemplo.
} 
O modelo proposto por Axelrod atraiu o interesse de cientistas sociais e de físicos. Segundo Castellano et al. [7], a origem do sucesso entre cientistas sociais estaria na tendência de agentes individuais se tornarem semelhantes quando há interação (influência social) e na tendência de indivíduos semelhantes ${ }^{12}$ ficarem mais próximos (homofilia), aumentando a frequência de interação entre eles. A origem do sucesso do modelo entre físicos estatísticos seria proveniente da sua simplicidade e da sua fenomenologia não-trivial.

\subsection{Objetivos}

Em nosso estudo desejamos entender algumas propriedades do modelo de Axelrod. Dessas propriedades, destacamos a pressão local exercida pela vizinhança em um indivíduo da rede, a relação entre o conjunto de valores $F$ e $Q$ e a configuração final e o efeito que perturbações internas causam na formação dos estados finais.

Para isso, organizamos o estudo nos seguintes capítulos:

Capítulo 2: nesse capítulo descrevemos algumas propriedades do modelo de Axelrod, como a formação dos regimes mono e multiculturais em função dos valores dos parâmetros $F$ e $Q$. Para tanto, apresentamos as definições dos parâmetros de ordem descritos na literatura: a fração $S$ da rede ocupada pelo maior cluster e a fração $g$ de clusters diferentes presentes na rede.

Capítulo 3: nesse capítulo propomos uma nova medida, chamada de atividade, para investigar as propriedades do modelo de Axelrod em uma rede quadrada. A atividade por agente é definida como o número de mudanças no conjunto de características culturais de cada agente. Verificamos que a atividade média do sistema apresenta um comportamento similar ao de um parâmetro de ordem e é útil na determinação da transição dos estados monoculturais para os multiculturais. A distribuição da atividade média apresenta dois picos no ponto de transição para $F \geq 3$ e um único pico para $F=2$. Nossos resultados concordam com os pontos de transição determinados usando-se outros parâmetros de ordem. Além disso, o mapa da atividade revela que a rede apresenta regiões em que os agentes sofrem maior pres-

\footnotetext{
${ }^{12}$ Aqui, um indivíduo é mais semelhante a outro quanto mais parecidos - mais crenças, atitudes e comportamento similares - eles forem. A proximidade de indivíduos semelhantes é verificada pela formação de aglomerados desses indivíduos.
} 
são local para se alinhar com seus vizinhos. Ainda, verificamos uma dependência em forma de lei de potência entre a atividade média de um aglomerado com o seu tamanho.

Capítulo 4: nesse capítulo procuramos correlacionar as configurações finais do modelo de Axelrod com o grau de desordem da configuração inicial. Essa correlação destina-se a oferecer uma aproximação numérica do diagrama de fases do modelo em na rede quadrada. Para fazer isso, nós definimos a susceptibilidade do parâmetro de ordem para determinar $Q_{c}(F, L)$ para cinco tamanhos de rede. Então, o valor crítico $Q_{c}(F)$ é estimado usando-se o algoritmo de extrapolação BST $[49,50]$. Os parâmetros de ordem que consideramos nessa análise são o tamanho do maior cluster [40] e a atividade média da rede [51]. Considerando que as condições de contorno podem desempenhar um papel importante na evolução da dinâmica [52], comparamos os resultados obtidos em redes abertas e fechadas de mesmo tamanho. Nossos resultados sugerem que há uma relação entre a probabilidade inicial de um par agente-vizinho não possuir nenhuma característica cultural em comum e o estado final do sistema. Verificamos, também, que essa relação independe das condições de contorno para redes grandes, como esperado [53].

Capítulo 5: nesse capítulo estudamos o comportamento do modelo de Axelrod sob efeito de perturbações internas causadas por agentes persistentes. Esses agentes são considerados como impurezas na rede. O vetor cultural $\psi_{P}$ de um agente persistente não muda durante a dinâmica. Em outras palavras, os agentes persistentes permanecem congelados enquanto o sistema evolui. Apesar disso, um agente persistente pode interagir com seus vizinhos espalhando suas características para eles. Similarmente aos estudos envolvendo campos externos, a introdução de agentes persistentes é realizada com a intenção de alinhar os vetores culturais da rede. Devido a esse papel na dinâmica, os agentes persistentes podem ser considerados como mídia interna. Nossos resultados sugerem que ambos os regimes são afetados pelos persistentes. O ponto de transição $Q_{c}$ separando esses regimes mudam de acordo com a concentração $p$ de agentes persistentes introduzidos. Esse resultado nos permite determinar o diagrama de fases no plano $(p, Q)$ ao plotar o caminho crítico $Q_{c}(p)$ para um $F$ fixo.

Capítulo 6: nesse capítulo ilustramos algumas possíveis aplicações das ferra- 
mentas desenvolvidas nos capítulos anteriores. Particularmente, apresentamos três propostas de estudo ${ }^{13}$ :

- Percolação: queremos estudar como e em quais condições ocorre a percolação de um vetor cultural específico no modelo de Axelrod;

- Diferenciação de espécies: sugerimos utilizar os vetores de opinião do modelo de Axelrod para representar o código genético de indivíduos diferentes e investigar como surgem novas espécies na rede através da interação/troca de material genético entre os agentes;

- Evolução dinâmica da atividade: a proposta de atividade realizada no Capítulo 3 pode ser utilizada para estudar como os mecanismos de pressão locais afetam os agentes em função do tempo de acordo com $F$ e $Q$.

Cada proposta contêm em sua respectiva seção uma breve descrição do problema de interesse, como se pretende abordá-lo inicialmente e alguns resultados preliminares. O capítulo é encerrado com uma conclusão geral que discorre sobre as implicações dos nossos resultados na interpretação de fenômenos sociais e de comportamentos coletivos que observamos em nossa sociedade.

Todos os resultados apresentados nesta tese foram obtidos com simulações computacionais desenvolvidas em FORTRAN.

\footnotetext{
${ }^{13}$ Tais estudos se encontram em andamento atualmente.
} 


\section{Capítulo}

\section{Propriedades do modelo de Axelrod}

"The present model offers a new way of looking at the dynamic process of social influence. The model is not intended to predict any particular historical events. Instead, it is meant to show the consequences of a few simple assumptions about how people (or groups) are influenced by those around them."

- Robert Axelrod

No modelo de Axelrod, um agente $i$ é representado por um vetor cultural $\psi_{i}$ de F componentes,

$$
\psi_{i}=\left(\sigma_{i, 1}, \sigma_{i, 2}, \ldots, \sigma_{i, k}, \ldots, \sigma_{i, F}\right),
$$

onde $\sigma_{i, k}$ denota a $k$-ésima característica cultural $(k=1,2, \ldots, F)$ e é especificado por um índice $q$ que indica o estado cultural correspondente $(q=1,2, \ldots, Q)$. Como mencionado na Introdução, cada característica representa uma questão cultural individual suscetível a influência do meio social. O estado cultural, por sua vez, determina a posição que o indivíduo assume em relação a dada característica. Se a característica for "time de futebol preferido", os estados representariam as opções disponíveis como Corinthians, São Paulo, Palmeiras, Santos, etc.

Os agentes são dispostos em uma rede celular quadrada de lado $L$. O sistema evolui a partir de uma condição inicial aleatória (onde o estado de cada característica 
cultural $\sigma_{i, k}$ é escolhido aleatoriamente entre os $Q$ estados possíveis) de acordo com os seguintes passos:

1) Um agente $i$ é escolhido aleatoriamente entre os $N=L^{2}$ agentes da rede $(i=1,2, \ldots, N)$.

2) Um agente $j$ é escolhido aleatoriamente entre os primeiros quatro vizinhos do agente $i$ (vizinhança de von Neumann).

3) Identifica-se o conjunto $\Theta$ das $n$ características culturais $\sigma_{i, k}$ cujos estados diferem de $\sigma_{j, k}$ (ou seja, $\sigma_{i, k} \neq \sigma_{j, k}$ para $k=k_{1}, k_{2}, \ldots, k_{n}$ ). Se $\Theta$ é um conjunto vazio então o vetor $\psi_{i}$ permanece inalterado. Caso contrário, uma característica cultural $\sigma_{i, k_{m}} \in \Theta$ é selecionada com probabilidade $1 / n$ e o valor de $\sigma_{j, k_{m}}$ é atribuído a $\sigma_{i, k_{m}}$ com probabilidade $P_{i, j}$ dada por

$$
P_{i, j}=\frac{1}{F} \sum_{k=1}^{F} \delta_{\sigma_{i, k} \sigma_{j, k}},
$$

onde o delta de Kronecker $\delta_{\sigma_{i, k} \sigma_{j, k}}$ é igual a $0\left(\right.$ se $\left.\sigma_{i, k} \neq \sigma_{j, k}\right)$ ou $1\left(\operatorname{se~} \sigma_{i, k}=\sigma_{j, k}\right)$.

A repetição desse processo $N$ vezes é contada como um passo de Monte Carlo e a atualização dos vetores culturais dos agentes é realizada assim que ela ocorre (a atualização é assíncrona). O sistema evolui durante sucessivos passos de Monte Carlo até o estado estacionário. Adotamos a condição periódica de contorno, de modo que os sítios da primeira linha estão conectados aos sítios da última e os sítios da primeira coluna estão conectados aos sítios da última (formando um toroide).

A probabilidade de interação $P_{i, j}$ de um par $(i, j)$ de agentes adjacentes é proporcional ao número de características culturais compartilhadas por eles. O modelo assume que, para haver interação entre dois indivíduos, ambos precisam possuir interesses em comum. Assim, a interação entre o par agente-vizinho ocorre quando $0<P_{i, j}<1$. Se $P_{i, j}=0$, o par agente-vizinho não compartilha nenhuma característica cultural e, por isso, eles não têm nenhuma interação social. Se $P_{i, j}=1$, os agentes $i$ e $j$ já compartilham os mesmos estados em todas as características e, desse modo, os vetores culturais permanecem inalterados. Observe que a interação entre dois agentes $(i, j)$ faz com que o agente $i$ adote $\left(\operatorname{com} P_{i, j}\right)$ o estado do vizinho $j$ para uma característica $k_{m}$ em que ambos diferiam. Logo, a interação sempre aumenta 
o número de características culturais compartilhadas pelo par $i$ e $j$ e aumenta a probabilidade de uma nova interação ocorrer.

Sempre que $P_{i, j}$ é igual a zero ou igual a um para todo par $(i, j)$, a configuração do sistema não muda mais: o sistema alcança um estado absorvente. O estado final absorvente também funciona como um critério de parada para a dinâmica porque ele tem probabilidade nula de ser alterado. Nesse estado, um ou mais aglomerados de agentes com o mesmo vetor cultural podem ser identificados. A configuração final é, então, caracterizada por uma fase monocultural (estado ordenado com um vetor cultural dominando a rede) ou por uma fase multicultural (estado desordenado com a presença de dois ou mais vetores culturais). A figura 2.1 ilustra as configurações inicial e final em uma rede quadrada de lado $L=4 \operatorname{com} F=3$ e $Q=2$. Cada sítio da rede é representado pelo vetor cultural de $F=3$ componentes. Os dois estados disponíveis $(Q=2)$ são ilustrados pelas cores cinza $(q=1)$ e preta $(q=2)$. Partindo de uma configuração inicial na qual os vetores iniciais de todos os agentes são sorteados aleatoriamente (figura 2.1(a)), observamos que o valor dos parâmetros $(F, Q)$ conduz o sistema para o regime final monocultural (figura 2.1(b)). Uma configuração final do tipo multicultural pode ser visualizada na figura 2.2 na qual a rede é quadrada $(L=4) \operatorname{com} F=3$ e $Q=15$. Cada agente da figura 2.2 é representado pelo vetor cultural de $F=3$ componentes, e cada componente é representada por uma das $Q=15$ diferentes tonalidades de cinza. Observe que partindo de uma configuração inicial na qual os estados dos agentes são sorteados aleatoriamente (figura 2.2(a)), o sistema evolui para uma configuração na qual há mais de um vetor cultural presente na rede (figura 2.2(b)).

As figuras 2.1 e 2.2 foram obtidas de dinâmicas que evoluíram em um mesmo tamanho de rede $(L=4)$, mesmo valor de $F(F=3)$ e diferentes valores de $Q$. Note que os valores de $F$ e $Q$ determinam apenas o número de possíveis vetores culturais diferentes que podem ser encontrados no instante inicial. Para quaisquer valores $(F, Q)$, há um total de $Q^{F}$ vetores diferentes. Logo, o tipo de configuração final do modelo de Axelrod está relacionado com a multiplicidade de vetores no início da dinâmica.

Como vimos na Introdução, um dos problemas de interesse no estudo dos modelos de dinâmica de opinião é a formação de um estado ordenado ou desordenado de 


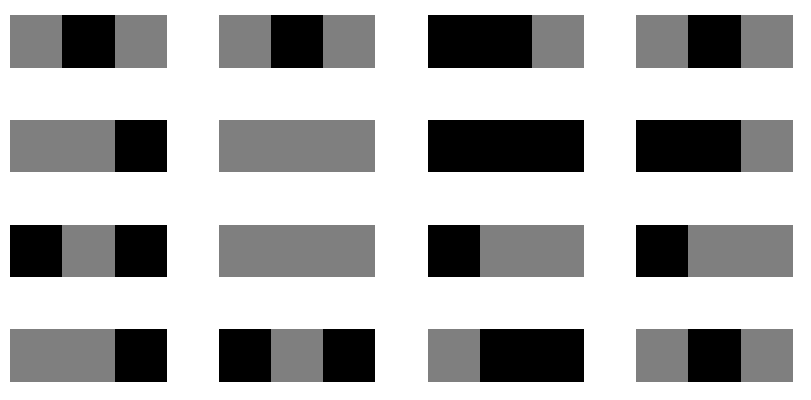

(a) Configuração inicial

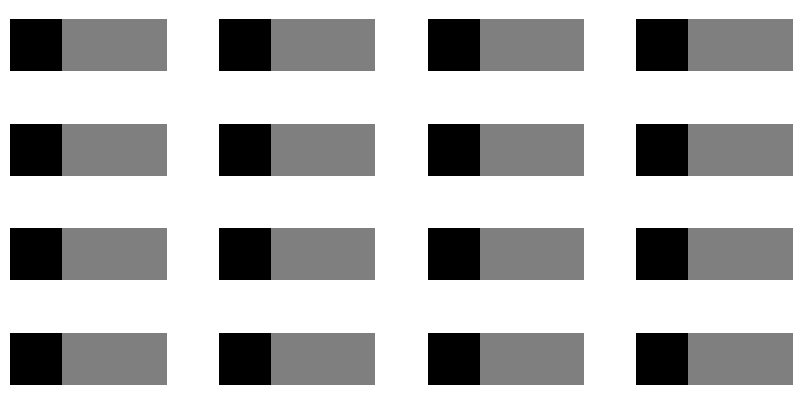

(b) Configuração final

Figura 2.1: Configurações inicial e final de uma rede quadrada de lado $L=4$, com $F=3$ e $Q=2$. Cada sítio da rede abriga um agente representado por seu vetor cultural de $F=3$ componentes, onde cada componente é representada pelos tons de cinza $(q=1)$ e preto $(q=2)$. Em (a), configuração inicial na qual os agentes têm os estados das $F$ componentes sorteados aleatoriamente. Em (b), o sistema atingiu uma configuração final monocultural. 


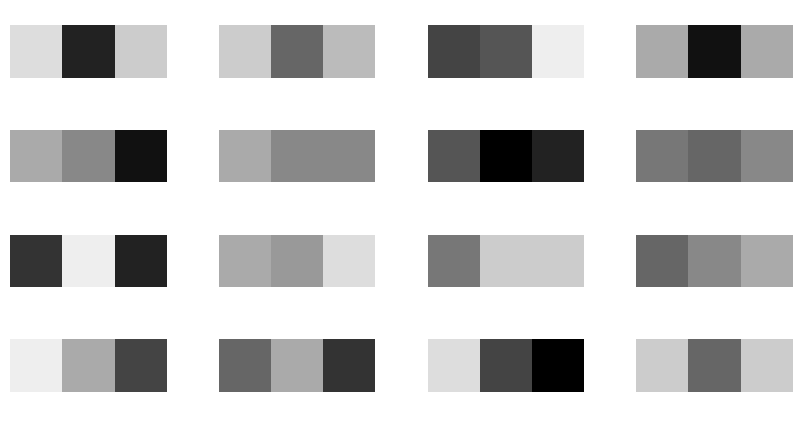

(a) Configuração inicial
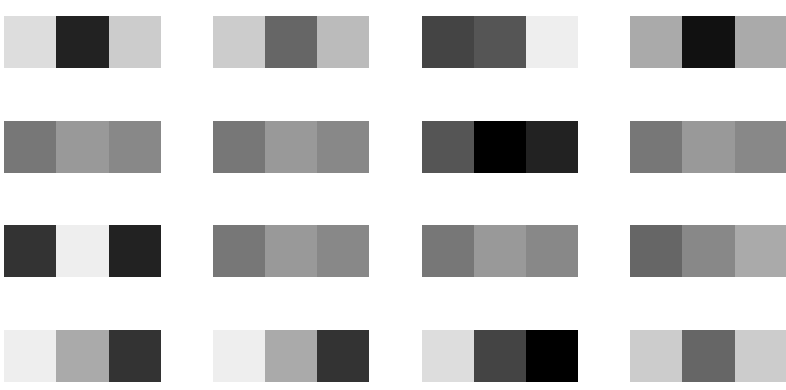

(b) Configuração final

Figura 2.2: Configurações inicial e final de uma rede quadrada de lado $L=4$, com $F=3$ e $Q=15$. Cada sítio da rede abriga um agente representado por seu vetor cultural de $F=3$ componentes, onde cada componente é representada por um de $Q=15$ diferentes tons de cinza. Em (a), configuração inicial na qual os agentes têm os estados das $F$ componentes sorteados aleatoriamente. Em (b), o sistema atingiu uma configuração final multicultural. 
acordo com os parâmetros do modelo. No contexto do modelo de dinâmica cultural de Axelrod, a dependência dos regimes mono e multicultural com os valores de $(F, Q)$ pode, a princípio, ser feita pela inspeção da configuração final. Contudo, o grau de ordem do sistema pode ser determinado com a introdução de parâmetros de ordem adequados.

\subsection{Parâmetro de ordem}

Um parâmetro de ordem é uma medida do grau de ordenação que um sistema possui. Considere, por exemplo, o modelo de Ising. Nesse modelo ferromagnético, cada sítio de uma rede é representado por um dos estados $s_{i}= \pm 1$. Esses estados representam a orientação para cima $(+1)$ ou para baixo $(-1)$ dos spins na rede. Considere a magnetização $m$ do modelo, dada por

$$
m=\sum_{i=1}^{N} s_{i}
$$

O valor da magnetização será nulo quando os spins estiverem orientados para cima e para baixo com igual probabilidade. Quando houver um maior número de spins com dada orientação, o valor da magnetização será diferente de zero $(m>0$ se a maioria estiver orientada para cima; $m<0$ se a maioria estiver orientada para baixo). Assim, considera-se um bom parâmetro de ordem o módulo da magnetização $|m|$. Observe que: se $|m|=0$, o sistema está desordenado, se $|m|>0$, o sistema possui algum grau de ordenação ${ }^{1}$.

Para o modelo de Axelrod em particular, Castellano et al. [40] propõe o uso do tamanho relativo do maior cluster como parâmetro de ordem. Um cluster (ou aglomerado) é formado por um grupo de agentes vizinhos que possuem o mesmo vetor cultural. Podemos definir o tamanho do maior cluster $S$ pela expressão

$$
S=\frac{N_{D}}{N}
$$

onde $N_{D}$ é o número de agentes que pertencem ao maior cluster da rede (cluster dominante) e $N$ é o número total de indivíduos na rede.

\footnotetext{
${ }^{1}$ Como discutido na Introdução, a semelhança do modelo de Ising com os modelos de dinâmica de opinião faz com que ferramentas do primeiro sejam utilizados no segundo. Desse modo, o módulo da magnetização $|m|$ também pode ser utilizado como parâmetro de ordem nos modelos votante e de maioria votante.
} 


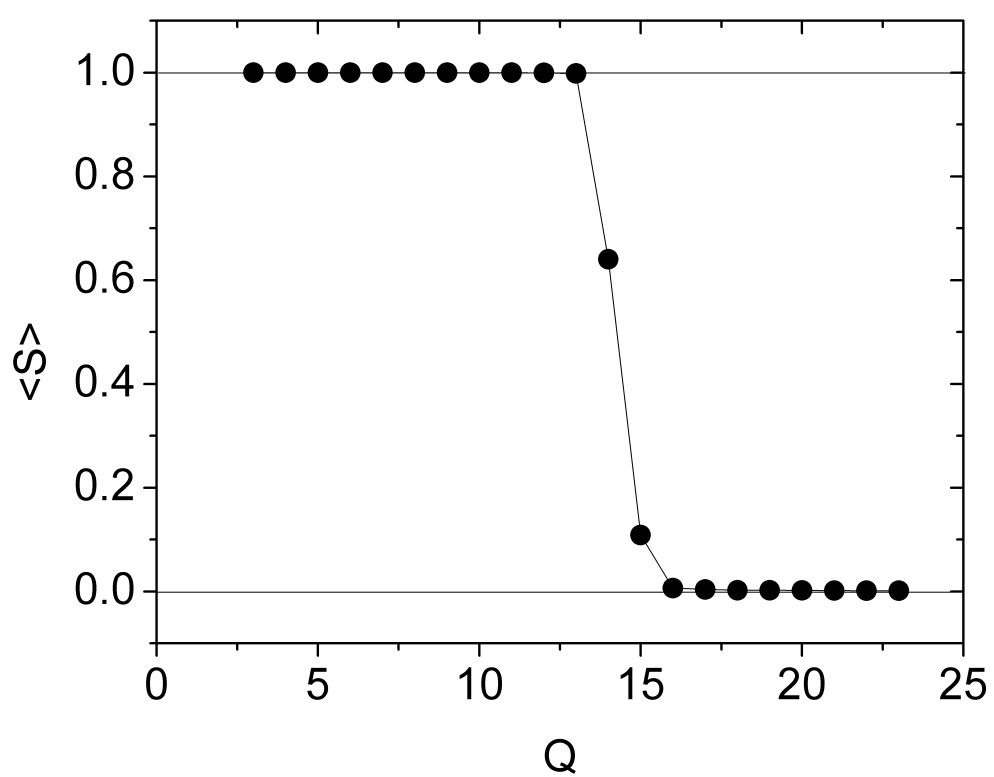

Figura 2.3: Relação do valor do parâmetro de ordem $\langle S\rangle$ com o número de estados $Q$ do modelo de Axelrod para $F=3$. Médias realizadas sobre 30 simulações com condições iniciais diferentes em uma rede $L=150$.

A medida de $S$ na configuração final auxilia na determinação da fase em que o sistema se encontra. Podemos ver na figura 2.3 os valores de $S$ para vários valores de $Q$ quando $F=3$. Nesse caso, as simulações foram realizadas em uma rede de lado $L=150$ e o valor médio $\langle S\rangle$ corresponde à média de $S$ sobre $M=30$ simulações com condições iniciais aleatórias diferentes. Observe que $\langle S\rangle \approx 1$ para uma região de valores $Q<Q_{c}$ e que $\langle S\rangle \approx 0$ para valores $Q>Q_{c}$. O valor de $S \approx 1$ indica que a rede possui um aglomerado de agentes que ocupa a rede toda. Esse valor, portanto, indica que o sistema está ordenado e o regime final é do tipo monocultural. O valor de $S \approx 0$ indica que o tamanho do maior aglomerado é muito pequeno (podendo atingir o valor limite inferior $S=1 / N$ quando o maior cluster é formado por apenas um agente). Esse valor, portanto, indica que o sistema está desordenado e o regime final é do tipo multicultural.

Um outro parâmetro de ordem muito utilizado no estudo do modelo de Axelrod é a fração $g$ de domínios culturais diferentes introduzido em [54], que pode ser definido 


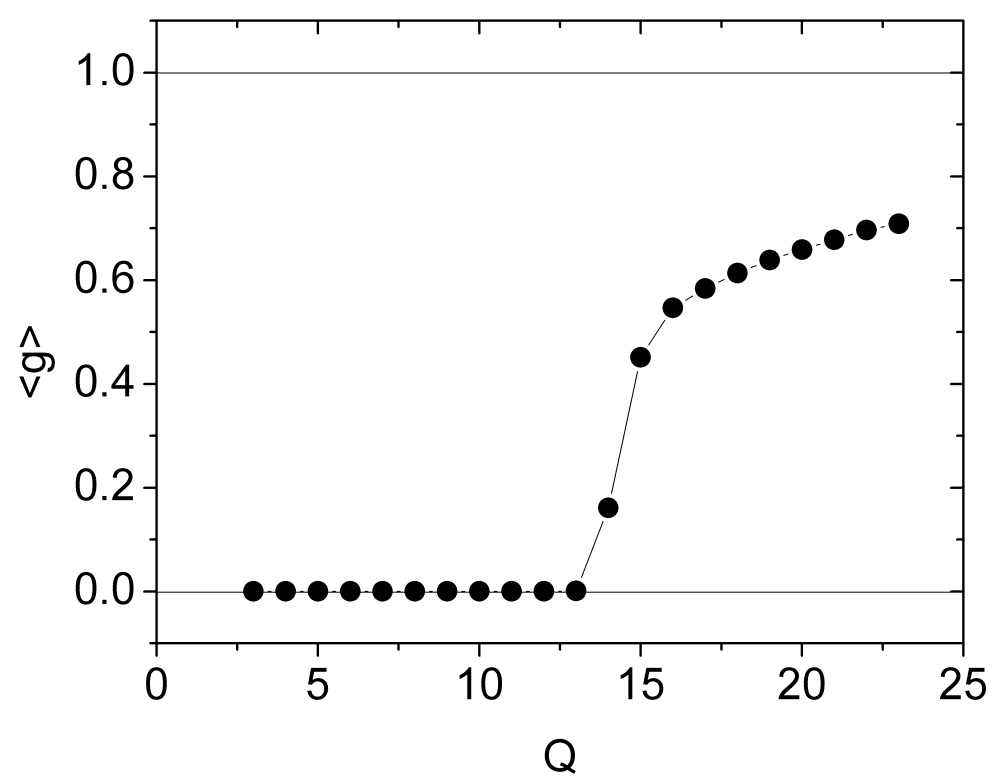

Figura 2.4: Relação do valor do parâmetro de ordem $\langle g\rangle$ com o número de estados $Q$ do modelo de Axelrod para $F=3$. Médias realizadas sobre 30 simulações com condições inciais diferentes em uma rede $L=150$.

pela expressão

$$
g=\frac{N_{g}}{N}
$$

onde $N_{g}$ é o número de domínios diferentes encontrados na configuração final do sistema. Os valores de $\langle g\rangle$ para $F=3$ e vários valores de $Q$ são mostrados na figura 2.4. Cada ponto corresponde a média dos valores $g$ sobre $M=30$ simulações independentes em uma rede quadrada de lado $L=150$.

Observe que $\langle g\rangle \approx 0$ para uma região de valores $Q<Q_{c}$ e que $\langle g\rangle>0$ para valores $Q>Q_{c}$. Os valores $g \approx 0$ correspondem à formação de um estado final no qual há apenas um único cluster na rede $(g=1 / N)$. Nesse caso, portanto, o sistema se encontra ordenado no estado final e o regime é monocultural. O aumento do valor de $Q$ faz com que a configuração final apresente cada vez mais um número maior de aglomerados diferentes, de modo que $g>0$. Nessa situação, o estado final é multicultural.

Note que, para ambos os parâmetros de ordem considerados, a transição dos 
valores de $Q$ nos quais o regime final é monocultural para os valores de $Q$ nos quais o regime final é multicultural ocorre em $Q_{c} \approx 14$. Este é, de fato, o valor $\left(Q_{c}=14\right)$ reportado por Gandica et al. em [55]. De acordo com Castellano et al. em [40], há uma dependência do valor do ponto de transição $Q_{c} \operatorname{com} F$, de modo que $Q_{c}(F)$ aumenta com o valor de $F$.

Podemos ver as curvas dos parâmetros de ordem $S$ e $g$ em função de $Q$ para os valores de $F=3,4,5,7,10$ na figura 2.5. Os resultados foram obtidos em uma rede $L=150$ e $M=30$ simulações. Ambos os parâmetros revelam que $Q_{c}(F)$ aumenta com o valor de $F$. Além disso, observamos que as curvas são semelhantes para os valores de $F$ considerados. Essa semelhança se deve ao tipo de transição observada: a transição (do estado monocultural para o estado multicultural) é descontínua no modelo de Axelrod na rede quadrada para $F \geq 3[7,40]$. Nesses casos, espera-se que a transição seja caracterizada por uma região metaestável em torno do ponto de transição $Q_{c}$ na qual encontramos coexistência de fases.

Os resultados para o caso particular $F=2$ são apresentados na figura 2.6. Vemos nessa figura a dependência de $S$ e $g$ com os valores de $Q$. Os pontos correspondem aos valores médios obtidos de $M=30$ simulações em uma rede com $L=150$. Podemos observar na figura 2.6(a) que a queda dos valores de $\langle S\rangle$ quando $F=2$ é mais suave que a observada nos casos em que $F \geq 3$ (figura 2.5(a)). Também observamos a ausência de um platô em torno de $S \approx 1$ - tal platô indicaria a presença de uma configuração final na qual todos os agentes possuem o mesmo vetor cultural. Contudo, há uma região de valores $Q<Q_{c}$ nos quais a configuração final apresenta um cluster dominante que pode ocupar até $80 \%$ da rede. Na figura 2.6(b) observamos que, para o mesmo tamanho de rede $(L=150)$, o salto nos valores de $g$ em $Q_{c}(F)$ para $F=2$ é mais suave que o salto o observado para $F=3,4,5,7,10$ (ver figura 2.5(b)). Nesse caso, notamos que $g \approx 0$ quando $Q<Q_{c}$ e que $g>0$ quando $Q>Q_{c}$. A transição parece ocorrer em torno de $Q_{c} \approx 7$, mesmo valor reportado por Gandica et al. em $[55]\left(Q_{c}=7\right)$ para uma rede quadrada de lado $L=40$.

A ordem da transição é determinada em [40] pela análise da distribuição acumulada dos tamanhos dos vários aglomerados encontrados na configuração final. Definindo $U_{L}(S, Q)$ como sendo a fração de regiões de tamanho maior que $S$ para 


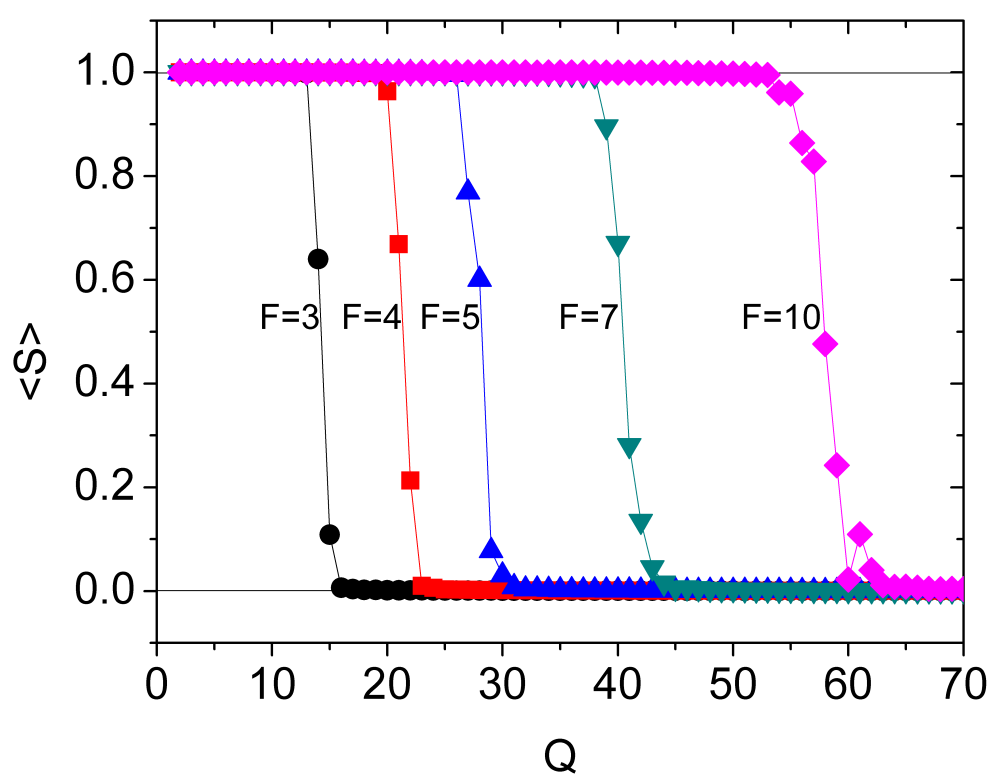

(a)

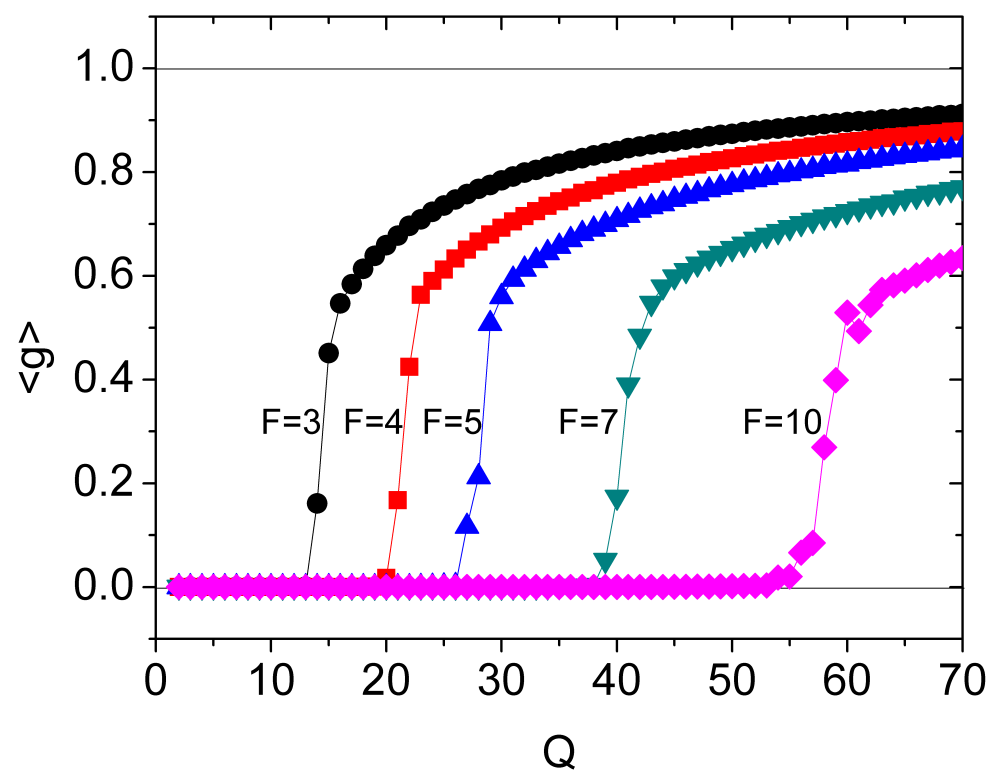

(b)

Figura 2.5: Relação do valor do parâmetro de ordem $\langle S\rangle$ em (a) e do parâmetro $\langle g\rangle$ em (b) com o número de estados $Q$ do modelo de Axelrod para $F=3,4,5,7,10$. Médias realizadas sobre 30 simulações com condições iniciais diferentes em uma rede $L=150$. 


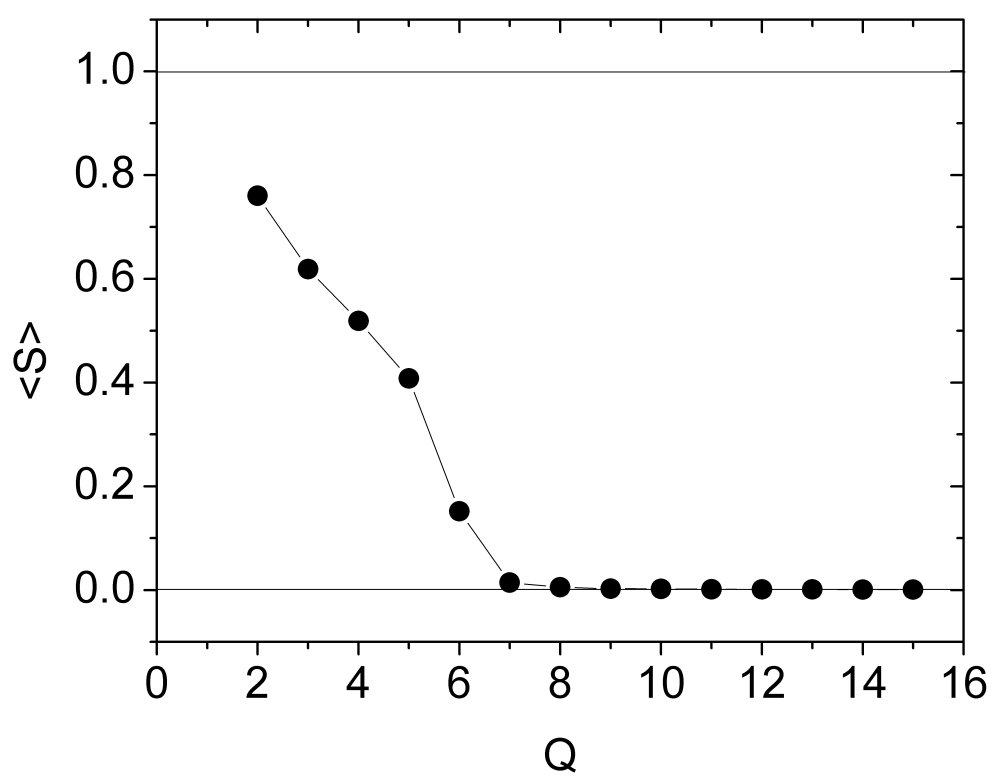

(a)

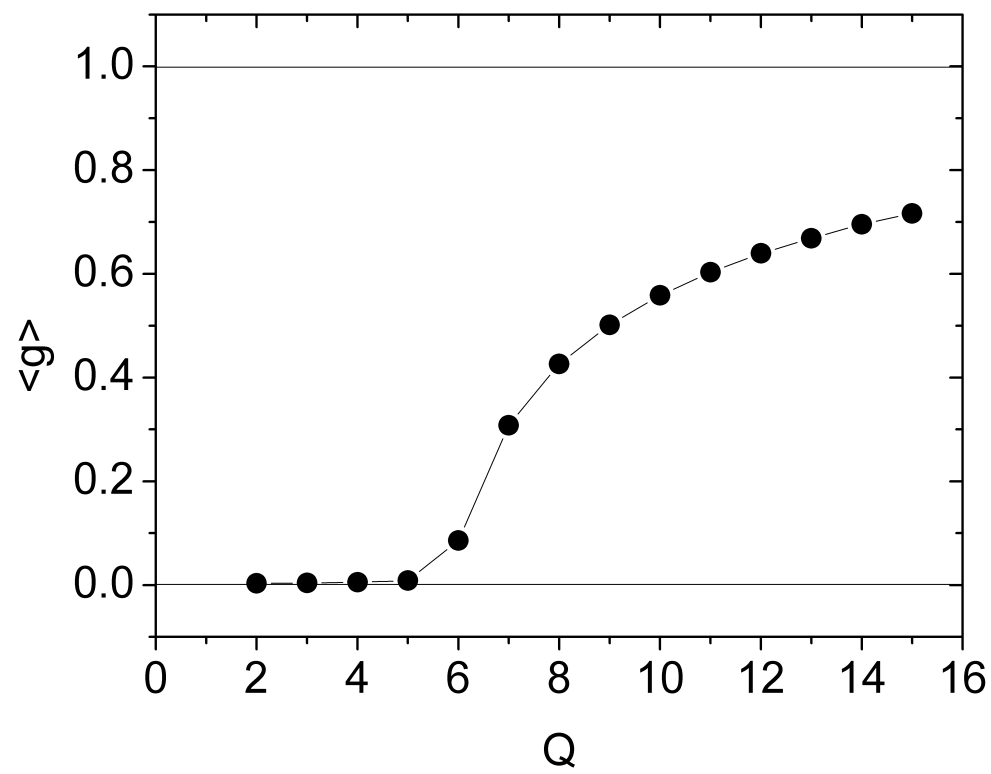

(b)

Figura 2.6: Relação do valor do parâmetro de ordem $\langle S\rangle$ em (a) e do parâmetro $\langle g\rangle$ em (b) com o número de estados $Q$ do modelo de Axelrod para $F=2$. Médias realizadas sobre 30 simulações com condições iniciais diferentes em uma rede $L=$ 150 . 
certo tamanho de rede $L$ e para dado $Q$, os resultados mostram que $U_{L}(S, Q)$ decai como uma lei de potência na forma $S^{1-\tau^{\prime}}$, onde $\tau^{\prime} \approx 2.6$ para $F \geq 3$ e $\tau^{\prime} \approx 1.6$ para $F=2$. Comparando estes resultados com o que ocorre na teoria de percolação [56], os autores mostram que a transição é contínua para $\tau^{\prime}<2(F=2)$ e descontínua para $\tau^{\prime}>2(F \geq 3)$.

Em [57], Klemm et al. analisam a distribuição dos valores do parâmetro $S$ para $F=10$, em $L=100$ e $M=100$ simulações independentes. Nessa análise, é observado que $S$ apresenta uma região de biestabilidade em torno de $Q_{c}=55$. Os autores argumentam que essa biestabilidade ocorre porque os valores de $S$ estão distribuídos em torno de $S \approx 1$ e $S \approx 0$ (visualizada através da apresentação do histograma de $S$ em $Q=Q_{c}$ ). Nesse caso, há uma região de coexistência de fases, e os dois picos da distribuição do parâmetro de ordem sugere que a transição é descontínua.

Os efeitos do tamanho de rede na dinâmica e na formação dos regimes finais podem ser visualizados na figura 2.7. Cada ponto corresponde a $M=30$ simulações nas redes $L=50,100,150$. Nas figuras 2.7 (a) e 2.7(b), mostramos os resultados de $\langle S\rangle$ e $\langle g\rangle$, respectivamente, para $F=3$ (escolhemos $F=3$ para exemplificar o que ocorre quando $F \geq 3$, pois nesses casos os comportamentos do sistema são semelhantes). Observe que a região de transição diminui com o aumento da rede e que a transição se torna mais abrupta. Esse resultado está de acordo com a equação (1.1), pois o desvio em torno do ponto de transição diminui com o aumento de $L\left(N=L^{2}\right)$. Esses desvios, que também são visualizados nas curvas $\langle S\rangle$ e $\langle g\rangle$ nas figuras $2.7(\mathrm{c})$ e $2.7(\mathrm{~d})$, são mais sutis (nos tamanhos de rede estudados) para $F=2$.

\subsubsection{Comentários sobre $F=2$ e $F=1$}

Devemos mencionar que em [40] os autores ressaltam que $F=2$ é um caso especial e diferente dos demais valores de $F$. Quando o vetor cultural tem dois elementos, a interação entre um par agente-vizinho só ocorre se um dos elementos (uma das características culturais) apresentar o mesmo estado em ambos os agentes. Consequentemente, uma única interação faz com que o vetor cultural do agente se torne exatamente igual ao vetor cultural do vizinho. Essa propriedade faz com que o caso $F=2$ possa ser considerado um processo de contato [40]. De acordo com Marro 


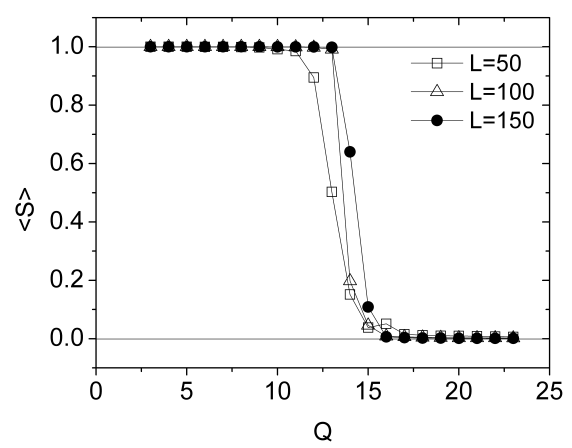

(a)

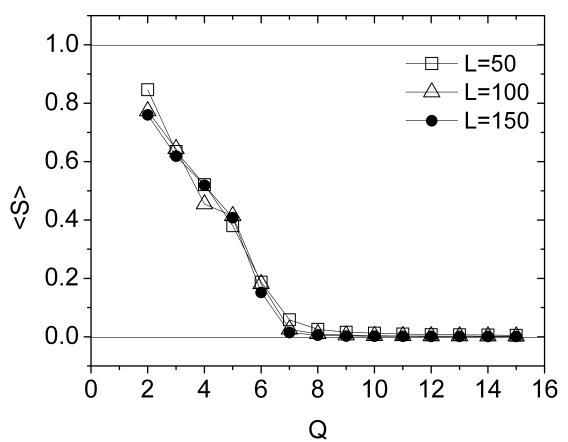

(c)

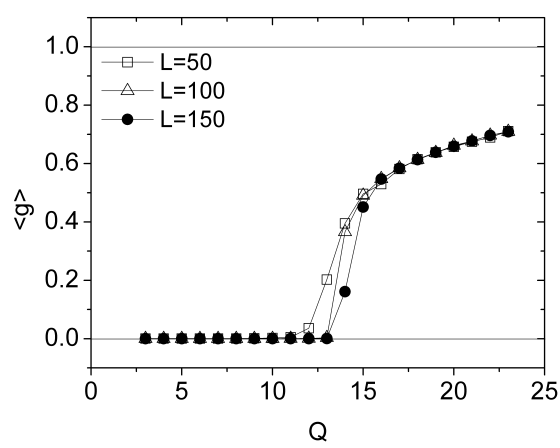

(b)

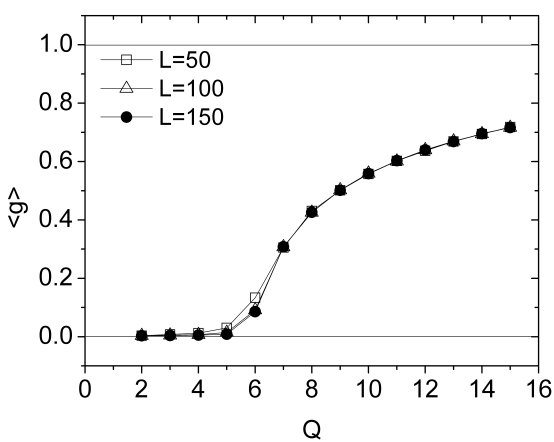

(d)

Figura 2.7: Em (a) e (b), dependência dos parâmetros de ordem $\langle S\rangle$ e $\langle g\rangle$, respectivamente, com o número de estados $Q$ para $F=3$ nos tamanhos de rede $L=50,100,150$. Em (c) e (d), dependência dos parâmetros de ordem $\langle S\rangle$ e $\langle g\rangle$, respectivamente, com o número de estados $Q$ para $F=2$ nos tamanhos de rede $L=50,100,150$. As médias foram realizadas sobre $M=30$ simulações independentes com condições iniciais diferentes.

e Dickman em [58], um processo de contato pode ser definido da seguinte forma: considere uma rede cúbica $d$ dimensional. Cada sítio dessa rede pode estar em um de dois estados: estado ocupado (ou infectado) ou estado vazio (ou sadio). Em cada instante de tempo, um agente pode infectar seus vizinhos com uma taxa $\lambda$. Se um agente está infectado, ele automaticamente se torna sadio no próximo instante de tempo.

Nesse modelo de processo de contato, deseja-se estudar se uma infecção consegue permanecer na rede no estado estacionário. Os resultados mostram que isso só acontece se a taxa de infecção $\lambda$ for superior a um valor crítico $\lambda_{c}$. Para o caso em 
que $\lambda<\lambda_{c}$, a infecção não prolifera com rapidez suficiente para se sustentar na rede e, portanto, todos os agentes são sadios no estado estacionário. Esse estado no qual todos os agentes são sadios é o estado absorvente do modelo ${ }^{2}$. Nesse sentido, o modelo de Axelrod (com $F=2$ ) se assemelha a um processo de contato com uma taxa de infecção $\lambda_{\text {Axelrod }}=1 / 2$ (pois só nesse caso a interação ocorre).

O modelo de Axelrod para $F=1$ não possui evolução dinâmica. Nesse valor de $F$, a comparação entre um par agente-vizinho resulta em $P_{i, j}=1$ se ambos possuírem o mesmo estado ou em $P_{i, j}=0$ se ambos possuírem estados diferentes. Considerando $Q=2$, por exemplo, o modelo de Axelrod é semelhante ao processo de percolação por sítio. Nesse processo de percolação, cada sítio pode estar ocupado ou vazio. Um sítio é ocupado com probabilidade $p$, e observa-se a formação de domínios de sítios ocupados. De acordo com Gastner em [59], o interesse maior da teoria de percolação é o estudo dos tamanhos dos domínios de sítios ocupados. Os resultados em [60] mostram que há uma probabilidade de ocupação crítica $p_{c}$ acima da qual um domínio grande o suficiente para conectar a rede de um lado a outro pode ser formado.

\subsection{Extensões do modelo}

Axelrod destaca que a simplicidade é uma das vantagens de seu modelo. Em sua opinião, essa simplicidade permite a implementação de novos ingredientes para o estudo de diversos fenômenos sociais adicionais. Ele menciona, como extensões potencialmente interessantes do modelo, os exemplos de cultural drift, que seriam representadas por mudanças espontâneas em um estado, terrain effects, em que alguns pares de agentes têm menos chance de interagir do que outros, early geographic differences, em que a distribuição inicial de estados é não-aleatória, public education and broadcasting, em que algumas interações são provenientes de informações disseminadas na rede, entre outros que podem ser conferidos em [48].

Em [40], os autores estudam a relação entre o grau de desordem da configuração

\footnotetext{
${ }^{2}$ Esse é um exemplo de transição para estado absorvente: se $\lambda<\lambda_{c}$, o sistema evolui para um estado absorvente único no qual todos os sítios estão sadios. A transição que observamos no modelo de Axelrod é diferente: é uma transição de um regime monocultural para um regime multicultural na qual todas as configurações finais são absorventes. Enquanto que o processo de contato possui um único estado absorvente, no modelo de Axelrod todo estado final é absorvente
} 
inicial com a configuração observada no estado estacionário. O grau de desordem se relaciona com os parâmetros $(F, Q)$ na medida em que o número de vetores culturais diferentes que podem ser encontrados na rede é $Q^{F}$. Logo, a configuração inicial é mais desordenada quanto maior forem $Q$ e $F$. Nesse estudo em particular, os estados iniciais dos vetores culturais são extraídos de uma distribuição de Poisson discreta com valor médio $Q$ real, e a interação entre um par agente-vizinho ocorre se ambos compartilham o mesmo estado para uma dada característica sorteada aleatoriamente. Os autores afirmam que a evolução do sistema é caracterizada por uma competição entre a desordem da configuração inicial e a capacidade de ordenação das interações locais. Eles mostram que, para dado $F$, o valor de $Q$ determina o tipo de configuração final e que a ordem da transição é contínua para $F=2$ e descontínua para $F \geq 3$.

Em [61], os autores consideram o modelo de Axelrod em uma rede unidimensional. Nesse estudo, é desenvolvida uma aproximação de campo médio para determinar o ponto de transição entre as fases ordenadas e desordenadas do modelo. Os resultados mostram que a natureza da transição depende também da configuração inicial: se a distribuição inicial dos estados é aleatória, o sistema sempre apresenta uma transição de fase quando $Q=Q_{c}(F)$; se a distribuição inicial dos estados segue uma distribuição de Poisson discreta, o sistema apresenta transição se $F>2$ (para $F=2$, a configuração final é sempre desordenada). Esses resultados, corroborados por simulações numéricas, permitem a determinação do diagrama de fases do modelo para o caso unidimensional.

O papel da dimensão também é explorado em [62]. Nesse artigo, os autores estudam o papel da dimensão para $F=10$. Os resultados mostram que as transições no caso unidimensional são de segunda ordem, enquanto que no caso bidimensional a ordem de transição possui uma dependência com os valores de $F$. A observação da dinâmica do modelo em outras topologias diferentes também são objetos de estudo em [57] e em [63], por exemplo.

Em [64], estuda-se o efeito do cultural drift, sugerido por Axelrod em [48], no modelo em uma e duas dimensões. O cultural drift é implementado na forma de um ruído que altera (com probabilidade $r$ ) o estado de um agente depois que o sistema atinge a configuração final. Ao testar a estabilidade dos estados multiculturais para 
uma rede quadrada quando $F=10$, os autores mostram que uma taxa de ruído baixa $\left(r \propto 10^{-5}\right)$ desestabiliza o regime desordenado e a configuração final passa a apresentar um cluster dominante. Estudo semelhante sobre o cultural drift também é encontrado em [65].

Dentre os demais trabalhos encontrados na literatura, destacamos os que introduzem campos locais, globais e externos na dinâmica. Em [66], González-Avella et al. introduzem o efeito de meios de comunicação de massa (mass media, no sentido de bradcasting mencionado por Axelrod) que são modelados na forma de um campo externo na dinâmica de Axelrod. Nesse modelo, o agente tem a opção de interagir com um agente virtual, que representa o campo externo, com probabilidade $B$. Os autores mostram que, para $F=10, Q=45$ (regime monocultural) e uma rede quadrada de lado $L=50$, a introdução do campo externo pode desestabilizar o regime monocultural, ou seja, a introdução do campo externo faz com que uma configuração monocultural em $B=0$ se torne multicultural quando $B>B_{c}$. A desestabilização do regime monocultural pela introdução de meios de massa também é analisada em [67]. Nesse estudo, os autores estudam a estabilidade das configurações monoculturais do modelo de Axelrod com $F=5$ e $Q=5$. Os valores de $F$ e $Q$ são escolhidos de modo a garantir que o sistema apresente um regime final ordenado na ausência de campo externo. Em [68], os autores explicam que a introdução do campo externo aumenta o número de domínios diferentes na rede porque pode haver um isolamento dos agentes que não tem nenhuma característica em comum com o agente virtual que representa o meio de massa ${ }^{3}$. Desse modo, a redução na intensidade do campo externo aumenta o papel das interações locais permitindo, assim, o estabelecimento de um estado menos fragmentado.

Em [43], os autores consideram três tipos de meios de massa atuando no modelo de Axelrod:

Campo externo: é um campo uniforme e constante, que atua na rede na forma de um agente virtual externo (o campo possui um vetor cultural com estados pré-definidos).

\footnotetext{
${ }^{3} \mathrm{Um}$ agente da rede interage com o agente virtual que representa o campo externo de acordo com a intensidade do campo (probabilidade $B$ ) e com a probabilidade de interação do modelo de Axerod $P_{i, j}$.
} 
Campo global: é um campo uniforme e que pode variar no tempo. Determina-se, entre os agentes da rede, qual o estado mais frequente para cada característica. O campo global é, então, formado pelo conjunto de características com os estados mais frequentes globalmente.

Campo local: é um campo não-uniforme e que pode variar no tempo. Determina-se, entre os agentes da vizinhança de um sítio $i$, quais os estados mais frequentes para cada característica. O campo local do agente $i$ será, então, formado pelo conjunto de características com estados mais frequentes localmente.

Os resultados mostram que, para $F=5$, enquanto um campo local com intensidade $B=10^{-5}$ promove uma desestabilização do regime multicultural, um campo global de mesma intensidade não afeta, aproximadamente, a formação dos regimes mono e multicultural. Contudo, mostra-se que o aumento da intensidade do campo global $(B=0.3)$ afeta a estabilidade do regime monocultural favorecendo a formação de configurações multiculturais. De acordo com os autores, o campo local tem um poder de ordenação maior que os campos externo e global. O papel de campos espacialmente não-uniformes na homogeneização do estado final também é abordado, em uma e duas dimensões, em [53].

Em suma, os trabalhos mencionados acima estudam os efeitos que as alterações na distribuição dos estados iniciais, que os diferentes tipos de perturbações, que a topologia e que a dimensão da rede causam na dinâmica de disseminação cultural do modelo de Axelrod. Todos os trabalhos compartilham a informação de que existe um valor $Q_{c}(F)$ tal que, para dado $F$, o regime é monocultural se $Q<Q_{c}(F)$ e multicultural se $Q>Q_{c}(F)$. A dependência de $Q_{c}(F)$ com o valor de $F$ ainda é desconhecida no caso bidimensional (para o caso unidimensional, Vilone et al. em [61] determinam que $\left.Q_{c}(F)=F\right)$. Atualmente, a determinação do ponto de transição $Q_{c}(F)$ foi feita apenas para alguns valores de $F$ através da inspeção do gráfico de transição do parâmetro de ordem [43], pela análise do histograma [57, 62], ou por outros métodos [61, 55], por exemplo.

Uma das dificuldades para a estimação numérica do diagrama de fases do modelo de Axelrod é o tempo computacional. O estado estacionário é facilmente determi- 
nado quando a probabilidade de interação de cada par agente-vizinho da rede ou é nula (quando não há nenhuma semelhança entre eles) ou é igual a um (quando o par compartilha dos mesmos estados em todas as $F$ características). Nessa situação, a configuração final é congelada e a dinâmica pode ser interrompida. Contudo, esse estado final congelado pode, para algumas configurações iniciais, levar muito tempo para ser atingido [53]. Consequentemente, a necessidade de se realizar várias simulações para obtenção de valores médios pode inviabilizar esse tipo de estimativa. 


\section{Capítulo}

\section{Atividade de um modelo de dinâmica social}

"The pursuit of truth and beauty is a sphere of activity in which we are permitted to remain children all our lives."

\section{- Albert Einstein}

O modelo de Axelrod foi proposto para se estudar as interações entre os agentes de uma sociedade e a formação de domínios culturais. Esse modelo apresenta uma transição de um estado monocultural para um estado multicultural que vem sendo estudada na literatura pelo cálculo do tamanho relativo do maior domínio cultural. Nesse capítulo, apresentaremos a proposta de novas medidas baseadas no conceito de atividade por agente para o estudo do modelo de Axelrod em uma rede quadrada. Mostramos que a variância da atividade do sistema pode ser usada para indicar os pontos de transição. Além disso, a distribuição de frequência da atividade do sistema mostra uma coexistência de fases típica de uma transição de fase de primeira ordem. Finalmente, verificamos uma dependência em forma de lei de potência entre a atividade e o tamanho de um domínio cultural nos estados multiculturais no ponto crítico.

\subsection{Atividade}

Neste capítulo consideramos o modelo de Axelrod em uma rede quadrada de lado $L$ com condições periódicas de contorno. Cada sítio da rede abriga um agente 
com vetor cultural $\psi$. O sistema evolui de uma condição inicial aleatória (onde os estados das características culturais são escolhidos aleatoriamente entre os $Q$ estados possíveis) de acordo com os passos descritos no Capítulo 2. Na literatura [40, 61], a transição entre os regimes ordenado e desordenado tem sido estudada através do cálculo do tamanho relativo $S$ do maior aglomerado (equação (2.3)). O valor médio $\langle S\rangle$ (média sobre $M$ simulações) tem sido usado como um parâmetro de ordem do sistema.

Esse parâmetro de ordem, no entanto, não é capaz de mostrar como as pressões locais da vizinhança afetam os agentes conforme o sistema evolui. De acordo com Axelrod [48], o estado final ordenado é causado por mecanismos de convergência local que, por sua vez, também podem levar o sistema a um estado final desordenado. Para elucidar o papel da pressão local e da convergência local na dinâmica, propomos o conceito de atividade para estudar esse sistema [51].

Definimos a atividade por agente $i$ no tempo $t$ como

$$
a_{i}(t)=\frac{N_{\psi_{i}}(t)}{t},
$$

onde $N_{\psi_{i}}(t)$ é o número de mudanças no vetor cultural $\psi_{i}$ durante os primeiros $t$ passos de Monte Carlo. A cada passo de tempo, um agente $i$ tem probabilidade $1 / N$ de ser escolhido aleatoriamente e probabilidade $P_{i, j}$ de interagir com algum vizinho $j$. Uma vez que $N$ agentes são aleatoriamente escolhidos em um dado passo de tempo, o valor esperado de $N_{\psi_{i}}(t)$ depois de $t$ passos de tempo se encontra entre 0 e $t$. Consequentemente, pode-se esperar que $0 \leq a_{i}(t) \leq 1$. Para nossos propósitos, nós estudamos a atividade por agente $A_{i}$ no tempo $t=T$, onde $T$ é o número de passos de tempo para o sistema alcançar o estado estacionário $\left(A_{i}=a_{i}(T)\right)$.

Como definimos, um agente muito ativo $\left(A_{i} \approx 1\right)$ enfrenta uma alta pressão cultural de seus vizinhos e experimenta vários vetores culturais até o estabelecimento do estado final. Por outro lado, um agente pouco ativo $\left(A_{i} \approx 0\right)$ permanece apegado aos seus próprios estados culturais, implicando na robustez desse agente à pressão da vizinhança pela mudança de suas características culturais. Nesse sentido, a atividade é inversamente proporcional à tendência de um agente em manter suas características culturais. Note que a atividade é diferente do conceito de persistência encontrado na literatura [69]: persistência é a probabilidade de que uma variável local (agente) 
não altera seu estado (vetor cultural) até o tempo $t$, enquanto que a atividade mede o número total de mudanças no estado de um agente nesse intervalo de tempo.

\subsection{Estados de equilíbrio}

Atividade do sistema $A$ é definida pela expressão

$$
A=\frac{1}{N} \sum_{i=1}^{N} A_{i}
$$

e é considerada uma medida global do sistema. Nesse contexto, a média $\langle A\rangle$ sobre $M$ simulações independentes é proposta como uma medida alternativa do grau de ordem do sistema e tem um comportamento semelhante ao de um parâmetro de ordem.

A dependência de $\langle A\rangle$ com o número de estados $Q$ é mostrada na figura 3.1 (para dados de $M=30$ simulações independentes em três tamanhos de rede diferentes). Pode-se ver que o parâmetro $\langle A\rangle$ nos permite a distinção de dois regimes:

i) $\langle A\rangle>0$ para $Q<Q_{c}$ : para um baixo número de estados $\left(Q<Q_{c}\right)$, as

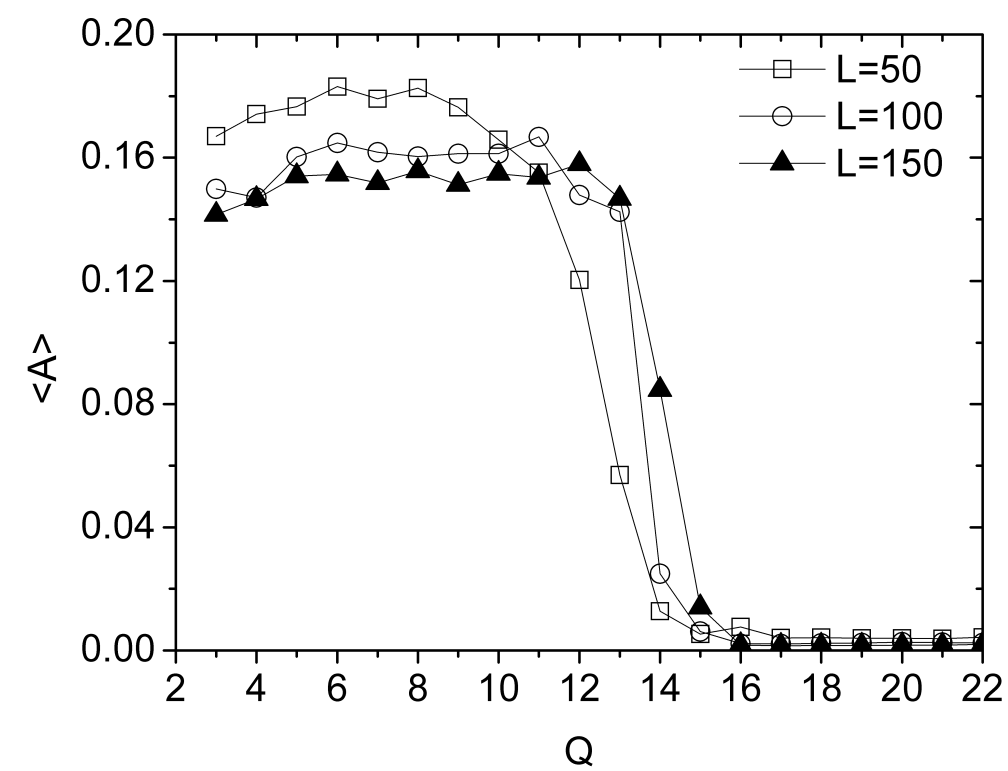

Figura 3.1: Parâmetro de ordem $\langle A\rangle$ em função de $Q$ para diferentes tamanhos de rede $L$ e $F=3$. A média $\langle A\rangle$ foi obtida de $M=30$ simulações independentes. 
interações entre os agentes são muito frequentes, resultando em $\langle A\rangle>0$. Logo, há a difusão de um vetor cultural através da rede que promove a ordenação do sistema em um estado final monocultural.

ii) $\langle A\rangle \approx 0$ para $Q>Q_{c}$ : para um alto número de estados $\left(Q>Q_{c}\right)$, as interações entre os agentes são menos frequentes, $\operatorname{logo}\langle A\rangle \approx 0$. Consequentemente, um grande número de pequenos domínios são encontrados no estado final da rede (multicultural) e o sistema se encontra desordenado.

O valor crítico $Q_{c}$ pode ser obtido relembrando o conceito de ponto de transição efetivo. De acordo com Landau [22], sistemas finitos não apresentam divergências em suas medidas estatísticas. Como consequência, procuramos por um ponto de transição efetivo $Q_{c}(L)$ em sistemas finitos onde a susceptibilidade do parâmetro de ordem alcança seu valor máximo. A susceptibilidade $\chi_{A}$ é proporcional à variância do parâmetro $A$,

$$
\chi_{A}=N\left(\left\langle A^{2}\right\rangle-\langle A\rangle^{2}\right) .
$$

A susceptibilidade do tamanho relativo do maior aglomerado $\left(\chi_{S}\right)$ é definida de modo análogo:

$$
\chi_{S}=N\left(\left\langle S^{2}\right\rangle-\langle S\rangle^{2}\right) .
$$

A figura 3.2(a) mostra as susceptibilidades de ambos os parâmetros $S$ e $A$ para $F=3, M=30$ e $L=150$. Os máximos das variâncias ocorrem no mesmo ponto de transição $Q_{c}=14$. A figura 3.2(b) mostra os pontos de transição $Q_{c}(L)$ para diferentes tamanhos de rede (de $L=25$ até $L=200$ ) obtido dos valores máximos de $\chi_{S}$ e $\chi_{A}\left(Q_{c}\left(\max \chi_{S}\right)\right.$ e $Q_{c}\left(\max \chi_{A}\right)$, respectivamente). Portanto, a atividade média $\langle A\rangle$ apresenta características de um parâmetro de ordem dado que ela é capaz de indicar a transição do estado final monocultural para o estado final multicultural.

A figura 3.3 mostra a dependência de $\langle A\rangle / F$ versus $Q$ para $F \geq 3(L=150$ e $M=30)$. Em conformidade com os resultados da literatura apresentados nos capítulos anteriores, observa-se que para $F \geq 3$ o parâmetro atividade cai abruptamente conforme $Q$ aumenta, um comportamento típico de transições de fase de primeira 


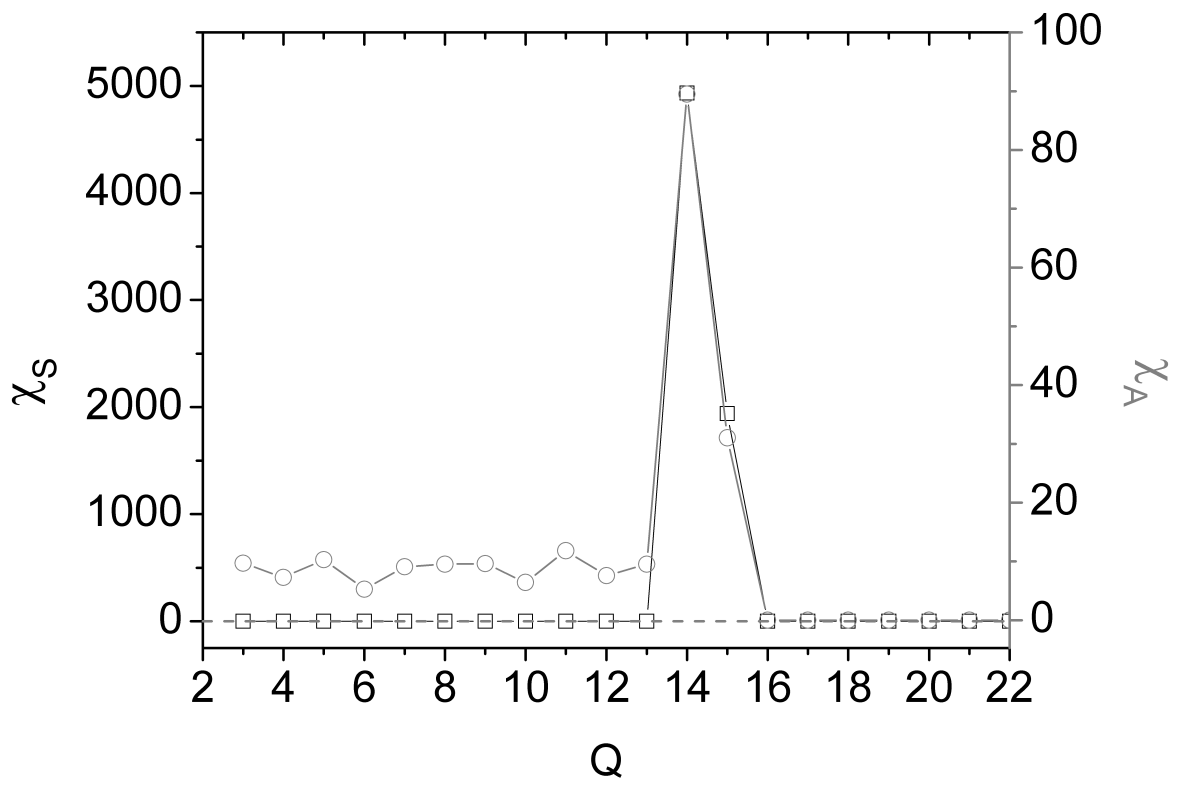

(a)

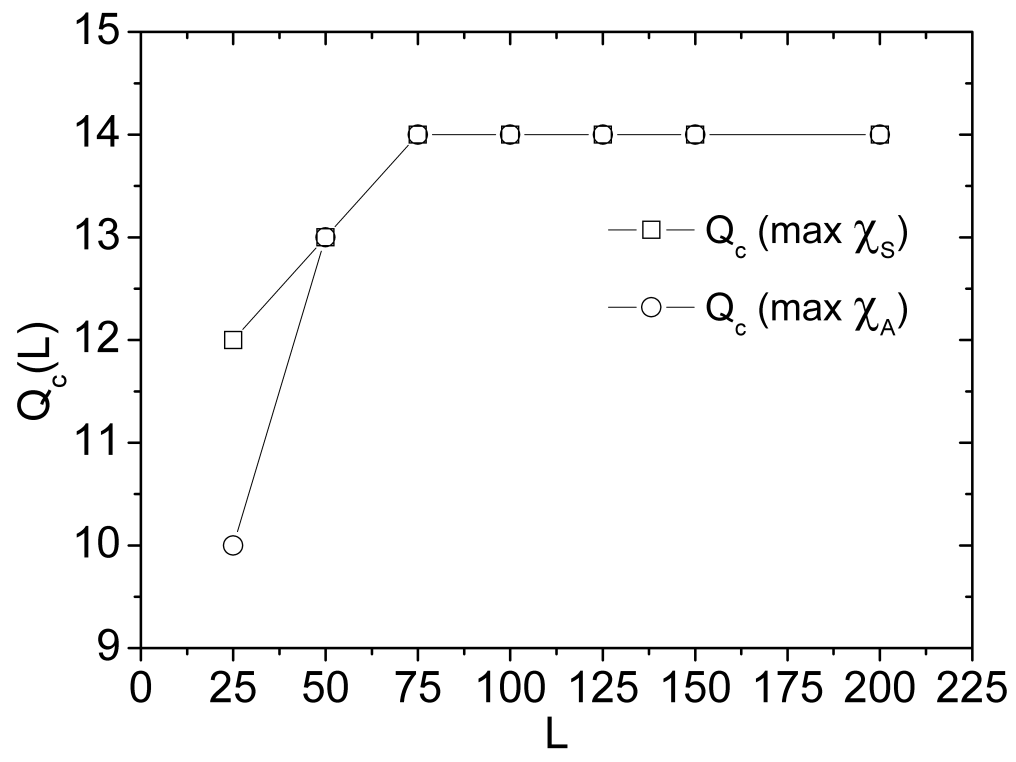

(b)

Figura 3.2: Comparação entre as susceptibilidades $\chi_{S}$ (quadrados) e $\chi_{A}$ (círculos) dos parâmetros de ordem $S$ e $A$, respectivamente. Em (a), temos $\chi_{S}$ no eixo da esquerda e $\chi_{A}$ no eixo da direita. As duas curvas apresentam um pico em $Q_{c}=14$ para $F=3, L=150$ e $M=30$. Em (b), $Q_{c}$ é determinado a partir dos parâmetros $A\left(Q_{c}\left(\max \chi_{A}\right)\right)$ e $S\left(Q_{c}\left(\max \chi_{S}\right)\right)$ para vários tamanhos de rede $L$. 


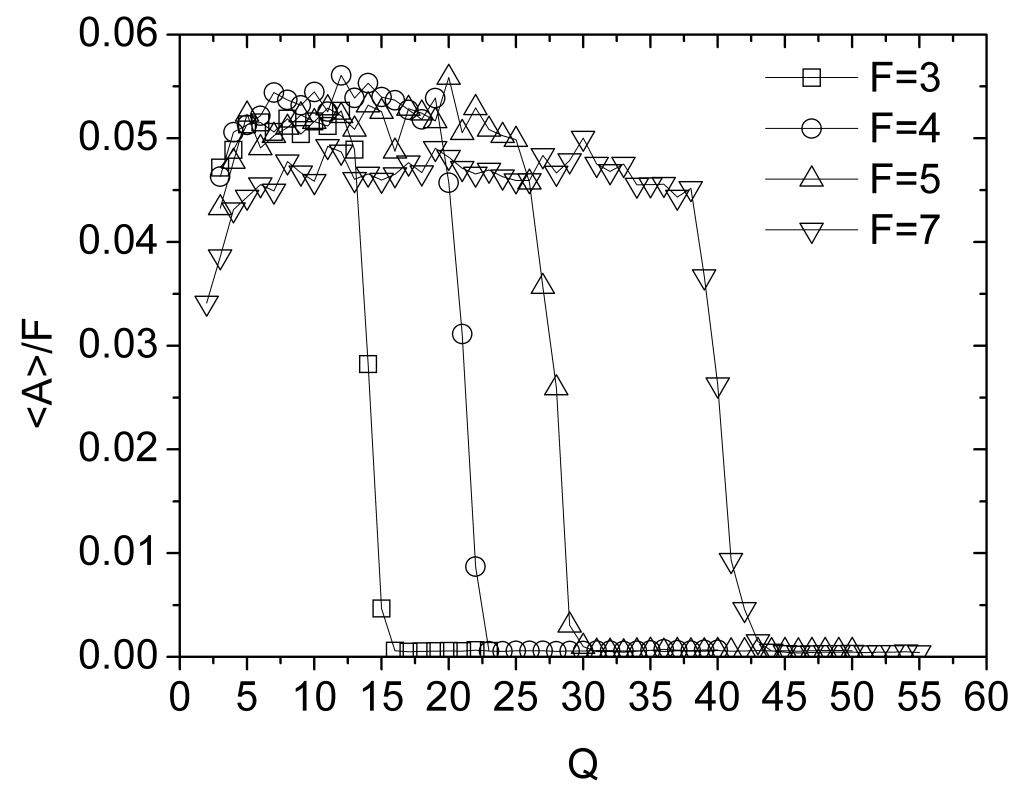

(a)

Figura 3.3: Parâmetro $\langle A\rangle / F$ versus $Q$ para $F=3,4,5,7$ e $L=150$. Os dados foram obtidos de $M=30$ simulações.

ordem. Separações do regime monocultural para o regime multicultural ocorrem nos valores $Q_{c}(F)$ que aumentam com $F$, como esperado [55]. Por outro lado, a curva de $\langle A\rangle / F$ versus $Q$ correspondendo à $F=2$ é mostrada na figura 3.4(a) para redes de tamanho $L=50,100,150$. A figura 3.4(b) apresenta $\langle S\rangle$ em função de $Q$ para os mesmos tamanhos de rede. Nesse caso, $\langle A\rangle / F$ (assim como $\langle S\rangle$ ) decai suavemente para zero conforme $Q$ aumenta de $Q=2$ até $Q=15$ e não são encontrados platôs quando $Q$ é baixo. Esse comportamento é típico de uma transição contínua (segunda ordem).

\subsection{Mapa da atividade}

O estado estacionário do sistema é caracterizado pela presença de domínios culturais que dependem dos valores de $F$ e $Q$. A figura 3.5(a) mostra uma configuração da rede para $F=3$ no ponto crítico $Q_{c}=14$. Cada tonalidade representa um vetor cultural $\psi_{i}$. Pode-se observar que, embora a rede esteja fragmentada, ainda encontramos domínios culturais de vários tamanhos. 


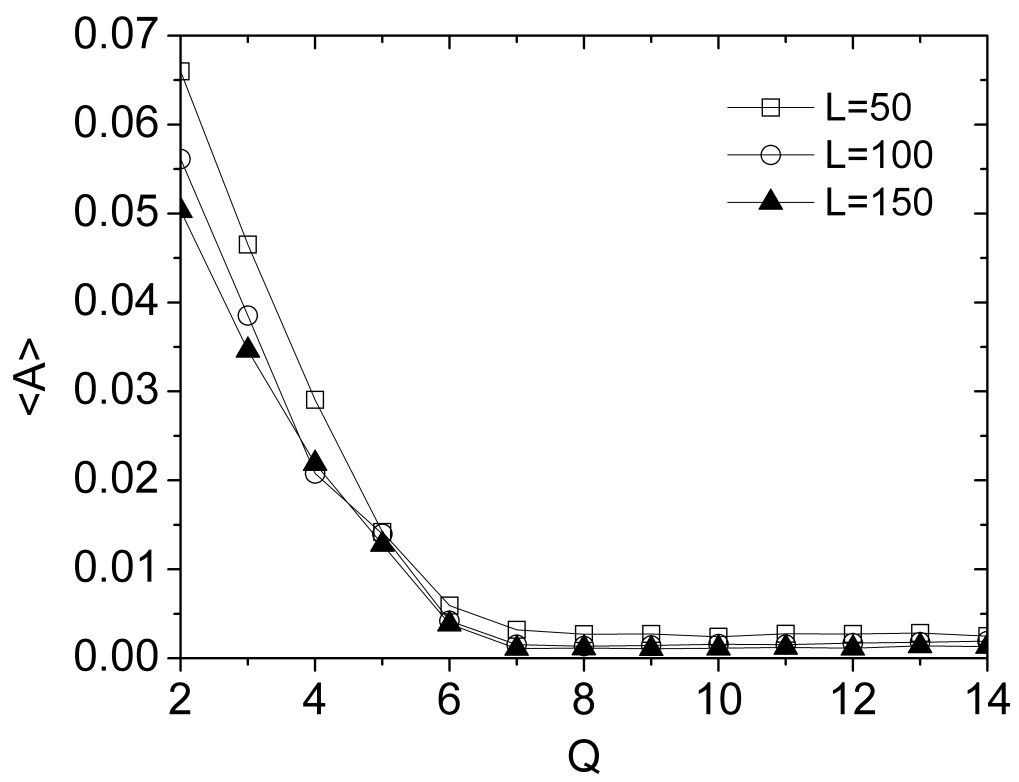

(a)

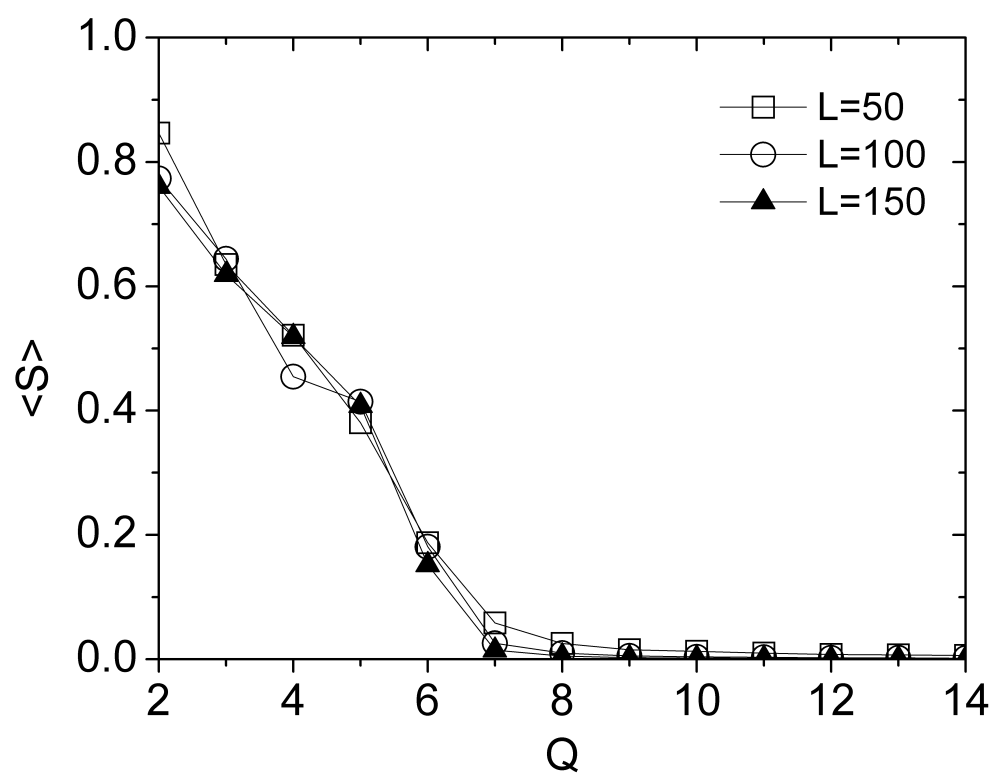

(b)

Figura 3.4: Parâmetro $\langle A\rangle / F$ em função de $Q$ em (a) e $\langle S\rangle$ em função de $Q$ em (b), para $F=2$ e $L=50,100,150$. Os dados foram obtidos de $M=30$ simulações. 


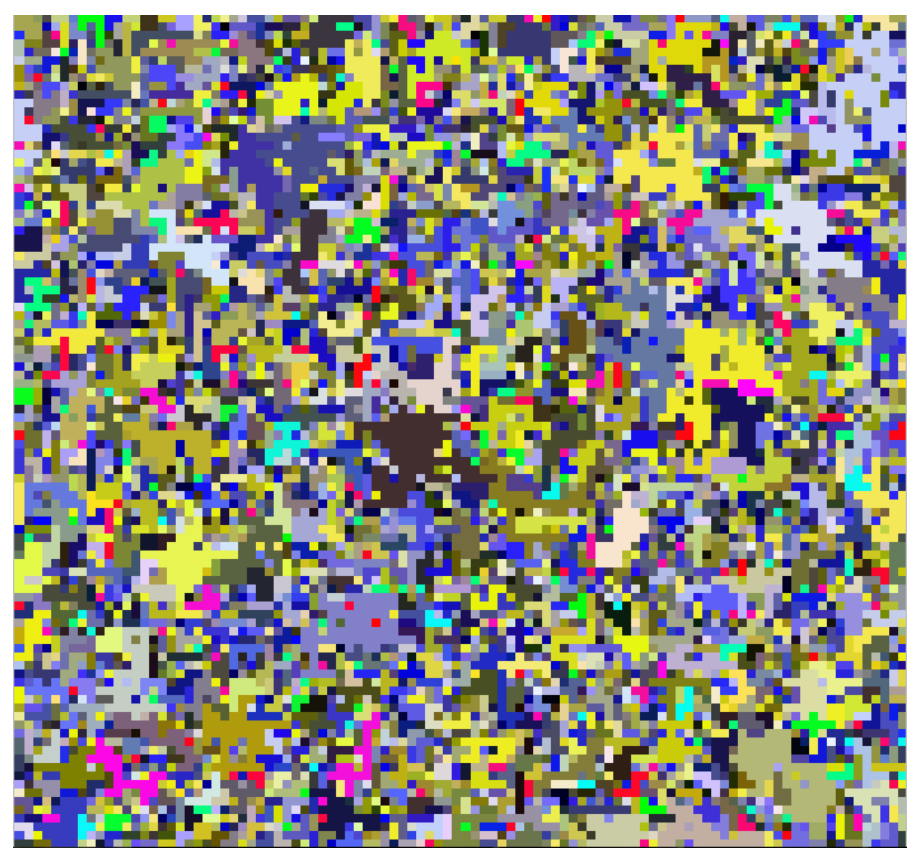

(a)

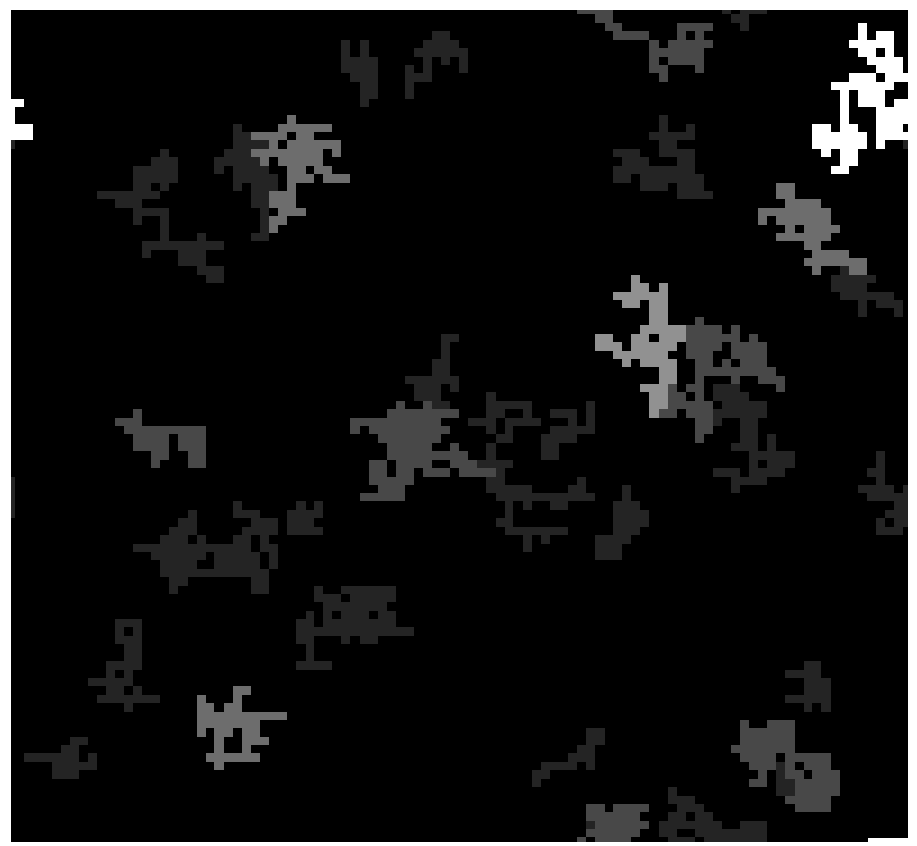

(b)

Figura 3.5: Estado estacionário (a) e mapa da atividade (b) obtidos de uma simulação com $L=100, F=3$ e $Q=14$. Na figura (a), cada vetor cultural $\psi_{i}$ é representado por uma tonalidade diferente. Na figura (b), a intensidade da cor representa a atividade do aglomerado, partindo de $A_{C}=0$ (preto) até $A_{C}=0.024$ (branco). 
Definimos a atividade de um cluster como

$$
A_{C}=\frac{1}{N_{C}} \sum_{k \in \mathcal{C}} A_{k}
$$

onde $\mathcal{C}$ é o conjunto de agentes que pertencem a um dado cluster e $N_{C}$ é o número de agentes de $\mathcal{C}$.

O mapa da atividade mostra a atividade média de cada domínio cultural. Um mapa da atividade para $F=3$ e $Q=14$ é mostrado na figura 3.5(b). Nessa figura, cada agente é representado pela atividade média $A_{C}$ do domínio ao qual ele pertence. As regiões mais claras indicam os domínios mais ativos e as regiões mais escuras indicam os grupos de agentes menos ativos. Comparando as figuras 3.5(a) e 3.5(b), podemos observar que as regiões mais claras na figura 3.5(b) correspondem aos maiores aglomerados da figura 3.5(a), enquanto que as regiões mais escuras correspondem aos aglomerados menores (e inclusive agentes individuais) encontrados nos estado estacionário. Esse resultado sugere uma correlação entre o tamanho de um aglomerado $\left(N_{C}\right)$ e sua atividade $\left(A_{C}\right)$.

\subsection{Tamanho do cluster}

A figura 3.6 é um gráfico que ilustra a dependência típica da atividade de um cluster $A_{C}$ (equação (3.5)) com o número de agentes $N_{C}$ do domínio. Esse resultado foi obtido de uma única simulação do sistema com parâmetros $F=3$ e $Q=14$. Nesse experimento, observa-se 4625 aglomerados distribuídos sobre 44 tamanhos de clusters diferentes. Um ajuste linear no gráfico log-log (na figura 3.6) indica uma dependência na forma de lei de potência,

$$
\left\langle A_{C}\right\rangle \propto N_{C}^{b}
$$

com expoente $b=1.05$ e coeficiente de determinação $r^{2}=0.93$.

Esse tipo de análise foi estendida para os dados resultantes de $M=1000$ simulações no ponto $Q=Q_{c}=14$. Para cada simulação, calculamos o número de tamanhos diferentes de clusters encontrados no estado estacionário e o expoente $b$ e o coeficiente $r^{2}$ foram determinados pelo ajuste linear dos dados à equação (3.6). Os resultados são apresentados na figura 3.7. Observamos que os dados podem ser 


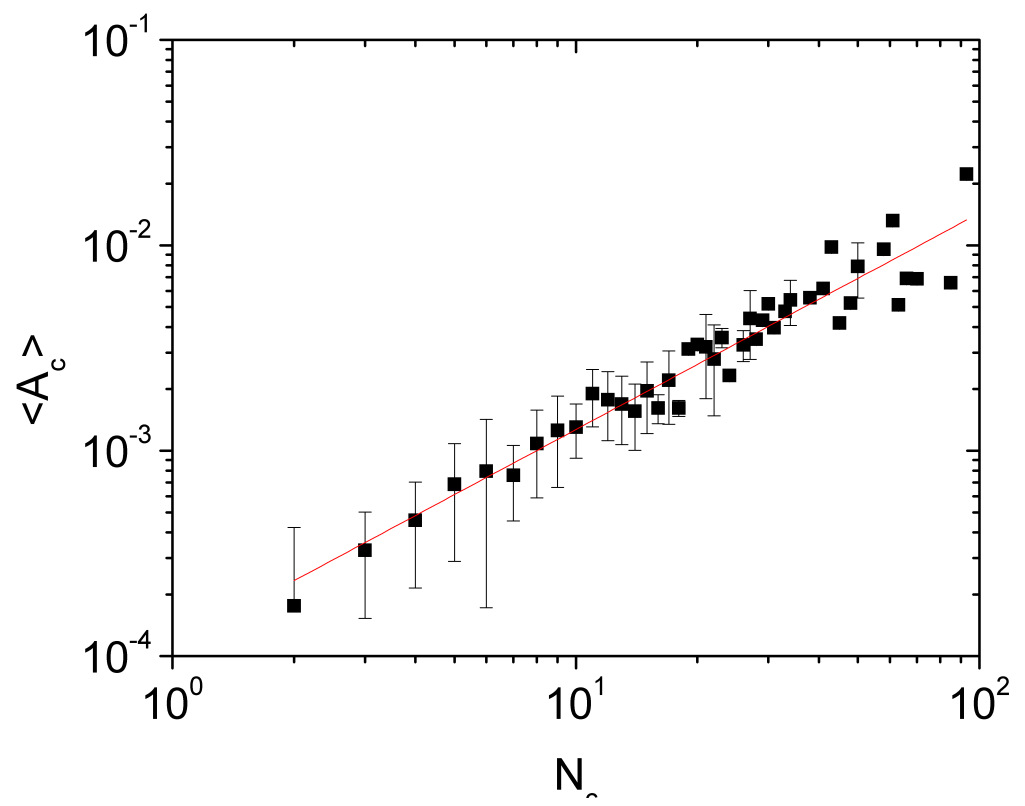

Figura 3.6: Atividade do cluster $\left\langle A_{C}\right\rangle$ como função do tamanho do cluster $N_{C}$. Dados obtidos de uma única simulação em uma rede $L=100$ com $F=3$ e $Q=14$.

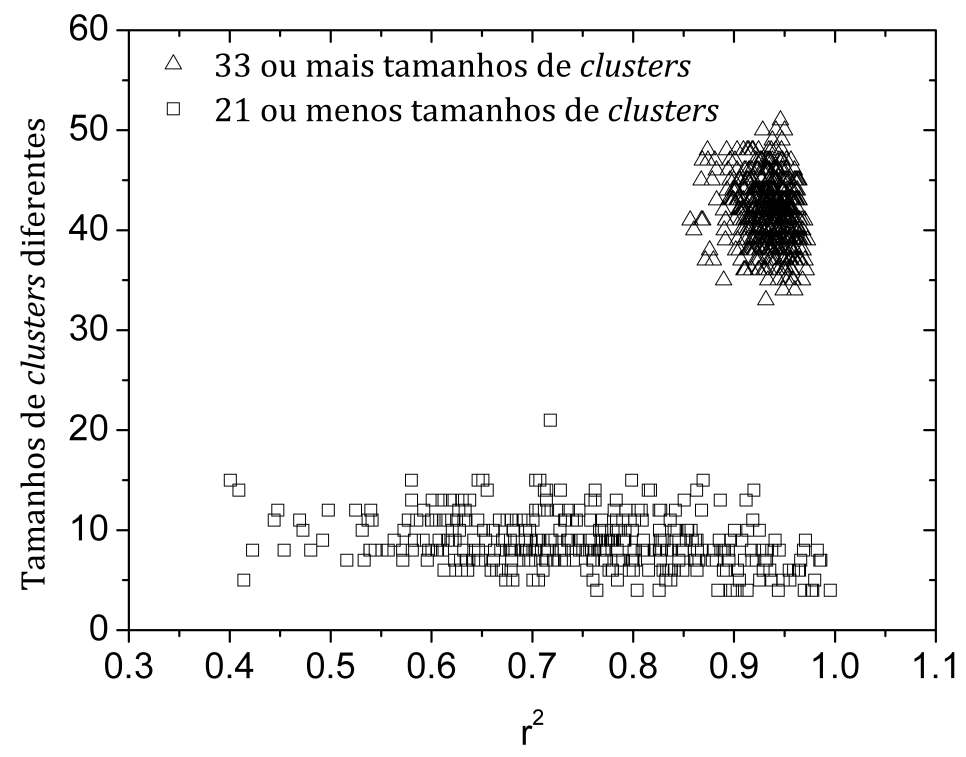

Figura 3.7: Número de clusters de tamanhos diferentes em função de $r^{2}$ em uma rede quadrada com $L=100, F=3$ e $Q=14$. Cada ponto corresponde à contagem de clusters diferentes e ao ajuste linear (com coeficiente de determinação $r^{2}$ ) de uma das $M=1000$ simulações independentes. 
divididos em dois grupos: grupo 1 e grupo 2. Os dados do grupo 1 (triângulo) resultam de $M_{1}=648$ simulações cujas configurações do estado estacionário apresentam 33 ou mais tamanhos diferentes de clusters. Uma boa estatística (com amostras maiores que 30) resulta dos dados desse grupo de pontos, onde também observamos que os coeficientes de determinação correspondentes ao ajuste em forma de lei de potência (da equação (3.6)) são altos $\left(r^{2}>0.85\right)$. Por outro lado, os dados do grupo 2 (quadrado) resultam de $M_{2}=352$ simulações cujas configurações do estado estacionário apresentam 22 ou menos tamanhos diferentes de clusters. Contudo, a estatística aqui não é tão robusta para verificar uma dependência na forma de lei de potência (os valores de $r^{2}$ são dispersos por uma região que vai de $r^{2} \approx 0.4$ até $\left.r^{2} \approx 1\right)$.

É interessante verificar que a separação entre os dois grupos está relacionada à coexistência de duas fases no ponto de transição $Q_{c}$. Deveras, a distribuição de frequências da atividade do sistema $A$ para todos esses dados pode ser dividida em regiões de alta e baixa atividades, como pode ser visto na figura 3.8. Baixos valores de atividade correspondem aos estados estacionários multiculturais e resultam de dados do grupo 1. Por outro lado, altos valores de atividade correspondem às confi-

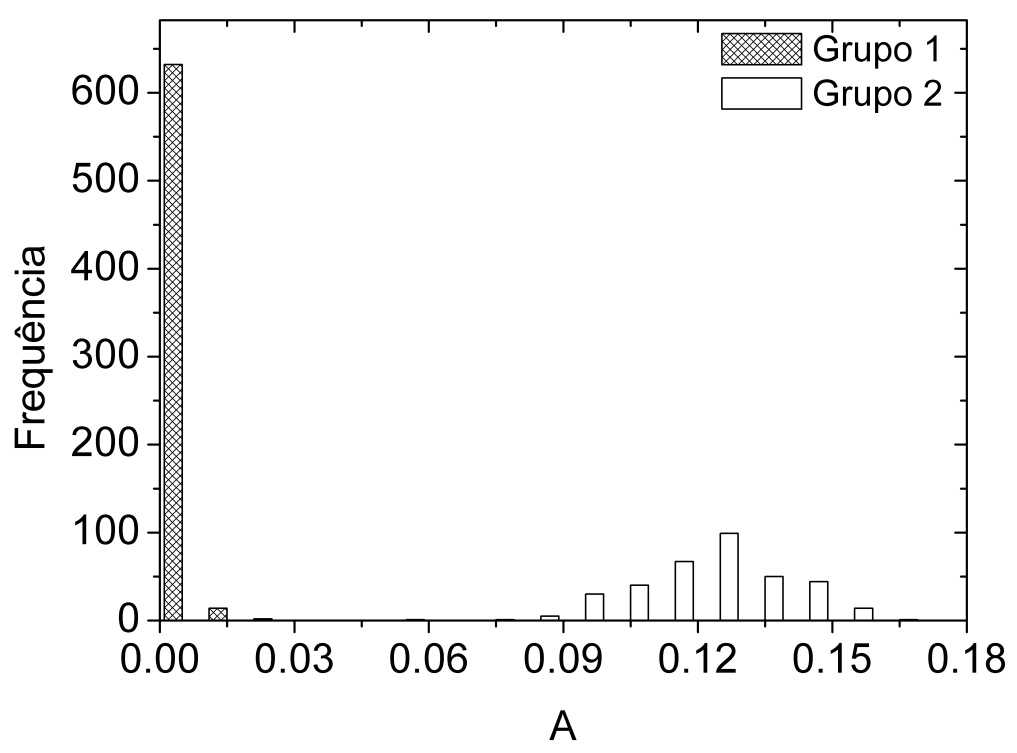

Figura 3.8: Distribuição de frequência da atividade do sistema $A$ para $M=1000$ simulações com $L=100, F=3$ e $Q=14$. 
gurações monoculturais e resultam de dados do grupo 2. Essa distribuição biestável é provavelmente devido à existência de estados metaestáveis no ponto de transição de uma transição de fase de primeira ordem [22, 19]. Portanto, encontramos que a dependência em forma de lei de potência entre a atividade de um cluster e o tamanho do cluster (equação (3.6)) é válida apenas para configurações multiculturais no estado estacionário no ponto crítico $Q_{c}$. Para esses dados, a média dos expoentes é estimada em $\bar{b}=1.07 \pm 0.05$.

Resultados semelhantes (característicos de uma transição de fase de primeira ordem) também podem ser encontrados para $F \geq 4$. Como comparação, observamos que para $F=2$ a distribuição de frequências de $A$ possui apenas um único pico e não se observa coexistência de fases conforme $Q$ aumenta de um valor abaixo $(Q=6)$ para um valor acima $(Q=8)$ do ponto de transição (figura 3.9). O deslocamento dessa distribuição (centrada em um único valor de $Q$ ) é um indicativo de que a transição de fase é de segunda ordem.

Além disso, calculamos a distribuição acumulada da atividade do cluster como

$$
U\left(A_{C}\right)=\sum_{A^{\prime}=A_{C}}^{\infty} P\left(A^{\prime}\right)
$$

onde $P\left(A^{\prime}\right)$ é a probabilidade de se encontrar um cluster com atividade $A^{\prime}$. Na figura 3.10, o gráfico log-log mostra que essa distribuição acumulada segue uma lei de potência: $U\left(A_{C}\right) \propto A_{C}^{-\tau}$ (para $A_{C}>10^{-4}$ ), com $\tau \approx 1.2$. Esse resultado pode ser comparado com a distribuição acumulada $U(S)$ para o tamanho do cluster $S$, que obedece uma lei de potência $U(S) \propto S^{1-\tau^{\prime}}$, com $\tau^{\prime} \approx 2.6$ para $F>2$ e $\tau^{\prime} \approx 1.6$ para $F=2$, como reportado em [40]. Curiosamente, a diferença de valores de $\tau^{\prime}$ que ocorre em $U(S)$ não é observada para o expoente $\tau$ em $U\left(A_{C}\right)$. Esse resultado sugere que a medida da atividade do cluster não é afetada pelos valores de $F$ ou pela ordem de transição do sistema.

\subsection{Conclusão}

Neste capítulo, propusemos novas medidas baseadas no conceito de atividade por agente para estudar o modelo de Axelrod. A atividade média do sistema $\langle A\rangle$ foi adotada como um parâmetro de ordem alternativo para indicar a transição dos es- 

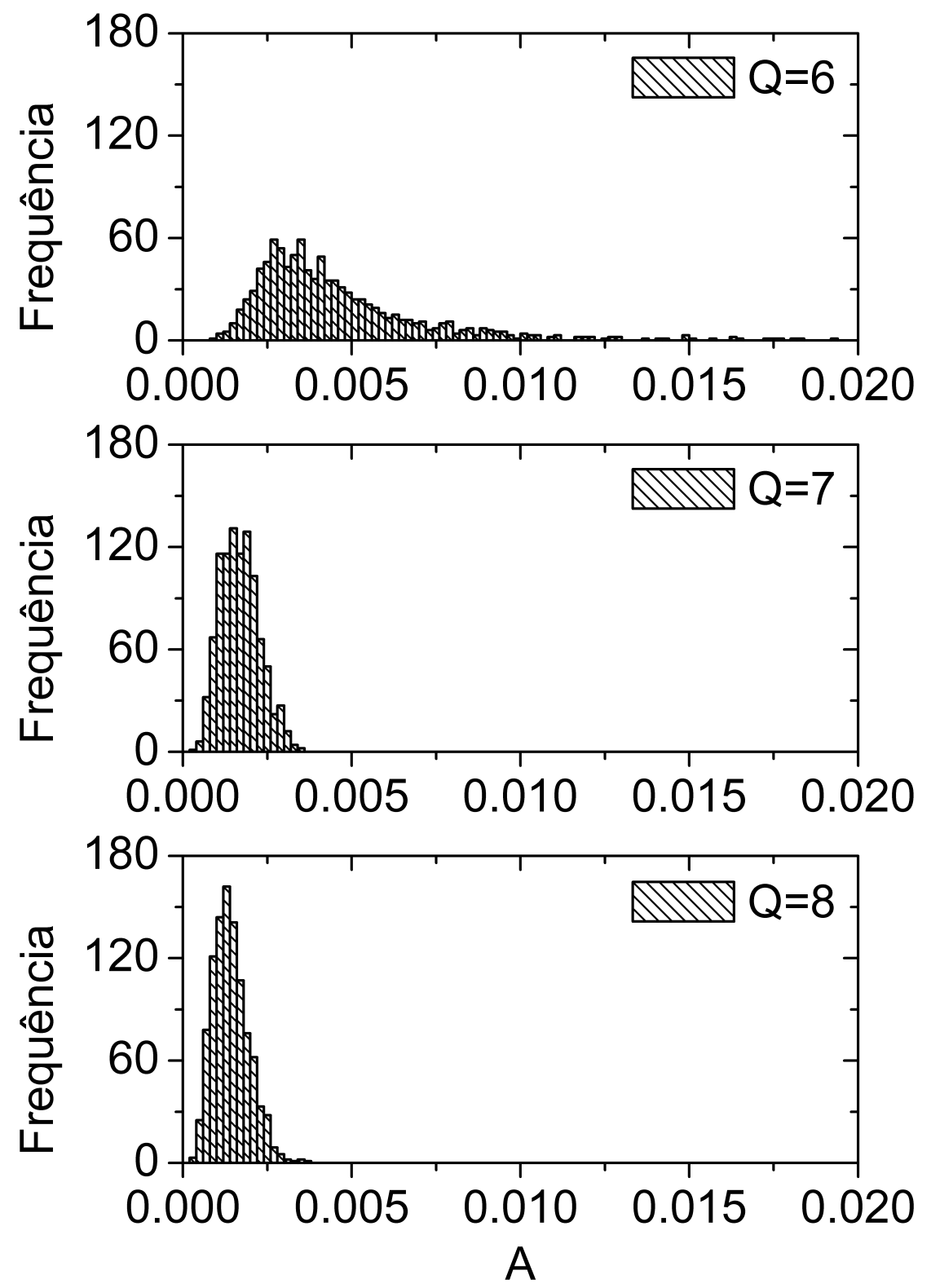

Figura 3.9: Distribuição de frequência da atividade do sistema $A$ para $F=2$ e $Q$ aumentando de um valor abaixo $(Q=6)$ para um valor acima $(Q=8)$ do ponto de transição. Dados obtidos de $M=1000$ simulações usando uma rede $L=100$.

tados estacionários monoculturais para os multiculturais. Os pontos críticos $Q_{c}$ foram estimados a partir dos picos das susceptibilidades da atividade do sistema $A$ e concordam com os valores encontrados na literatura. Vimos que a distribuição de frequência da atividade do sistema $A$ apresenta dois picos para $F \geq 3$ (sugerindo uma transição de fases de primeira ordem) e apresenta um único pico para $F=2$ 


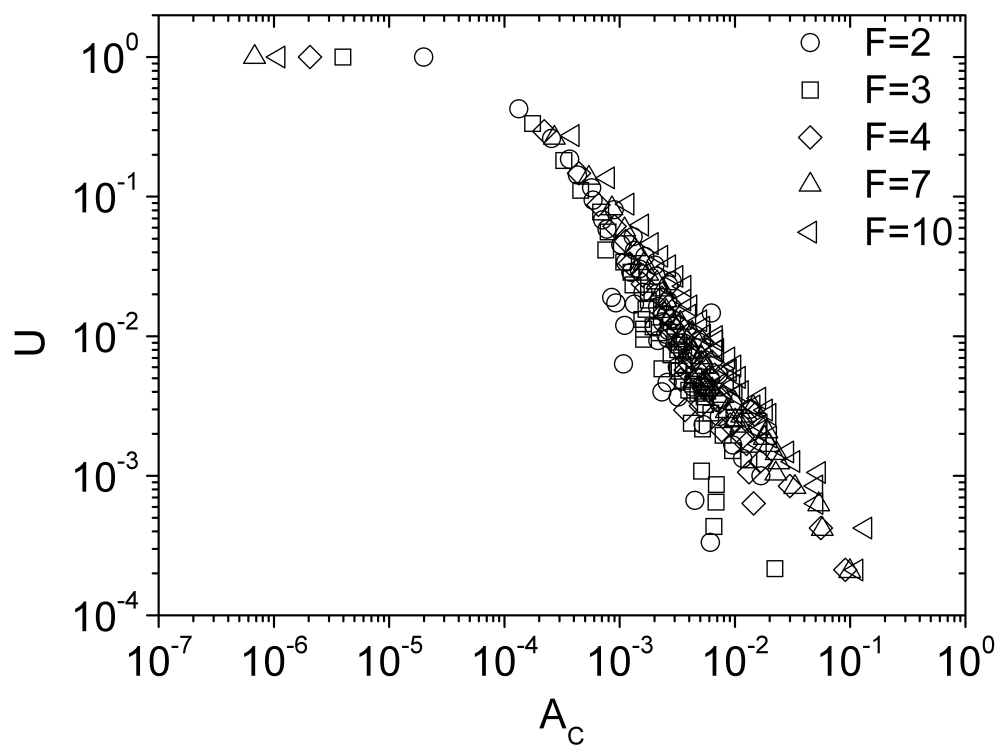

Figura 3.10: Distribuições acumuladas $U$ da atividade do cluster $A_{C}$ para valores diferentes de $F$ no ponto $Q=Q_{c}$ em uma rede $L=100$.

(sugerindo uma transição de fases de segunda-ordem). Acreditamos que o conceito de atividade pode ser útil para se estudar outros sistemas de agentes interagentes que podem evoluir para estados absorventes, como o modelo de Parisi [70]. Também seria interessante se estudar o comportamento dinâmico do modelo de Axelrod considerando a dependência temporal da atividade definida na equação (3.1).

Devemos ressaltar que implementamos o algoritmo de Hoshen-Kopelman de detecção de clusters, descrito em [71], para calcular os parâmetros $S$ e $g$. O custo computacional destes cálculos, que necessitam da execução do algoritmo supracitado para detectar e enumerar os aglomerados diferentes, é maior que o cálculo da atividade do sistema $A$. Logo, o parâmetro atividade proposto neste capítulo possui a vantagem adicional de determinar a ordem final do sistema utilizando menos tempo computacional. Esta vantagem se torna mais evidente quanto maiores forem a rede estudada e o número de simulações utilizados para determinar a fase do sistema no estado estacionário.

O mapa da atividade revelou a formação de grupos com maior e menor atividade. Verificamos uma dependência em forma de lei de potência entre a atividade e o tamanho de um cluster para os estados estacionários multiculturais do ponto 
crítico. Nossos resultados indicam que agentes mais ativos tendem a se agrupar em aglomerados maiores. Admitindo que a atividade pode ser entendida como o esforço de um agente para pertencer a um grupo que compartilha as mesmas características culturais, podemos supor que a formação de um consenso demanda mais esforço dos integrantes de grandes comunidades. 


\section{Capítulo}

\section{Transição de fase}

"Life is pleasant. Death is peaceful. It's the transition that's troublesome."

- Isaac Asimov

Na literatura, encontramos estudos sobre a influência de ruídos, de campos (local, global e externo) e de aspectos topológicos nas propriedades do modelo de Axelrod Contudo, uma questão de interesse permanece em aberto: para um dado parâmetro $F$ fixo, qual o valor crítico do parâmetro $Q\left(Q_{c}(F)\right)$ em uma rede bidimensional? A resposta a essa questão permite não só o conhecimento do ponto de transição mas também qual será a configuração final na rede para um par $(F, Q)$. Alguns valores $Q_{c}(F)$ foram estimados numericamente em casos específicos, mas ainda não encontramos na literatura nenhum diagrama de fases do modelo. Nesse sentido, propomos a utilização da susceptibilidade do parâmetro de ordem para determinar $Q_{c}(F)$ para alguns valores de $F$ e estimar o diagrama através de uma função de ajuste. Além disso, relacionamos $Q_{c}(F)$ com a probabilidade nula de interação entre dois indivíduos na configuração inicial para derivar, alternativamente, uma regra geral que também permite estimar o diagrama de fases do modelo de Axelrod na rede quadrada com condição de contorno aberta e fechada.

\subsection{Determinação dos pontos de transição}

Sabemos que o modelo de Axelrod apresenta uma transição de fases em um ponto $Q_{c}(F)$ que depende do parâmetro $F$ do modelo. Para determinar o ponto $Q_{c}$ que 
separa o regime final monocultural (se $Q<Q_{c}$ ) do multicultural (se $Q>Q_{c}$ ), fazemos uso do conceito de ponto de transição efetivo introduzido nos capítulos anteriores. O ponto de transição efetivo corresponde ao valor do parâmetro de controle $Q_{c}(L)$, para uma rede de tamanho $L$, no qual a susceptibilidade (que é função da variância do parâmetro de ordem do sistema) é máxima. Para nosso estudo, consideramos os parâmetros de ordem tamanho do maior cluster $S$ (equação (2.3)) e a atividade do sistema $A$ (equação (3.2)). Comparamos os resultados obtidos com a atividade com os resultados obtidos com o tamanho do maior cluster a fim de verificar a robustez do parâmetro $A$ que propusemos no Capítulo 3. Como definido nas equações (3.4) e (3.3), calculamos as susceptibilidades do tamanho do maior cluster $\chi_{S}$ e da atividade $\chi_{A}$, respectivamente

$$
\begin{aligned}
& \chi_{S}=N\left(\left\langle S^{2}\right\rangle-\langle S\rangle^{2}\right), \\
& \chi_{A}=N\left(\left\langle A^{2}\right\rangle-\langle A\rangle^{2}\right) .
\end{aligned}
$$

Apresentamos o comportamento do parâmetro $\langle S\rangle$ e de $\chi_{S}$ para $F=3 \mathrm{em}$ função de $Q$ na figura 4.1. Os resultados foram obtidos nos tamanhos de rede $L=8,16,32,64,128$. Cada ponto corresponde a médias realizadas sobre $M=$ 1000 simulações nas redes $L=8,16,32$ e $M=100$ em $L=64,128$. Na figura 4.1(a), observamos que o decaimento de $\langle S\rangle$ se torna mais abrupto com o aumento do tamanho da rede. Logo, a região de transição, na qual há coexistência das fases mono e multicultural, diminui com o aumento do número de agentes da rede. Na figura 4.1(b), notamos que as curvas de susceptibilidade $\chi_{S}$ se deslocam para a direita conforme a rede aumenta. Além do deslocamento, notamos que há o arredondamento da curva de susceptibilidade para redes pequenas. O aumento da rede diminui o efeito de arredondamento e a susceptibilidade passa a apresentar um pico pronunciado (ver seção 1.2).

Resultados semelhantes são observados ao considerar a atividade do sistema $\langle A\rangle$ como parâmetro de ordem e a susceptibilidade $\chi_{A}$. A figura 4.2 apresenta resultados para $F=3$ nas redes $L=8,16,32,64,128$. Cada ponto corresponde a médias realizadas sobre $M=1000$ simulações nas redes $L=8,16,32$ e $M=100$ em $L=64,128$. Observamos que o decaimento de $\langle A\rangle$ se torna mais abrupto com o 


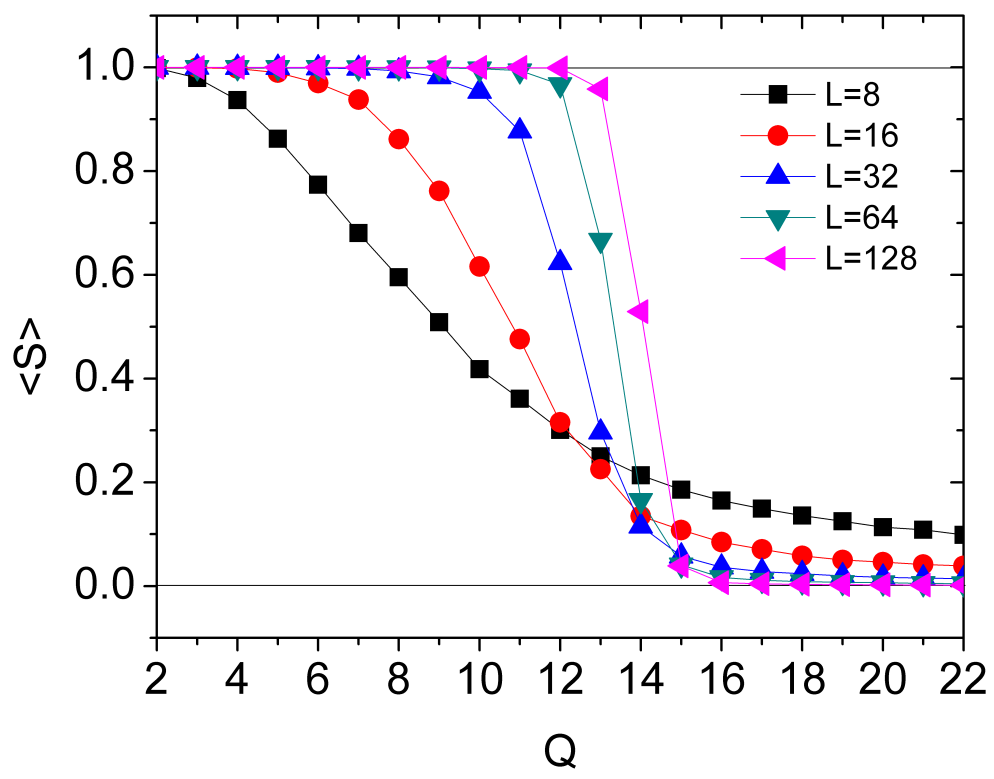

(a)

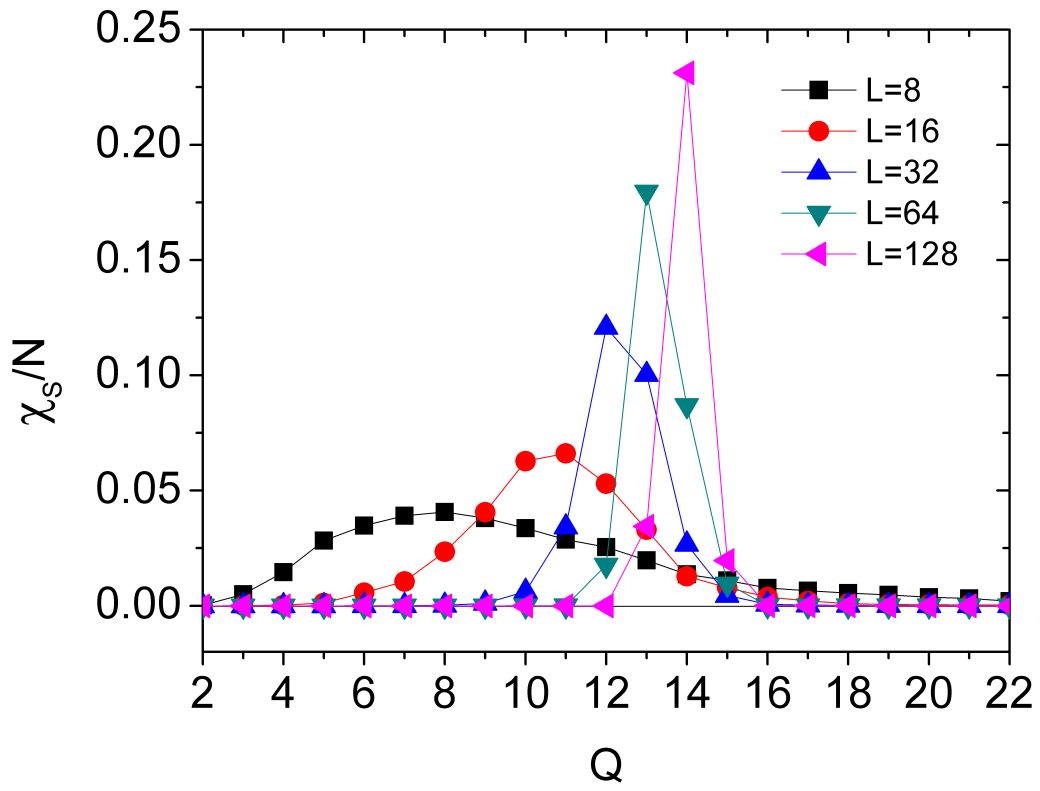

(b)

Figura 4.1: Medidas de $\langle S\rangle$ em (a) e $\chi_{S}$ em (b) como função de $Q$ para $F=3$ nas redes $L=8,16,32,64,128$. Cada medida corresponde a médias sobre $M=1000$ simulações nas redes $L=8,16,32$ e $M=100$ nas redes $L=64,128$. 


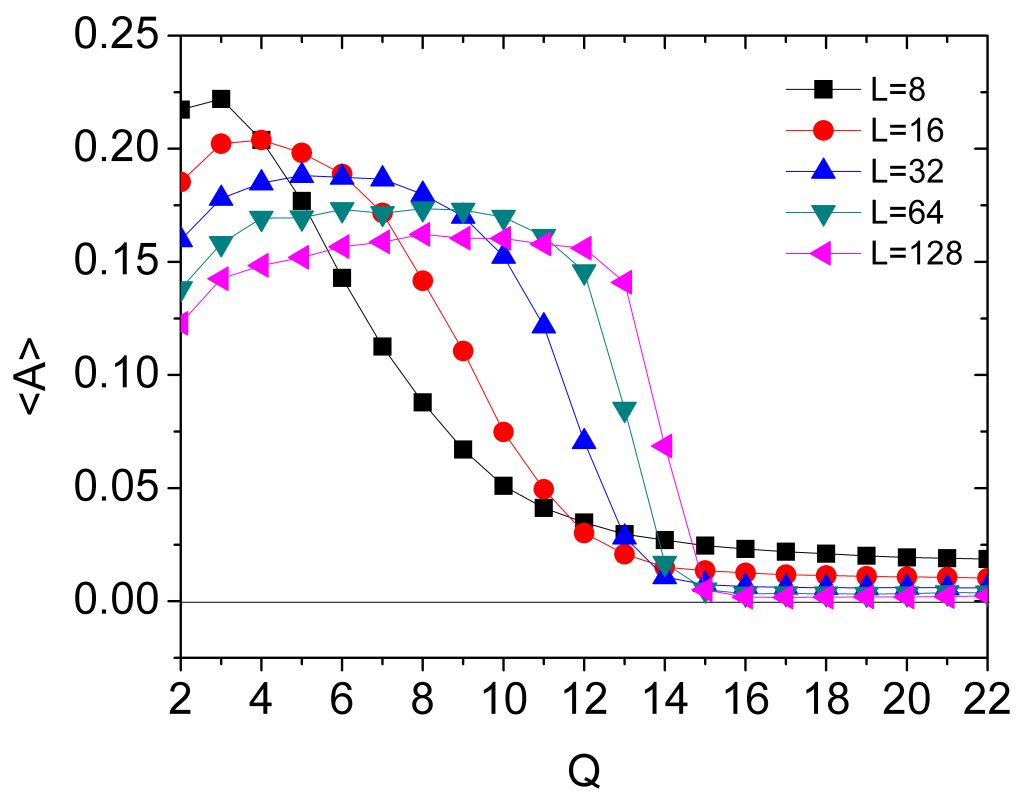

(a)

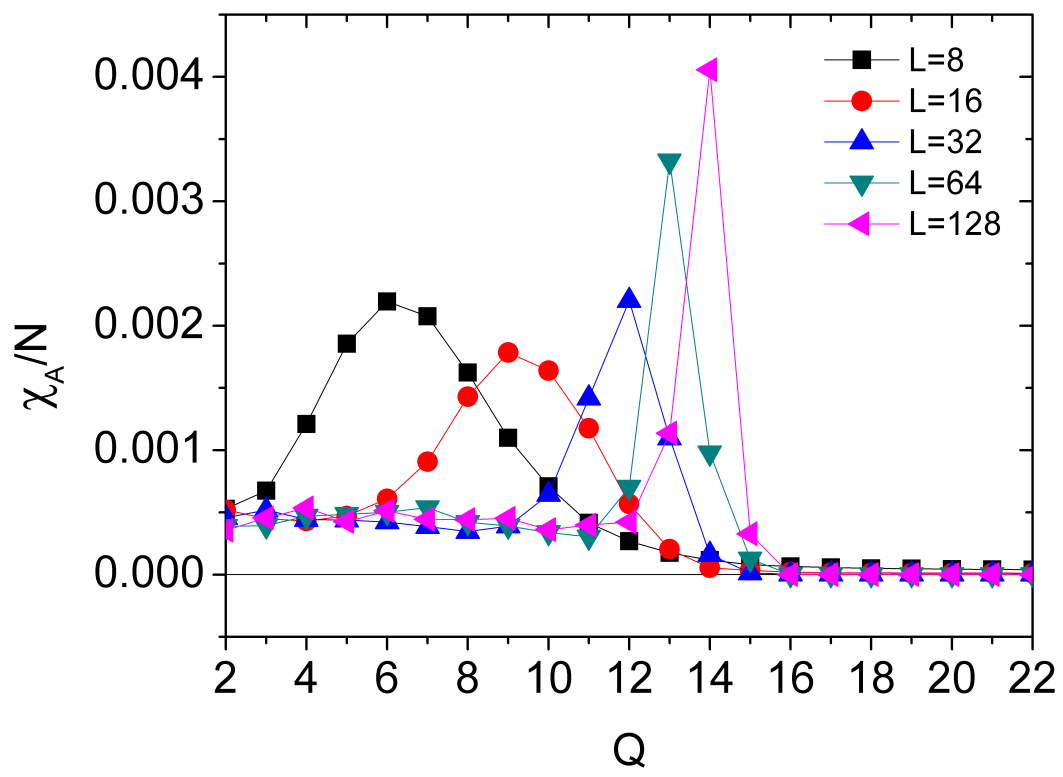

(b)

Figura 4.2: Medidas de $\langle A\rangle$ em (a) e $\chi_{A}$ em (b) como função de $Q$ para $F=3$ nas redes $L=8,16,32,64,128$. Cada medida corresponde a médias sobre $M=1000$ simulações nas redes $L=8,16,32$ e $M=100$ nas redes $L=64,128$. 
aumento da rede, bem como o máximo de $\chi_{A}$ se torna mais pronunciado com o aumento do número de agentes da rede, evidenciando os efeitos de tamanho finito. Os valores dos máximos das susceptibilidades $\chi_{S}$ e $\chi_{A}$ coincidem em $Q=12$ para $L=32$, em $Q=13$ para $L=64$ e em $Q=14$ para $L=128$.

Apresentamos na figura 4.3 os histogramas dos valores de $S$ e $A$ para $F=3 \mathrm{em}$ torno do ponto de transição: $Q=12$ (regime monocultural), $Q=13$ (ponto de transição) e $Q=14$ (regime multicultural). Os dados são provenientes de $M=10000$ simulações em uma rede de lado $L=64$. Os histogramas são expressos em termos de $P(S)$ (coluna esquerda), que corresponde à probabilidade de se encontrar uma simulação cuja configuração final apresenta um aglomerado dominante de tamanho $S$, e de $P(A)$ (coluna direita), que corresponde à probabilidade de se encontrar uma simulação cuja dinâmica resultou em uma atividade do sistema $A$.

Para ambos os parâmetros, as distribuições de probabilidades $P(S)$ e $P(A)$ apresentam um único pico no regime monocultural $(Q=12)$. Nesse caso, as distribuições estão centradas nos valores de $S$ e $A$ encontrados na fase ordenada do modelo de Axelrod. Quando $Q=13$, as distribuições de probabilidades $P(S)$ e $P(A)$ apresentam dois picos. Esses picos estão centrados nos valores de $S$ e $A$ que correspondem aos regimes mono e multicultural. A biestabilidade das distribuições nesse valor de $Q$ indica que o sistema apresenta coexistência entre esses dois regimes e que $Q_{c}=13$. Os resultados para $Q=14$ mostram que as probabilidades $P(S)$ e $P(A)$ estão centradas nos valores de $S$ e $A$ característicos do regime multicultural.

A discussão realizada para $F=3$ também se aplica aos demais valores de $F>3$. Nesses casos, os comportamentos dos parâmetros de ordem $(S$ e $A)$, das curvas de susceptibilidade $\left(\chi_{S}\right.$ e $\left.\chi_{A}\right)$ e das distribuições de probabilidade $(P(S)$ e $P(A))$ em função de $Q$ são semelhantes aos mostrados para $F=3$. Consequentemente, podemos determinar os pontos $Q_{c}^{\chi_{S}}(F, L)$ e $Q_{c}^{\chi_{A}}(F, L)$ pela inspeção das curvas de susceptibilidade. Os $\left(Q_{c}^{\chi_{S}}(F, L), Q_{c}^{\chi_{A}}(F, L)\right)$ são apresentados na tabela 4.1 para $F=3,4,5,6,7,8,9,10$ em redes de tamanho $L=8,16,32,64,128$. Note que esses pontos de transição convergem para os mesmos valores quando $L$ aumenta. 


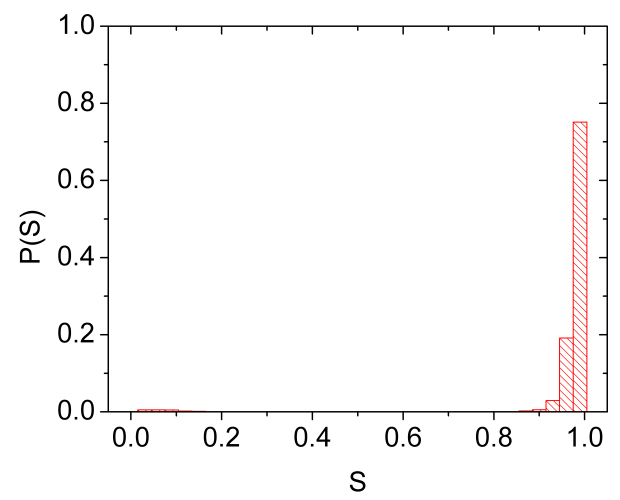

(a) $\mathrm{Q}=12$ (regime monocultural)

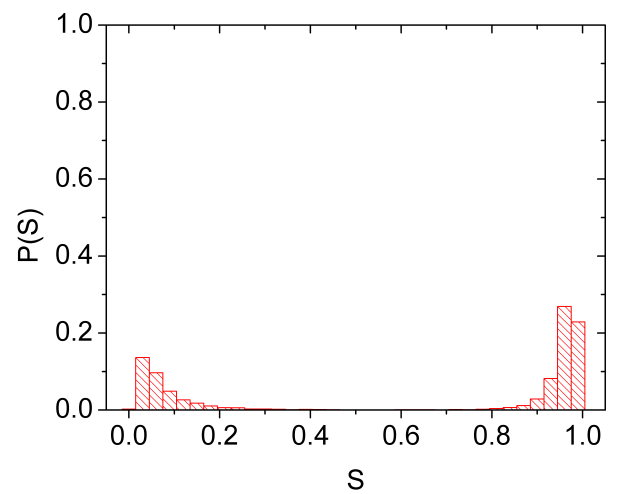

(c) $\mathrm{Q}=13$ (ponto de transição)

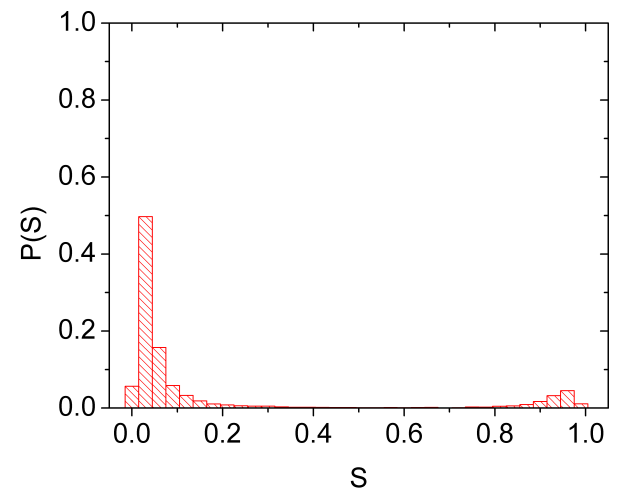

(e) $\mathrm{Q}=14$ (regime multicultural)

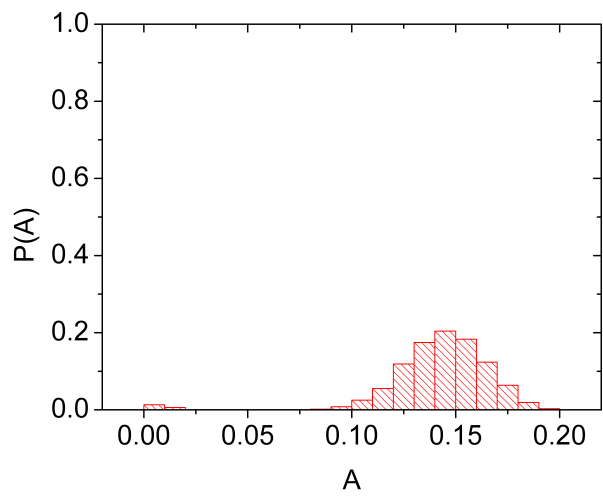

(b) $\mathrm{Q}=12$ (regime monocultural)

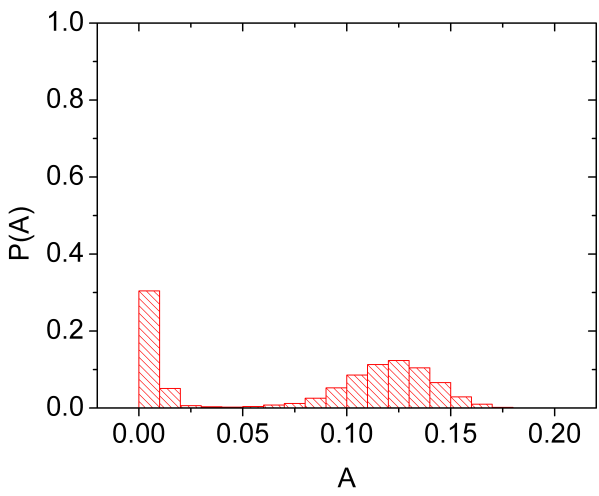

(d) $\mathrm{Q}=13$ (ponto de transição)

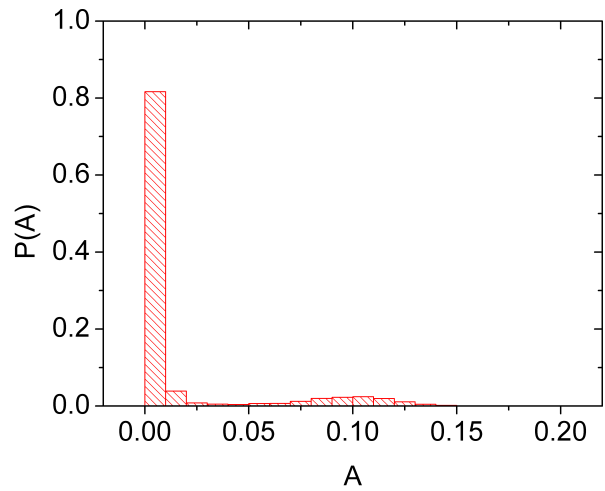

(f) $\mathrm{Q}=14$ (regime multicultural)

Figura 4.3: Distribuição de probabilidade de $P(S)$ em função de $S$ (coluna a esquerda) e de $P(A)$ em função de $A$ (coluna à direita) para $F=3$ e $Q=12$ (regime monocultural), $Q=13$ (ponto de transição em $L=64$ ), $Q=14$ (regime multicultural). Os dados correspondem à $M=10000$ simulações em uma rede $L=64$. 


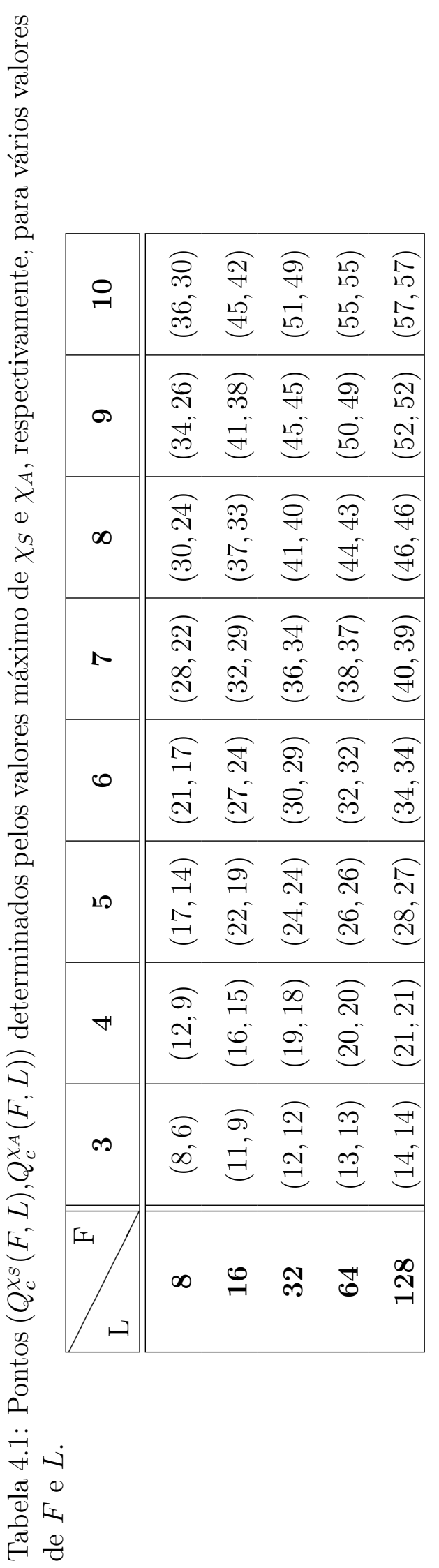


Para o caso $F=2$ em particular, o comportamento dos parâmetros $\langle S\rangle$ e $\langle A\rangle$ em função de $Q$ pode ser visualizado na figura 3.4. Nessa situação, as curvas da susceptibilidade $\chi_{S}$ e $\chi_{A}$ (calculadas sobre as médias de $M=1000$ simulações nas redes $L=8,16,32$ e sobre $M=100$ em $L=64,128)$ não apresentam um pico bem definido nos tamanhos de rede estudados.

\subsection{Algoritmo BST}

O máximo da susceptibilidade do parâmetro de ordem em uma dada rede de tamanho $L$ permite a determinação do ponto de transição efetivo $Q_{c}(L)$. A pergunta que surge, naturalmente, é: qual o valor de $Q_{c}(L)$ no limite termodinâmico (quando $L \rightarrow \infty)$ ? Para abordar essa questão, fazemos uso do algoritmo de extrapolação BST.

O algoritmo BST, descrito aqui com base nos trabalhos de U. P. da Costa Neves [20] e de M. Henkel e G. Schütz [50], é um algoritmo de extrapolação de sequências. Considere, como o exemplo dado em [20], que o parâmetro de controle seja a temperatura. Isso quer dizer que, a partir de uma sequência de temperaturas de transição efetiva $T_{c}(L)$ (em sistemas finitos de tamanho $L$ ), é possível extrapolarmos a temperatura crítica no limite termodinâmico com o uso do BST.

Para utilizar o algoritmo BST, considere uma sequência $h_{n}(n=0,1,2, \ldots)$ tal que $h_{n} \rightarrow 0$ quando $n \rightarrow \infty$. Em muitos casos, como em nosso trabalho, é conveniente definir $h_{n}=1 / L$, em que $L$ é o tamanho do sistema, e $n$ aumenta com $L$.

Seja $T(h)$ uma função com expansão

$$
T(h)=T_{c}+a_{1} h^{\omega}+a_{2} h^{2 \omega}+\ldots,
$$

onde $T_{c}$ é a temperatura crítica no limite $n \rightarrow \infty, \omega$ é um expoente livre e os termos $a_{1}, a_{2}, \ldots$ são constantes. O algoritmo BST permite estimar o limite $T_{c}$ a partir de uma tabela de extrapolantes, como mostrado na figura 4.4. Os valores $T_{m}^{(n)}$ são calculados de acordo com as expressões: 


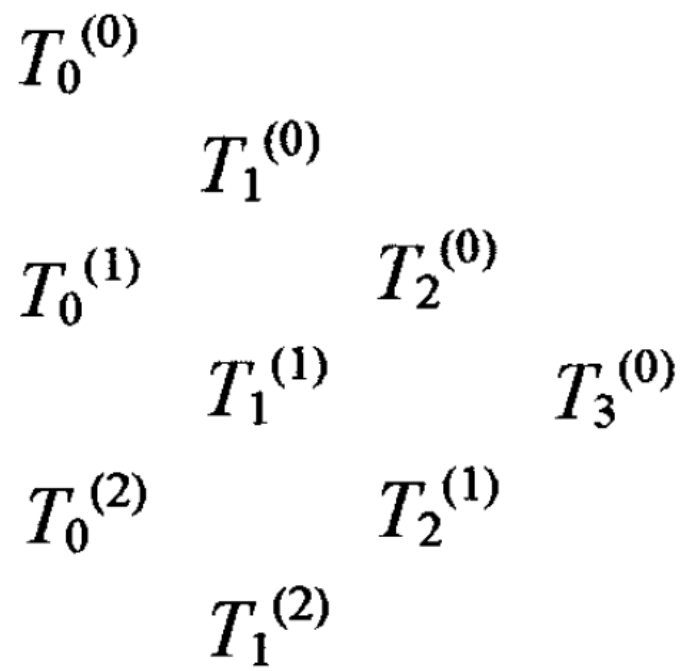

\section{$T_{0}^{(3)}$}

Figura 4.4: Tabela de extrapolantes do algoritmo BST. Extraído de [42].

$$
\begin{aligned}
T_{(-1)}^{(n)} & =0 \\
T_{(0)}^{(n)} & =T\left(h_{n}\right) \\
T_{(m)}^{(n)} & =T_{(m-1)}^{(n+1)}+\left(T_{(m-1)}^{(n+1)}-T_{(m-1)}^{(n)}\right)\left[\left(\frac{h_{n}}{h_{n+m}}\right)^{\omega}\left(1-\frac{T_{(m-1)}^{(n+1)}-T_{(m-1)}^{(n)}}{T_{(m-1)}^{(n+1)}-T_{(m-2)}^{(n+1)}}\right)-1\right]^{-1} .
\end{aligned}
$$

Como o expoente $\omega$ é livre, devemos escolher $\omega$ tal que o erro da extrapolação $\varepsilon=\left|2\left(T_{m}^{(1)}-T_{m}^{(0)}\right)\right|$ (calculado no penúltimo passo da extrapolação) seja mínimo.

A estimativa de $Q_{c}$ é realizada aplicando-se o algoritmo BST no conjunto de valores $Q_{c}(F, L)$ apresentados na tabela 4.1. Os valores extrapolados são apresentados na tabela 4.2. O algoritmo é aplicado aos valores $Q_{c}(F, L)$ fazendo $T_{(0)}^{(0)}=Q\left(h_{0}\right)$, em que $h_{0}=1 / 8$ e $Q\left(h_{0}\right)=Q_{c}(F, L=8)$. Consequentemente, $T_{(0)}^{(1)}=Q\left(h_{1}=1 / 16\right)$, $T_{(0)}^{(2)}=Q\left(h_{2}=1 / 32\right), T_{(0)}^{(3)}=Q\left(h_{3}=1 / 64\right), T_{(0)}^{(4)}=Q\left(h_{4}=1 / 128\right)$. Como exemplo, mostramos na figura 4.5 a tabela de extrapolação dos pontos $Q_{c}^{\chi_{S}}(F, L)$ apresentados na tabela 4.1 para $F=3$. Nesse caso, escolhemos $w=2.55$ para minimizar o erro da extrapolação. 
Tabela 4.2: Determinação dos pontos de transição $Q_{c}^{\chi_{S}}$ e $Q_{c}^{\chi_{A}}$ através da aplicação do algoritmo de extrapolação BST nos pontos $Q_{c}^{\chi_{S}}(F, L)$ e $Q_{c}^{\chi_{A}}(F, L)$, respectivamente, apresentados na tabela 4.1.

\begin{tabular}{c|c|c|c|c}
\hline \hline & \multicolumn{2}{|c|}{$\operatorname{BST}\left(\chi_{S}\right)$} & \multicolumn{2}{c}{$\operatorname{BST}\left(\chi_{A}\right)$} \\
\hline$F$ & $Q_{c}^{\chi_{S}}$ & $\omega$ & $Q_{c}^{\chi_{A}}$ & $\omega$ \\
\hline 3 & 14.45 & 2.55 & 14.88 & 1.16 \\
\hline 4 & 21.77 & 1.15 & 21.79 & 1.26 \\
\hline 5 & 28.88 & 2.56 & 27.79 & 1.25 \\
\hline 6 & 36.65 & 1.70 & 34.42 & 1.12 \\
\hline 7 & 44.65 & 0.59 & 40.05 & 1.08 \\
\hline 8 & 49.19 & 0.77 & 48.22 & 1.12 \\
\hline 9 & 54.69 & 0.88 & 55.35 & 1.66 \\
\hline 10 & 59.03 & 1.04 & 58.51 & 1.28 \\
\hline \hline
\end{tabular}

\subsection{Diagrama de fases}

A extrapolação dos pontos de transição $Q_{c}^{\chi_{S}}(F, L)$ e $Q_{c}^{\chi_{A}}(F, L)$ (que correspondem aos valores de $Q$ nos quais as susceptibilidades $\chi_{S}$ e $\chi_{A}$ apresentam um máximo, respectivamente) pelo algoritmo BST resulta nos valores $Q_{c}^{\chi_{S}}$ e $Q_{c}^{\chi_{A}}$ apresentados na tabela 4.2. As dependências de $Q_{c}^{\chi_{S}}$ e $Q_{c}^{\chi_{A}}$ com $F$ podem ser visualizadas na figura 4.6. A figura 4.6(a) mostra os pontos $Q_{c}^{\chi_{S}}(F)$ indicados pelos símbolos $(\square)$

$\begin{array}{rrrrr}8.00000 & 11.92048 & 12.24141 & 14.45567 & 14.44478 \\ 11.00000 & 12.22892 & 13.41183 & 14.44479 & \\ 12.00000 & 13.22697 & 14.41183 & & \\ 13.00000 & 14.22532 & & & \\ 14.00000 & & & & \end{array}$

Figura 4.5: Extrapolação de $Q_{c}^{\chi_{S}}$ para $F=3$. Os valores $Q_{c}^{\chi_{S}}(F, L)$ foram extraídos da tabela 4.1. 
ajustados linearmente pela função

$$
Q_{c}^{S}(F)=-3.6+6.5 F \quad(3 \leq F \leq 10),
$$

representada pela reta contínua. A figura 4.6(b) mostra os pontos $Q_{c}^{\chi_{A}}(F)$ indicados pelos símbolos $(\times)$. Para esses pontos, o ajuste (representado pela reta contínua) é realizado pela função

$$
Q_{c}^{A}(F)=-4.2+6.4 F \quad(3 \leq F \leq 10) .
$$

As curvas dadas pelas equações (4.3) e (4.4) delimitam, no espaço de fase $(F, Q)$, as regiões nas quais a configuração final é monocultural ou multicultural. Para isso, assumimos que os comportamentos de $Q_{c}^{S}(F)$ e $Q_{c}^{A}(F)$ descritos pelas equações (4.3) e (4.4) na região $(3 \leq F \leq 10)$ também sejam válidos nas regiões em que $F>10$. Com esse resultado, o estado final do sistema, se ordenado ou desordenado, pode ser inferido a priori e sem a necessidade de simulações computacionais.

\subsubsection{Configuração inicial e ponto de transição}

Já mencionamos anteriormente (Capítulo 2) que a configuração final depende do número de vetores culturais $\left(Q^{F}\right)$ diferentes encontrados na configuração inicial. Dado que a atribuição inicial dos estados $(q=1,2, \ldots, Q)$ dos $F$ elementos dos vetores culturais é realizada de modo independente, a probabilidade de se encontrar um par agente-vizinho $(i, j)$ compartilhando $k$ características iguais no início da dinâmica é dada pela expressão binomial

$$
P_{k}=\left(\begin{array}{l}
F \\
k
\end{array}\right)\left(\frac{1}{Q}\right)^{k}\left(1-\frac{1}{Q}\right)^{F-k},
$$

onde o coeficiente binomial $\left(\begin{array}{l}F \\ k\end{array}\right)=\frac{F !}{k !(F-k) !}$.

Um par de agentes adjacentes $(i, j)$ não interage se $P_{i, j}=0$, ou seja, se $k=0$. A probabilidade de se encontrar um par agente-vizinho com probabilidade nula de interação no instante inicial será

$$
P_{0}=\left(1-\frac{1}{Q}\right)^{F}
$$




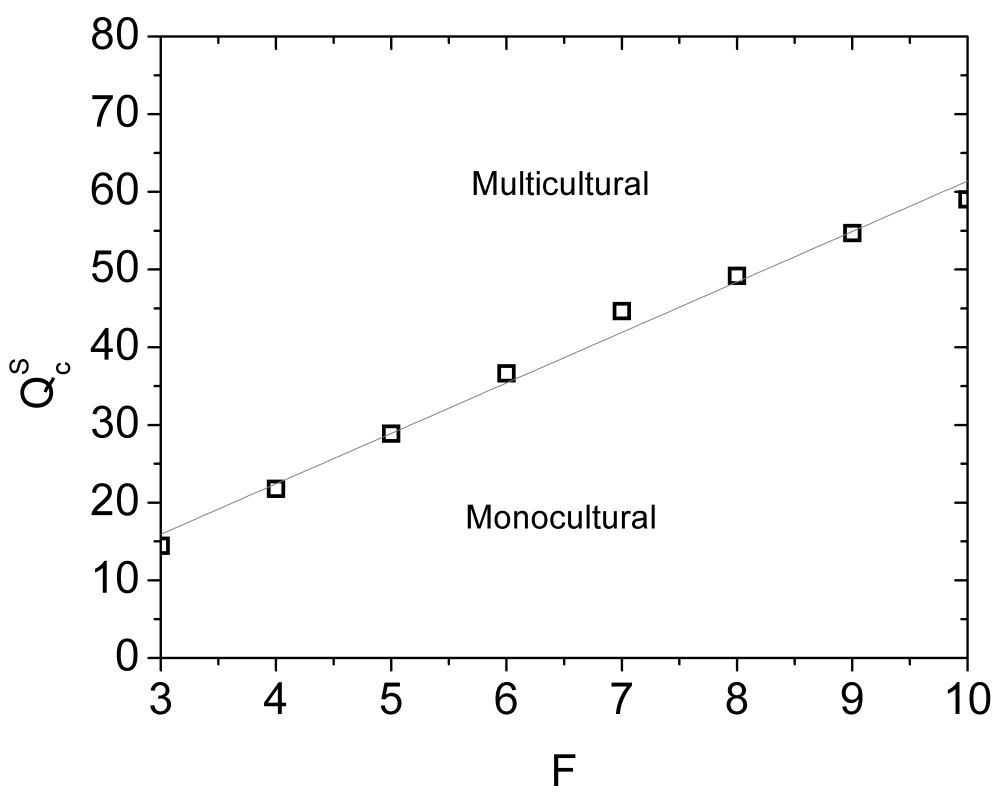

(a)

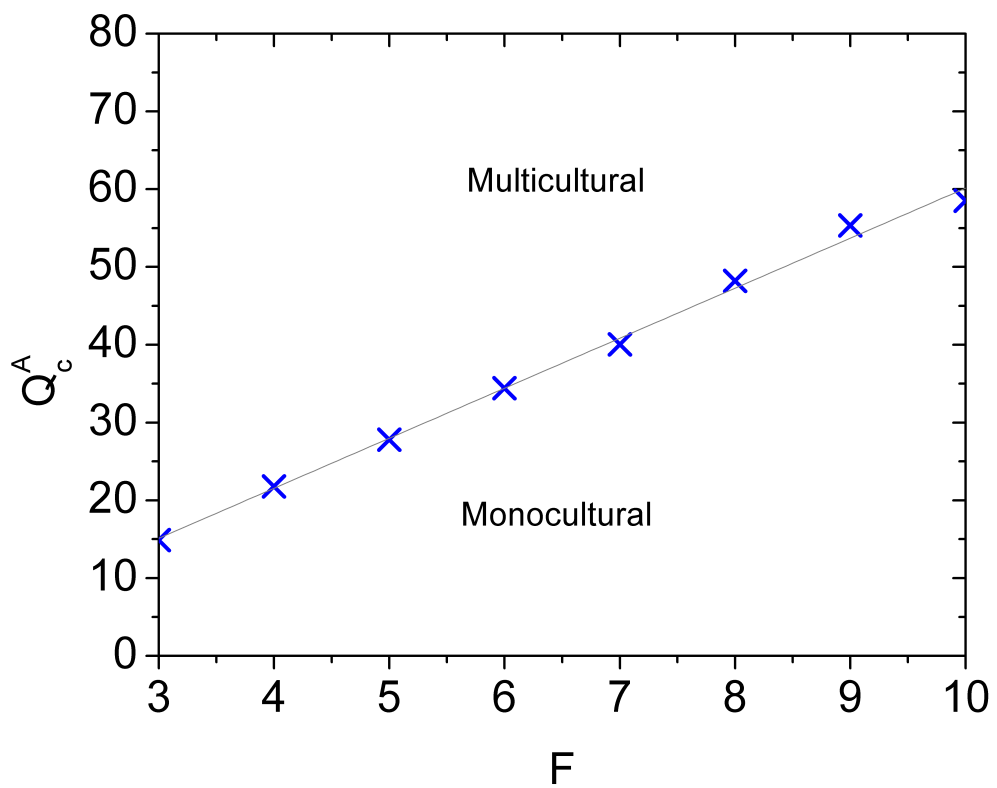

(b)

Figura 4.6: Em (a), pontos $Q_{c}^{\chi_{S}}(F)$ indicados pelos símbolos $(\square)$ ajustados linearmente pela função $Q_{c}^{S}(F)$ dada pela equação 4.3 (representada pela reta). Em (b), pontos $Q_{c}^{\chi_{A}}(F)$ indicados pelos símbolos $(\times)$ ajustados linearmente pela função $Q_{c}^{A}(F)$ dada pela equação 4.4 (representada pela reta). 
Como o critério de parada da dinâmica do modelo de Axelrod é o estado absorvente, qualquer par agente-vizinho com probabilidade não-nula de interação tem tempo suficiente para interagir e trocar características culturais. Logo, qualquer par agentevizinho de domínios diferentes tem probabilidade nula de interação no estado final. Desse modo, investigamos a relação entre a probabilidade de não interação $P_{0}$ no instante inicial e os pontos de transição $Q_{c}^{\chi_{S}}$ e $Q_{c}^{\chi_{A}}$ para os valores de $F(3 \leq F \leq 10)$ quando a condição inicial é aleatória.

Substituindo na equação (4.6) os valores de $Q_{c}^{\chi_{S}}$ e $Q_{c}^{\chi_{A}}$ encontrados na tabela 4.2, calculamos $P_{0}^{\chi_{S}}$ e $P_{0}^{\chi_{A}}$ para cada valor de $F$ no ponto de transição (tabela 4.3). Os valores estão divididos em duas categorias. A categoria BST-S indica que os valores substituídos $\left(Q_{c}^{\chi_{S}}\right)$ correspondem aos pontos de transição que foram extrapolados a partir de medidas de $S$, enquanto que a categoria BST- $A$ indica que os valores dos pontos $\left(Q_{c}^{\chi_{A}}\right)$ foram extrapolados a partir de medidas de $A$. A dependência de $P_{0}^{\chi_{S}}$ e $P_{0}^{\chi_{A}}$ com $F$ também pode ser visualizada na figura 4.7. Nessa figura, $P_{0}^{\chi_{S}}$ é indicado pelos símbolos $(\square)$ e $P_{0}^{\chi_{A}}$ pelos símbolos $(\times)$. Os cálculos dos valores médios de $P_{0}^{\chi_{S}}$ e $P_{0}^{\chi_{A}}$ (apresentados na tabela 4.3) conduzem ao resultado $P_{0}=0.84 \pm 0.01$. Esse resultado sugere que há uma probabilidade de não interação característica $\left(P_{c} \approx 0.84\right.$, representada pela linha contínua na figura 4.7$)$ que determina a configuração encontrada no estado final.

Curiosamente, observamos que a probabilidade de não interação $P_{0}$ é aproximadamente invariante com a mudança do parâmetro $F(3 \leq F \leq 10)$ quando calculada sobre os pontos de transição. Admitindo-se que tal invariância se mantém para valores maiores de $F$, manipulamos a equação (4.6) para obter uma expressão para o diagrama de fases válida para condição inicial aleatória:

$$
Q_{c}(F)=\frac{1}{1-\left(P_{c}\right)^{1 / F}} .
$$

Substituindo $P_{c}=0.84$, temos a equação

$$
Q_{c}(F)=\frac{1}{1-(0.84)^{1 / F}} .
$$

Essa equação, assim como as equações (4.3) e (4.4), oferecem uma estimativa do ponto de transição $Q_{c}(F)$ para qualquer $F$. Uma comparação entre as curvas 
Tabela 4.3: Cálculo de $P_{0}^{\chi_{S}}$ e $P_{0}^{\chi_{A}}$ a partir de dados $Q_{c}^{\chi_{S}}$ e $Q_{c}^{\chi_{A}}$ apresentados na tabela 4.2. Denominamos BST- $S$ os dados resultantes da extrapolação das medidas de $S$, e BST- $A$ os dados resultantes da extrapolação das medidas de $A$.

\begin{tabular}{c|c|c|c|c}
\hline \hline \multirow{2}{*}{} & \multicolumn{2}{|c|}{$\mathrm{BST}-S$} & \multicolumn{2}{c}{$\mathrm{BST}-A$} \\
$F$ & $Q_{c}^{\chi_{S}}$ & $P_{0}^{\chi_{S}}$ & $Q_{c}^{\chi_{A}}$ & $P_{0}^{\chi_{A}}$ \\
\hline 3 & 14.45 & 0.806 & 14.88 & 0.812 \\
\hline 4 & 21.77 & 0.829 & 21.79 & 0.829 \\
\hline 5 & 28.88 & 0.838 & 27.79 & 0.833 \\
\hline 6 & 36.65 & 0.847 & 34.42 & 0.838 \\
\hline 7 & 44.65 & 0.853 & 40.05 & 0.838 \\
\hline 8 & 49.19 & 0.848 & 48.22 & 0.846 \\
\hline 9 & 54.69 & 0.847 & 55.35 & 0.848 \\
\hline 10 & 59.03 & 0.843 & 58.51 & 0.841 \\
\hline & Média & $0.84 \pm 0.01$ & Média & $0.84 \pm 0.01$ \\
\hline
\end{tabular}

$Q_{c}^{S}(F), Q_{c}^{A}(F)$ e $Q_{c}(F)$ (estimadas pelas três equações: (4.3), (4.4) e (4.8), respectivamente) é apresentada na figura 4.8. Observamos que as curvas coincidem para pequenos valores de $F$. Quando $F$ aumenta, a curva dada pela equação $Q_{c}(F)$ se afasta das curvas dadas pelas equações $Q_{c}^{S}(F)$ e $Q_{c}^{A}(F)$.

O resultado apresentado na figura 4.8 contém três propostas de estimativas de determinação da linha de transição do modelo de Axelrod. As três estimativas coincidem no regime de valores de $F$ considerados em nosso estudo $(3 \leq F \leq 10)$. Simulações em redes maiores e com valores de $F$ mais altos devem ser realizadas e comparadas com ambos os métodos de extrapolação.

\subsubsection{Comentário sobre caso unidimensional}

Em [61] é determinado analiticamente o diagrama de fases do modelo de Axelrod em uma rede unidimensional. A transição é contínua para todos os valores de $F$ [62] e a linha crítica é dada por $Q_{c}(F)=F$ quando a condição inicial é aleatória. Substituindo essa relação na equação (4.6), podemos calcular a probabilidade de 


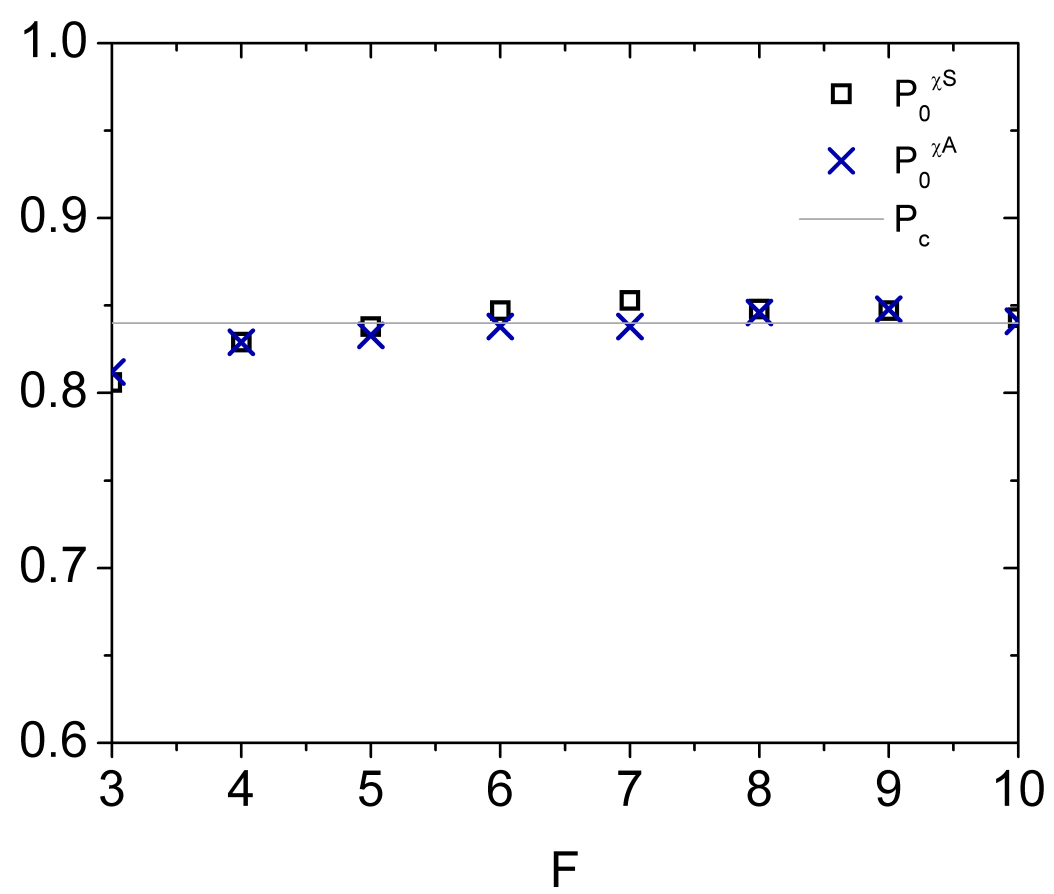

Figura 4.7: Probabilidade $P_{0}$ de não interação entre um par agente-vizinho qualquer em uma configuração inicial aleatória. Os valores de $P_{0}^{\chi_{S}}$ são indicado pelos símbolos $(\square)$, e os valores de $P_{0}^{\chi_{A}}$ pelos símbolos $(\times)$. A linha contínua representa o valor $P_{c}=0.84$.

interação nula entre dois agentes vizinhos na configuração inicial sobre a linha crítica da rede unidimensional:

$$
P_{0}=\left(1-\frac{1}{F}\right)^{F}
$$

Essa expressão resulta em $P_{0}=0.25$ se $F=2, P_{0} \approx 0.32$ se $F=5$ e $P_{0} \approx 0.35$ se $F=10$. É interessante notar que o limite assimptótico de $P_{0}$ quando $F \rightarrow \infty$ é dado pela relação

$$
\lim _{F \rightarrow \infty} P_{0}=\lim _{F \rightarrow \infty}\left(1-\frac{1}{F}\right)^{F}=e^{-1} .
$$

Na figura 4.9, os valores de $P_{0}$ (calculados a partir da equação (4.9)) são representados pelos pontos $(\square)$ que se aproximam de $e^{-1}$ (indicado pela linha contínua) conforme $F$ aumenta.

No caso unidimensional, $P_{c} \approx 0.37$ para altos valores de $F$. Esse valor é menor 


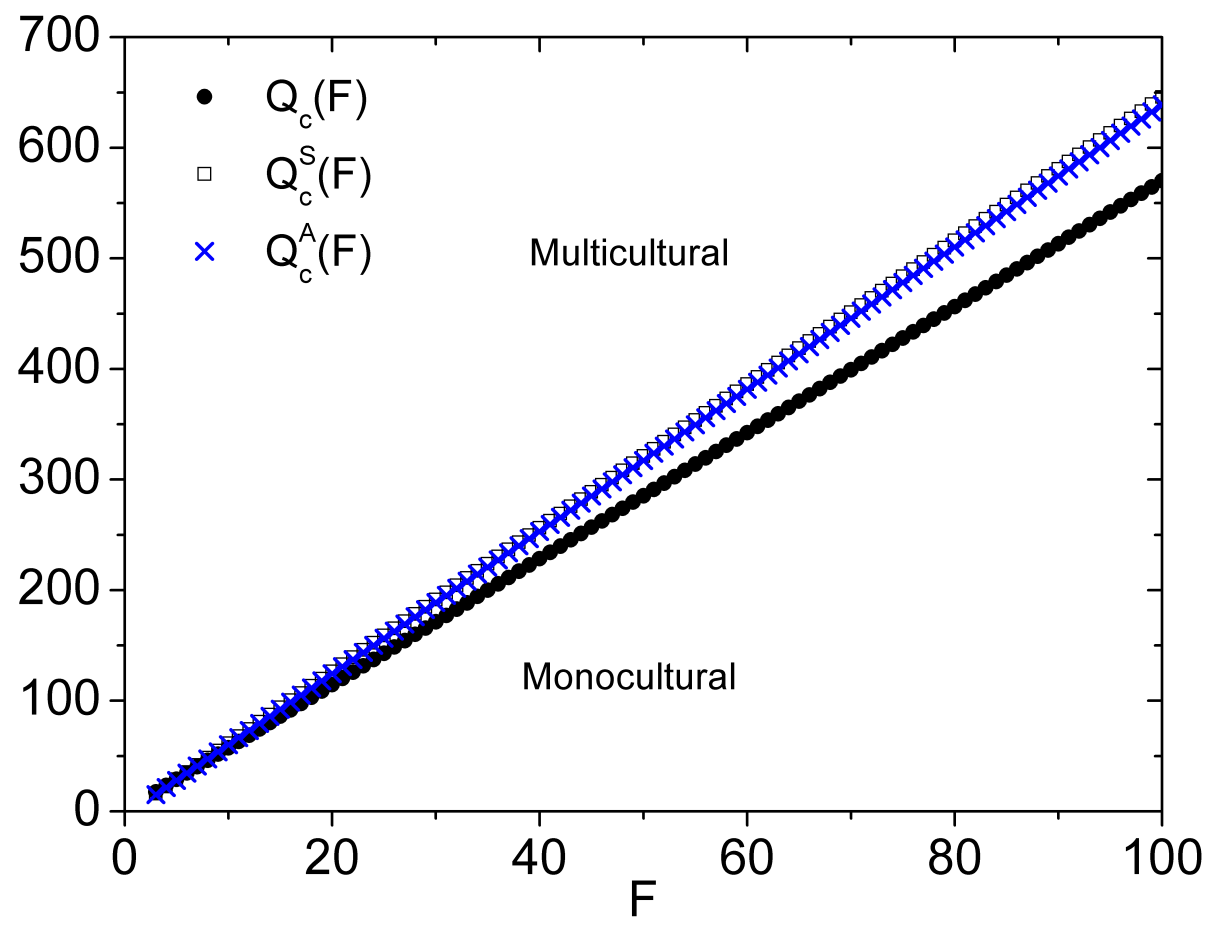

Figura 4.8: Estimativas do diagrama de fases. Linhas de transição determinadas pelas expressões $Q_{c}^{S}(F), Q_{c}^{A}(F)$ e $Q_{c}(F)$.

que o encontrado para o caso bidimensional e sugere uma relação de $P_{c}$ com a dimensão e/ou o número de agentes na vizinhança (ou número de coordenação ${ }^{1}$ ).

\subsection{Condição de contorno}

O tipo de condição de contorno pode afetar a dinâmica dos modelos computacionais. Consequentemente, deve-se estar atento à influência das bordas da rede nas medidas realizadas. Em [52], por exemplo, os autores mostram que as condições de contorno aberta e fechada conduzem a resultados divergentes quando se estuda o comportamento dinâmico do autômato Game of Life.

Para investigar a influência das condições de contorno no modelo de Axelrod, reproduzimos a análise da seção anterior (realizada com condições periódicas de contorno) para resultados do modelo em uma rede quadrada com condição de contorno aberta. Nesse tipo de contorno, a vizinhança dos agentes do centro da rede é

\footnotetext{
${ }^{1}$ Do inglês coordination number.
} 


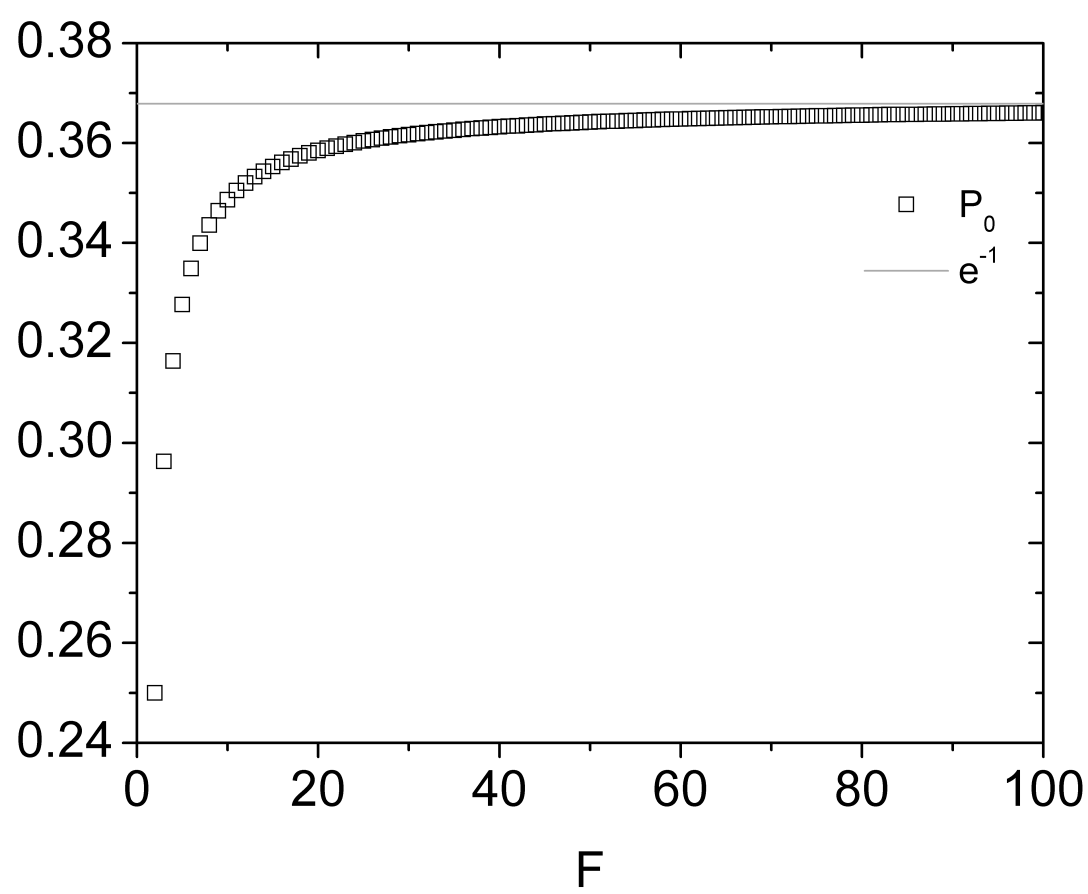

Figura 4.9: Comportamento de $P_{0}$ (dado pela equação (4.9)) em função de $F$ para o caso unidimensional. A linha contínua representa o valor limite $e^{-1}$.

composta pelos quatros vizinhos mais próximos, a vizinhança dos agentes dos lados da rede é composta pelos três vizinhos adjacentes e a vizinhança dos agentes dos cantos da rede é composta pelos dois agentes adjacentes [72].

As curvas dos parâmetros de ordem $\langle S\rangle$ e $\langle A\rangle$ juntamente com as curvas de susceptibilidades $\chi_{S}$ e $\chi_{A}$ (figuras 4.10 e 4.11) foram determinadas a partir de $M=$ 1000 simulações para as redes $L=8,16,32$ e $M=100$ para as redes $L=64,128$. Os valores $\left(Q_{c}^{\chi_{S}}(F, L), Q_{c}^{\chi_{A}}(F, L)\right)$ obtidos através dos máximos das susceptibilidades $\chi_{S}$ e $\chi_{A}$, respectivamente, são apresentados na tabela 4.4. Observamos que os pontos $Q_{c}^{\chi_{S}}(F, L)$ e $Q_{c}^{\chi_{A}}(F, L)$ se aproximam do mesmo valor com o aumento do tamanho da rede. A comparação desses resultados com os dados da tabela 4.1 (que apresenta $\left(Q_{c}^{\chi_{S}}(F, L), Q_{c}^{\chi_{A}}(F, L)\right)$ para a condição de contorno periódica) revela que a influência do tipo de contorno diminui quando $L$ aumenta. 


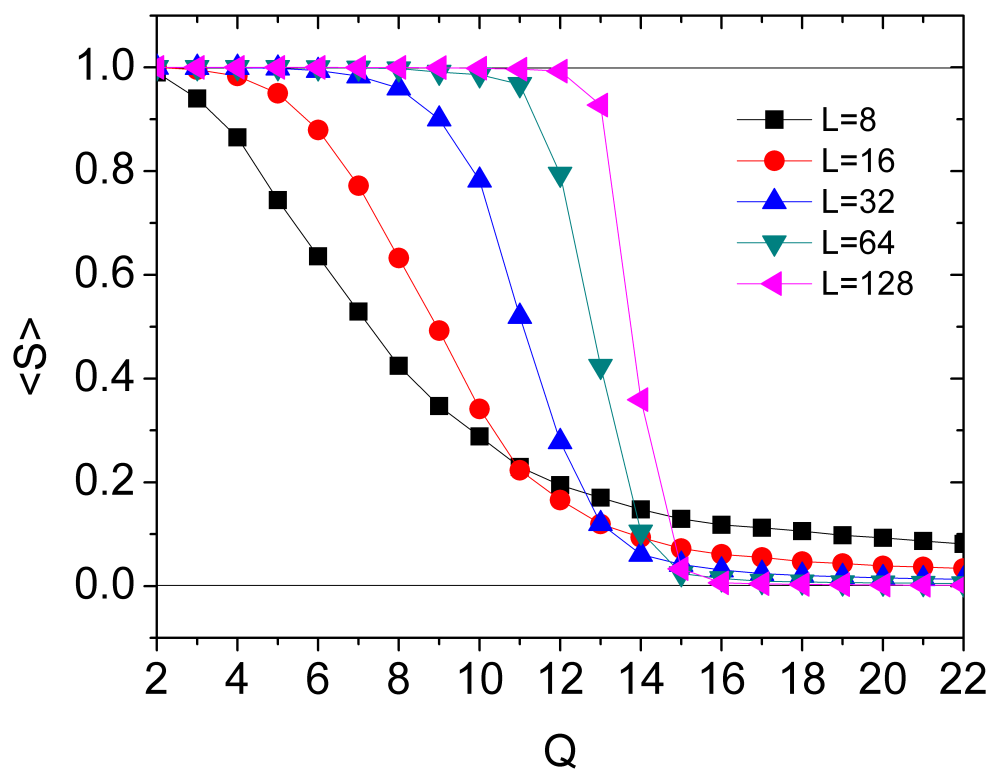

(a)

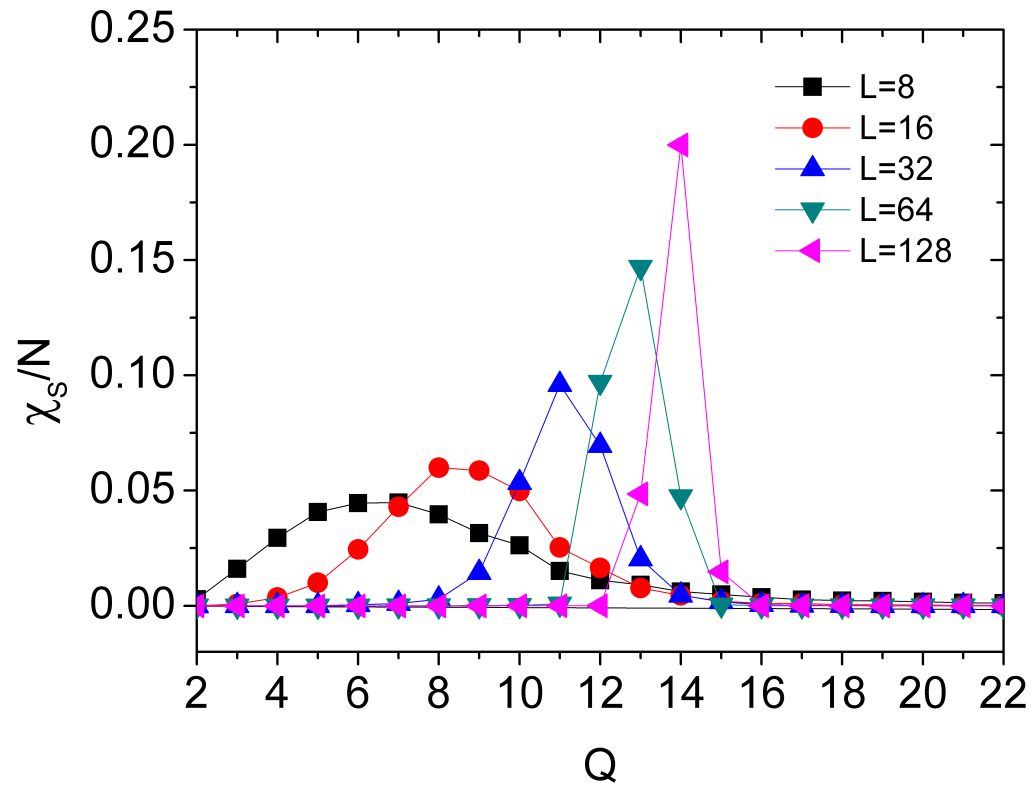

(b)

Figura 4.10: Medidas de $\langle S\rangle$ em (a) e $\chi_{S}$ em (b) como função de $Q$ para $F=3$ nas redes $L=8,16,32,64,128$. Cada medida corresponde a médias sobre $M=1000$ simulações nas redes $L=8,16,32$ e $M=100$ nas redes $L=64,128$ com condição de contorno aberta. 


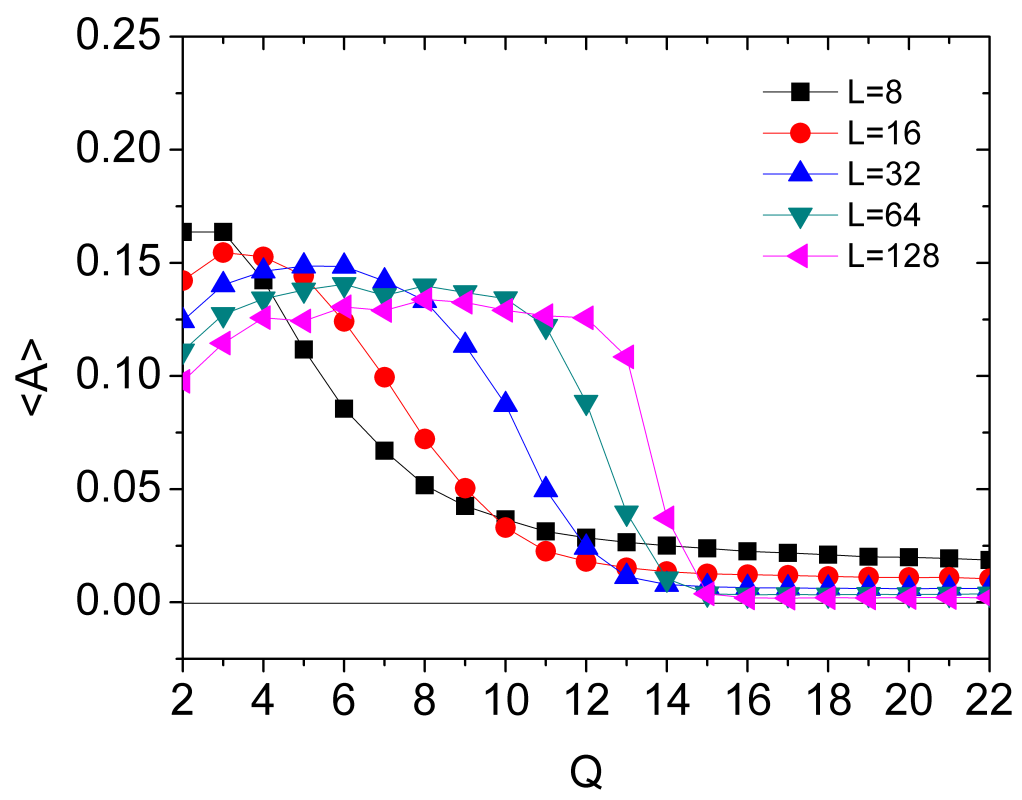

(a)

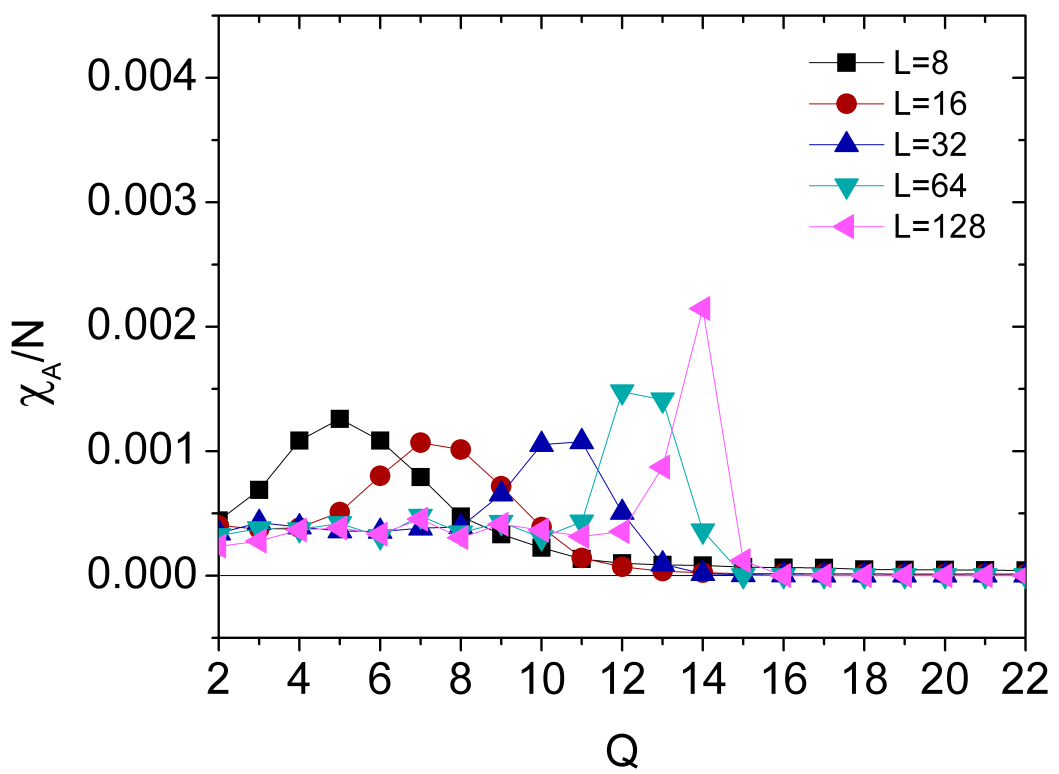

(b)

Figura 4.11: Medidas de $\langle A\rangle$ em (a) e $\chi_{A}$ em (b) como função de $Q$ para $F=3$ nas redes $L=8,16,32,64,128$. Cada medida corresponde a médias sobre $M=1000$ simulações nas redes $L=8,16,32$ e $M=100$ nas redes $L=64,128$ com condição de contorno aberta. 


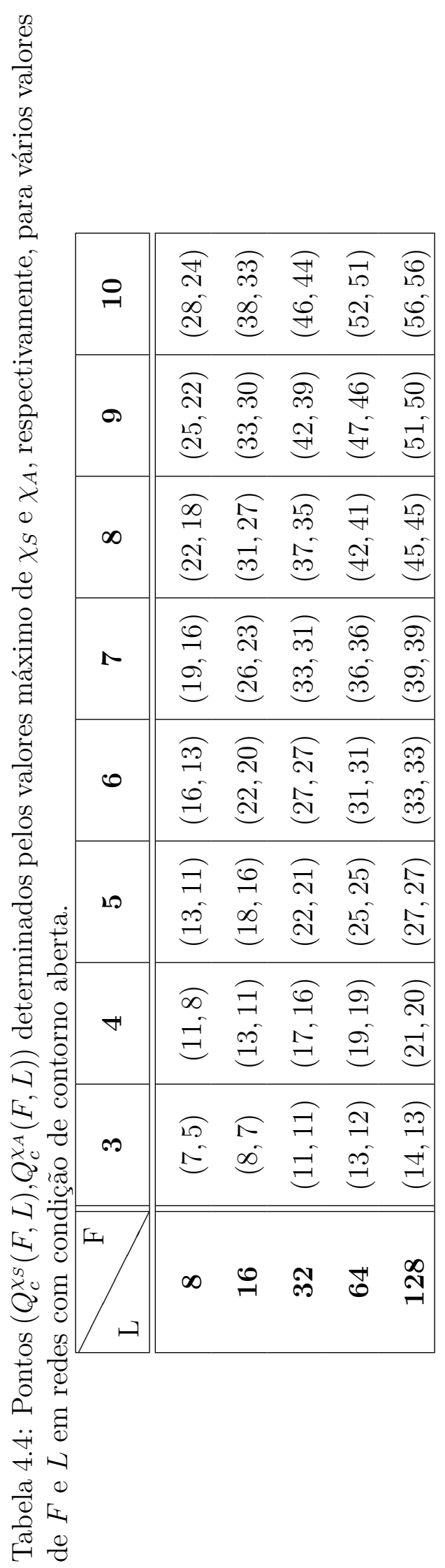


A extrapolação dos pontos de transição $Q_{c}^{\chi_{S}}(F, L)$ e $Q_{c}^{\chi_{A}}(F, L)$ com o algoritmo BST resulta nos valores $Q_{c}^{\chi_{S}}$ e $Q_{c}^{\chi_{A}}$ apresentados na tabela 4.5. A coluna $\operatorname{BST}\left(\chi_{S}\right)$ indica que os valores extrapolados correspondem a medidas de $S$, enquanto que a coluna $\operatorname{BST}\left(\chi_{A}\right)$ indica que os valores dos pontos foram extrapolados a partir de medidas de $A$. Os ajustes lineares dos pontos $Q_{c}^{\chi_{S}}$ e $Q_{c}^{\chi_{A}}$ resultam em, respectivamente,

$$
\begin{array}{ll}
Q_{c}^{S *}=-3.4+6.5 F & (3 \leq F \leq 10), \\
Q_{c}^{A *}=-5.5+6.7 F & (3 \leq F \leq 10) .
\end{array}
$$

Substituindo na equação (4.6) os valores de $Q_{c}^{\chi_{S}}$ e $Q_{c}^{\chi_{A}}$ encontrados na tabela 4.5, calculamos $P_{0}^{\chi_{S}}$ e $P_{0}^{\chi_{A}}$ para cada valor de $F$ no ponto de transição. Obtemos o valor médio $P_{0}=0.84 \pm 0.02$ para as medidas de ambos os parâmetros de ordem considerados $(S$ e $A)$. Observe que esse valor empírico de $P_{0}$ é igual ao obtido quando o modelo é implementado com condição periódica de contorno. Logo, esse resultado sugere que a probabilidade de não interação característica $\left(P_{c} \approx 0.84\right)$

Tabela 4.5: Determinação dos pontos de transição $Q_{c}^{\chi_{S}}$ e $Q_{c}^{\chi_{A}}$ através do algoritmo de extrapolação BST. Os pontos $Q_{c}^{\chi_{S}}(F, L)$ e $Q_{c}^{\chi_{A}}(F, L)$ foram obtidos através dos pontos de máximo das susceptibilidades $\chi(S)$ e $\chi(A)$ apresentados na tabela 4.4.

\begin{tabular}{c|c|c|c|c}
\hline \hline & \multicolumn{2}{|c|}{$\operatorname{BST}\left(\chi_{S}\right)$} & \multicolumn{2}{c}{$\operatorname{BST}\left(\chi_{A}\right)$} \\
\hline$F$ & $Q_{c}^{\chi_{S}}(F, L)$ & $\omega$ & $Q_{c}^{\chi_{A}}(F, L)$ & $\omega$ \\
\hline 3 & 14.72 & 1.37 & 14.26 & 1.01 \\
\hline 4 & 22.36 & 1.55 & 20.35 & 2.04 \\
\hline 5 & 29.01 & 1.31 & 28.05 & 1.76 \\
\hline 6 & 36.63 & 0.83 & 34.54 & 1.29 \\
\hline 7 & 42.71 & 0.94 & 42.16 & 1.08 \\
\hline 8 & 50.16 & 0.70 & 49.50 & 1.22 \\
\hline 9 & 53.71 & 1.36 & 53.70 & 0.98 \\
\hline 10 & 60.14 & 1.27 & 60.25 & 1.28 \\
\hline \hline
\end{tabular}




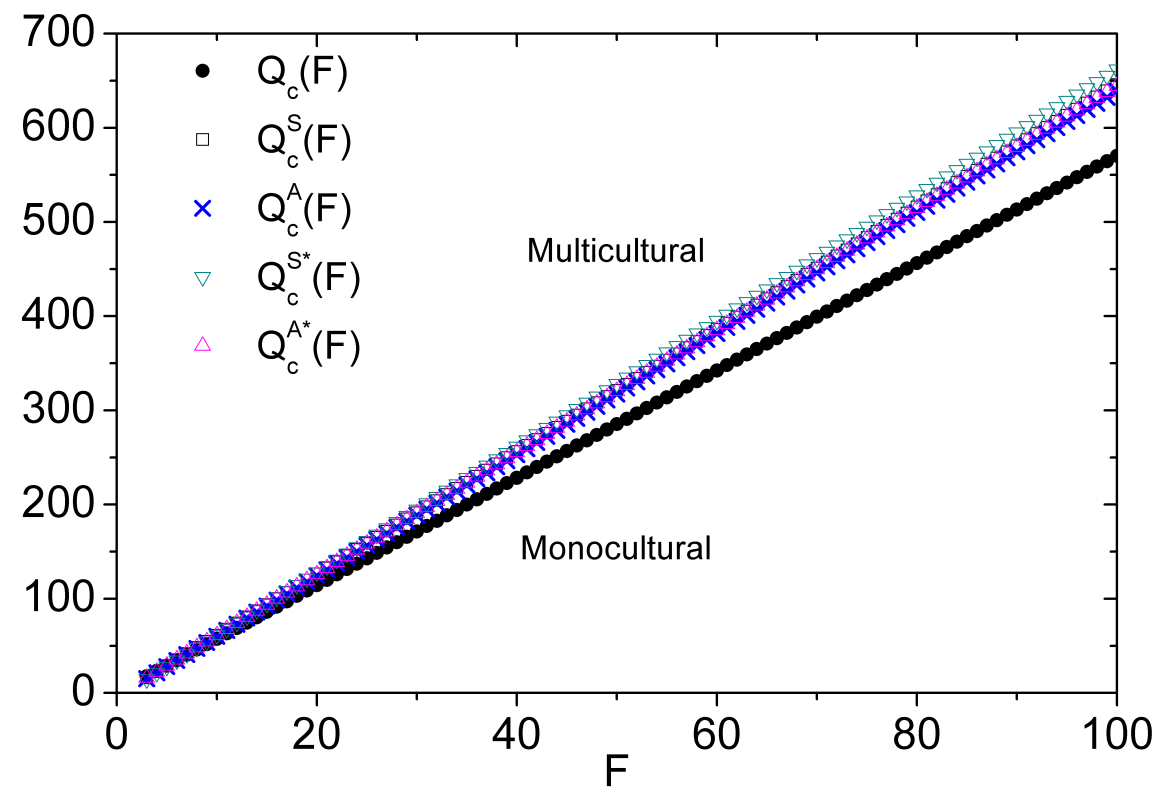

Figura 4.12: Estimativas do diagrama de fases. Linhas de transição determinadas pelas expressões $Q_{c}^{S}(F)$ e $Q_{c}^{A}(F)$ (condições de contorno periódicas), $Q_{c}^{S *}(F)$ e $Q_{c}^{A *}(F)$ (condição de contorno aberta) e $Q_{c}(F)$.

independe do contorno utilizado.

As curvas $Q_{c}^{S *}(F)$ e $Q_{c}^{A *}(F)$ ajustadas aos pontos do intervalo $(3 \leq F \leq 10)$ nas simulações com condição de contorno aberta e extrapoladas para os demais valores de $F>10$ são mostradas na figura 4.12. Nessa figura vemos que os resultados das funções $Q_{c}^{S *}(F)$ e $Q_{c}^{A *}(F)$ são praticamente indistinguíveis dos resultados obtidos com condições de contorno periódica $\left(Q_{c}^{S}(F)\right.$ e $\left.Q_{c}^{A}(F)\right)$. Consequentemente, podemos inferir que a escolha da condição de contorno não exerce influência significativa na extrapolação dos pontos de transição e na dinâmica do modelo.

\subsection{Conclusão}

Nesse capítulo, utilizamos a susceptibilidade para obter os valores dos pontos de transição efetivos $Q_{c}(F, L)$. Mostramos, pela análise da distribuição dos parâmetros $S$ e $A$, que os $Q_{c}^{\chi_{S}}(F, L)$ e $Q_{c}^{\chi_{A}}(F, L)$ obtidos desse modo correspondem, de fato, aos pontos de transição. A forma bimodal da distribuição nesses pontos sugere a coexistência de duas fases diferentes. Essa coexistência de fases, por sua vez, 
indica que o tipo de transição encontrado quando se varia $Q$ (para dado $F \geq 3$ ) é descontínua.

Nossos resultados foram obtidos na região $(3 \leq F \leq 10)$. Assumindo que os comportamentos de $Q_{c}^{S}(F)$ e $Q_{c}^{A}(F)$ (condição de contorno fechada) e $Q_{c}^{S *}(F)$ e $Q_{c}^{A *}(F)$ (condição de contorno aberta) observados nessa região se mantêm quando $F>10$, realizamos a extrapolação dessas curvas para valores maiores de $F$. Essa extrapolação nos permitiu esboçar numericamente o diagrama de fases do modelo de Axelrod em uma rede quadrada com condições de contorno aberta e fechada. Curiosamente, nossos resultados sugerem que a probabilidade característica de não interação $P_{c}$ é aproximadamente invariante quando, para dado $F$, se escolhe $Q$ tal que $Q=Q_{c}(F)$. A obtenção de $P_{c}$ permite extrapolar a curva de ajuste $Q_{c}(F)$ para estimar o diagrama de fases. Nesse contexto, podemos supor que a transição de fases é, na verdade, caracterizada por $P_{c}$, pois $P_{c}$ faz o papel de uma grandeza universal que indica o ponto de transição para qualquer conjunto de parâmetros $(F, Q)$.

Observamos também que os pontos de transição obtidos com os dois parâmetros considerados $(S$ e $A$ ) se aproximam dos mesmos valores conforme o tamanho da rede aumenta. Logo, esses resultados corroboram a aplicação da atividade como parâmetro de ordem. Além disso, mostramos que o tipo de condição de contorno não têm influência nas medidas do modelo em redes grandes. Esse resultado confirma a expectativa de [53].

Uma das limitações da abordagem utilizada é dependência com o tamanho da rede. Em [73], o autor afirma que o algoritmo BST não é muito sensível às variações nos parâmetros de entrada. No entanto, a extrapolação de $Q_{c}$ pelo algoritmo BST será melhor quanto maiores forem as redes utilizadas. 


\section{Capítulo}

\section{Efeitos de mídia interna}

"The more social media we have, the more we think we're connecting, yet we are really disconnecting from each other."

- Jessica R. P. Bird

O modelo de dinâmica social de Axelrod tem sido estudado sob efeito de mídia externa. Aqui estudamos a formação de domínios culturais no modelo com a introdução de agentes persistentes para modelar efeitos de mídia interna. As características culturais desses agentes são fixas e podem ser difundidas na rede através de interações com a vizinhança local. Sabe-se que, na ausência de mídia interna, o sistema apresenta transição de um regime final monocultural para um regime multicultural em um valor crítico de $Q$ (número de estados). Nossos resultados revelam uma dependência do valor crítico de $Q$ com a probabilidade de ocupação $p$ de agentes persistentes. Essa dependência nos permite obter o diagrama de fases do modelo no plano $(p, Q)$. A linha crítica é explicada pela competição de duas forças opostas que denominamos efeito de barreira e efeito de ligação. Verificamos que tais forças são causadas por agentes não-persistentes que aderem (agentes aderentes) ao conjunto de estados culturais dos agentes persistentes. Encontramos que a aderência (concentração de agentes aderentes) em função de $p$ decai se $Q$ é constante e decai linearmente se $p$ aumenta conforme caminhamos na linha crítica. Além disso, obtemos que a aderência em função de $Q$ decai como uma lei de potência se $p$ é fixo. Utilizando dados de simulações em redes finitas, extrapolamos o diagrama de fases no limite termodinâmico e também mostramos que o comportamento do sistema independe do valor de $F$ (para $F \geq 3$ ). 


\subsection{Agentes persistentes como mídia interna}

Para estudar a formação dos regimes mono e multiculturais do modelo com perturbações internas, agentes persistentes são introduzidos em sítios da rede sorteados aleatoriamente com probabilidade de ocupação $p[77]^{1}$. Os agentes persistentes são caracterizados pelo mesmo vetor cultural $\psi_{P}$ que é mantido fixo durante toda a dinâmica.

A fim de entender o papel dos agentes persistentes na rede, lembramos do conceito de resoluto elaborado por Penrose em [1]. Como descrito na Introdução, Penrose afirma que as pessoas podem ser resolutas ou indiferentes. Se por um lado os resolutos têm uma opinião forte e bem definida sobre um determinado assunto, por outro os indiferentes não têm uma posição bem definida. Penrose argumenta que um pequeno grupo de resolutos tem uma influência poderosa em toda a sociedade controlando as decisões de um eleitorado composto majoritariamente por indiferentes. De maneira semelhante, agentes persistentes mantêm firmemente suas opiniões e procuram persuadir os vizinhos a adotarem uma dada cultura em cada tentativa de interação. Consequentemente, eles estão constantemente trabalhando para controlar as opiniões da vizinhança. Nesse sentido, acreditamos que os persistentes desempenham o papel de um tipo de mídia interna local dado que agentes de mídia podem ser encarados como "instrumentos para controlar as opiniões das pessoas" [68].

Uma vez que os agentes persistentes tendem a espalhar suas características culturais através da vizinhança, agentes não-persistentes caracterizados pelo mesmo vetor cultural $\psi=\psi_{P}$ (chamados agentes aderentes) podem ser encontrados no estado estacionário. Nesse contexto, a aderência da rede $\tilde{A}$ é definida como

$$
\tilde{A}=\frac{\tilde{N}}{N}
$$

onde $\tilde{N}$ é o número de agentes aderentes. Analogamente, a aderência do cluster dominante $\tilde{A}_{D}$ é definida pela razão do número de agentes adentes pertencentes ao maior cluster pelo número de total de agentes desse cluster.

A transição de fase no modelo de Axelrod é caracterizada pela distinção entre

\footnotetext{
${ }^{1}$ Tal estudo encontrava-se em fase de revisão quando a versão original da tese foi depositada.
} 


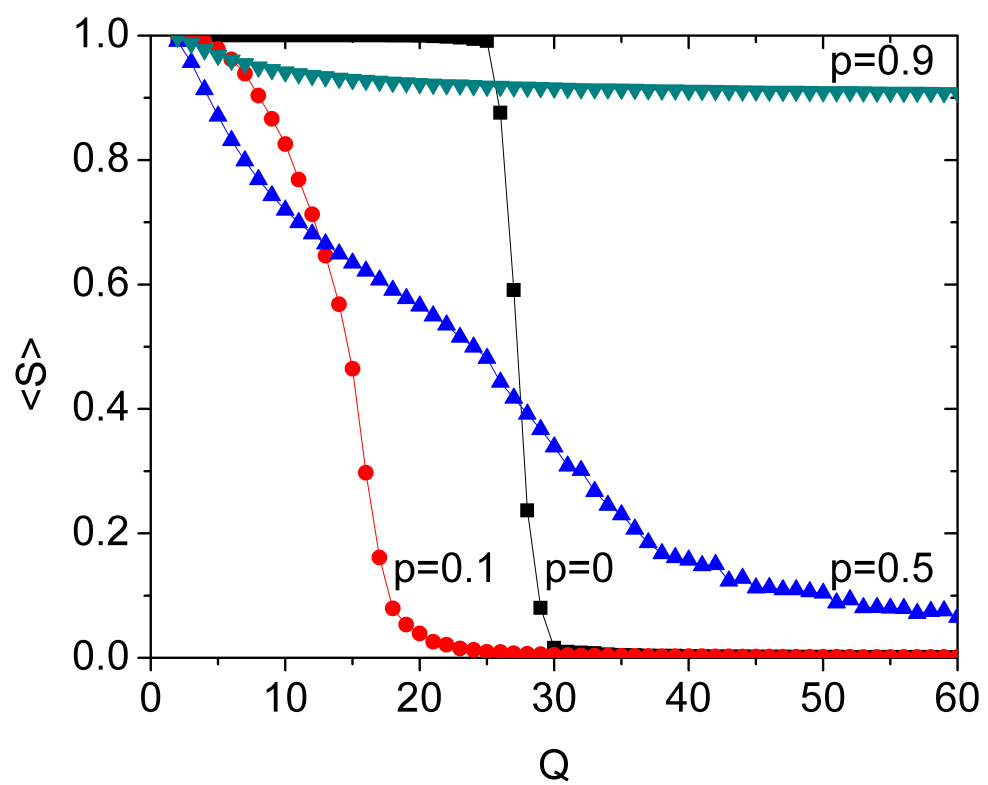

Figura 5.1: Parâmetro de ordem $\langle S\rangle$ em função de $Q$ para $p=0,0.1,0.5$ e 0.9 , obtido de $M=100$ simulações com $F=5$ e $L=100$.

o regime monocultural e o regime multicultural em algum valor crítico de $Q$. Na ausência de agentes persistentes $(p=0$ ), há a transição (veja figura 5.1) de um regime onde $\langle S\rangle \approx 1$ para $Q<Q_{c}$ (correspondendo a uma configuração homogênea com um cluster dominante se espalhando por toda a rede) para um regime onde $\langle S\rangle \approx 0$ para $Q>Q_{c}$ (correspondendo a uma configuração heterogênea com um grande número de aglomerados pequenos). Tal comportamento é típico de uma transição descontínua e ocorre para $F \geq 3$. Sendo assim, estudamos a estabilidade de um sistema sob efeito de perturbações internas escolhendo $F=5$ como feito por Peres e Fontanari [68, 53], Shibanai et al. [74], e outros autores [43, 75].

Podemos notar na figura 5.1 que a adição de agentes persistentes altera o valor do ponto de transição $Q_{c}$. As baixas concentrações de agentes persistentes $(p=$ 0.1) desestabilizam a formação de configurações homogêneas. Consequentemente, o parâmetro de ordem $\langle S\rangle$ tende a decair em um valor crítico $Q_{c}(p)$ menor. Por outro lado, uma concentração alta de impurezas $(p=0.9)$ promove a formação de um grande domínio de agentes (mesmo para altos valores de $Q$ ), evitando, assim, a formação de um regime multicultural. Para uma concentração intermediária ( $p=$ 
0.5) os regimes mono e multiculturais são afetados pelos agentes persistentes.

\subsection{Diagrama de fases}

Para estudar como o ponto de transição $Q_{c}$ depende da concentração $p$, nós determinamos o diagrama de fases do modelo no plano $(p, Q)$. Cada ponto crítico $Q_{c}(p)$ é obtido a partir do pico da susceptibilidade do parâmetro de ordem (equação (3.4)),

$$
\chi_{S}=N\left(\left\langle S^{2}\right\rangle-\langle S\rangle^{2}\right),
$$

como função de $Q$. É importante notar que $Q_{c}(p)$ corresponde ao ponto de transição efetivo de um sistema em uma rede finita $(L=100)$ [22].

Os pontos críticos $Q_{c}(p)$ são representados pelos pontos quadrados na figura 5.2. A linha contínua indica uma transição de primeira ordem de uma fase multicultural para uma fase monocultural. Devemos notar que os pontos circulares e a linha tracejada (cinza) apenas indicam a existência de picos da susceptibilidade dentro da fase monocultural e que, portanto, não representam nenhuma transição. Tais picos são devidos à flutuações no tamanho do cluster dominante e não estão relacionados com coexistência de fases.

O diagrama de fases revela que, para $p<0.48$, o ponto de transição $Q_{c}(p)$ é menor que o valor crítico $Q_{c}(0)=27$. Conforme $p$ aumenta de $p=0$ até $p \approx 0.25$, observamos um decaimento de $Q_{c}(p)$. Pequenas concentrações de agentes persistentes criam um "efeito barreira" que torna mais difícil a propagação dos diversos traços culturais encontrados na rede. Tal efeito tende a fragmentar os domínios culturais e favorecer o regime multicultural. Se $p$ continua aumentando, domínios com agentes persistentes se tornam maiores e os agentes aderentes tendem a estabelecer conexões entre esses domínios. Esse "efeito de ligação" favorece o regime monocultural. Para altos valores de $p$, o estado estacionário é sempre monocultural independentemente do valor de $Q$.

Um dos interesses dos físicos estatísticos é analisar o comportamento do sistema no limite termodinâmico (no qual o tamanho de rede $L \rightarrow \infty$ ). Nesse sentido, apresentamos na figura 5.3 os diagramas de fases no plano $(p, Q)$ do modelo nas redes $L=50,75,100$ e 125. Cada ponto corresponde a um valor $Q_{c}(p, L)$ no qual o máximo da susceptibilidade $\chi_{S}$ indica a transição entre as fases mono e multiculturais 


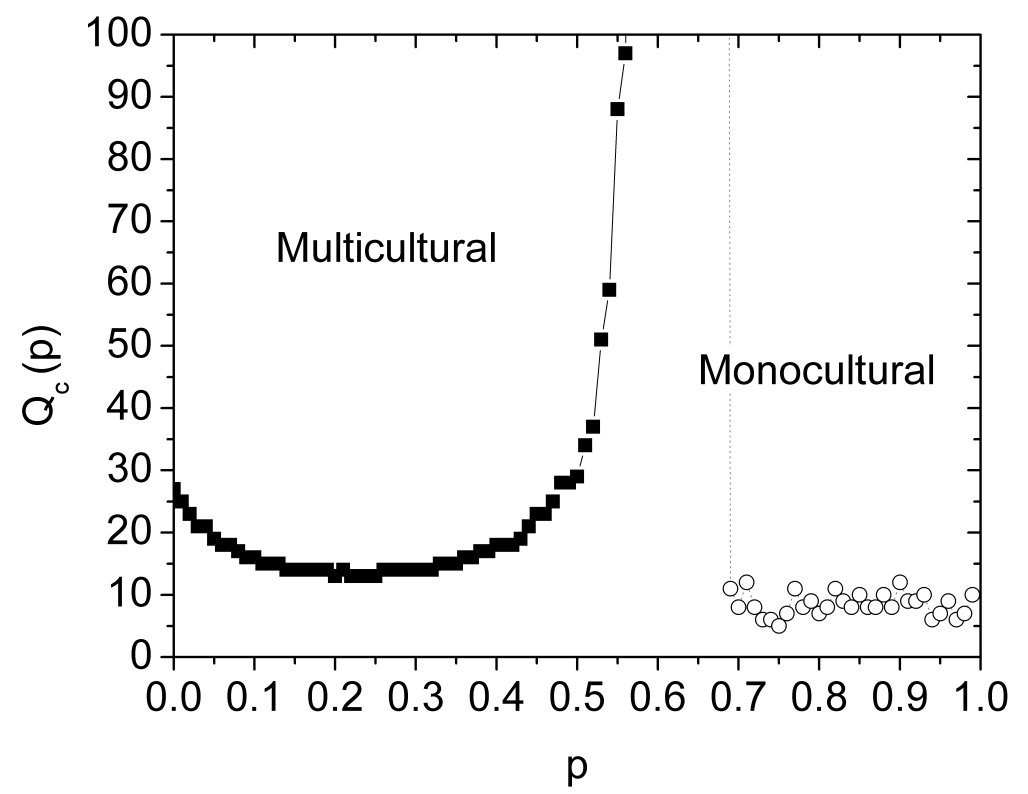

Figura 5.2: Diagrama de fases no plano $(p, Q)$ para $F=5$ (obtido a partir de $M=$ 100 simulações e $L=100)$. O caminho crítico $Q_{c}(p)$ é representado pelos pontos quadrados e pela linha contínua separando a fase multicultural da fase monocultural. Os pontos circulares e a linha tracejada em cinza apenas indicam a existência de picos da susceptibilidade dentro do regime monocultural.

nas redes de tamanho finito $L=50$ (quadrado), $L=75$ (círculo), $L=100$ (triângulo) e $L=125$ (triângulo invertido). A linha contínua corresponde aos pontos $Q_{c}$ extrapolados quando $L \rightarrow \infty$. Para determinar $Q_{c}$, analisamos a dependência dos pontos $Q_{c}(p, L)$ em função de $1 / L$. Em seguida, propomos uma função linear da forma $Q_{c}(p, L)=C_{1}+C_{2} x$, onde $C_{1}$ e $C_{2}$ são constantes e $x=1 / L$, para o ajuste destes pontos. Com essa função, o limite termodinâmico $(L \rightarrow \infty)$ é estimado fazendo $x \rightarrow 0$ [76].

Para ilustrar a competição entre o efeito barreira e o efeito de ligação, apresentamos algumas configurações da rede no estado estacionário para concentrações diferentes de agentes persistentes de simulações com $F=5, Q=21$ e $L=100$ (figuras 5.4 e 5.5). Na coluna da esquerda das duas figuras, as configurações são representadas por agentes persistentes (em branco), agentes aderentes (em cinza) e os demais agentes (em preto). Na coluna da direita, as configurações são representadas pelos agentes persistentes e aderentes que pertencem ao maior domínio cultural 


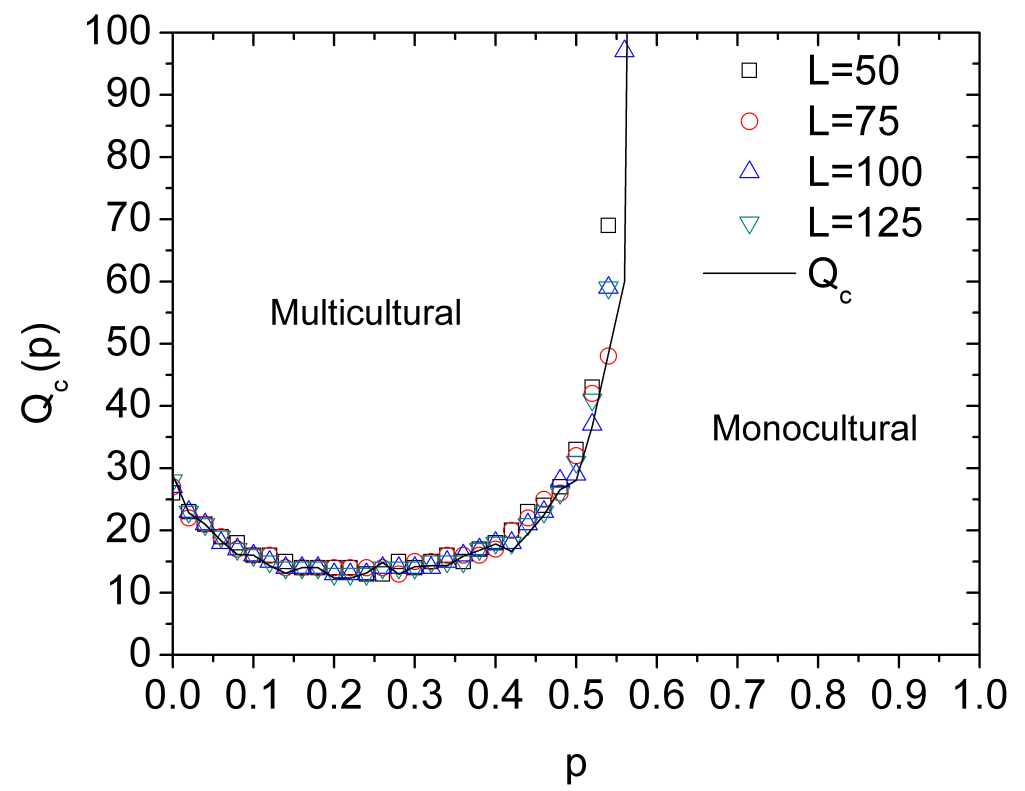

Figura 5.3: Diagrama de fases no plano $(p, Q)$ para $F=5$ (obtido a partir de $M=100$ simulações nas redes $L=50,75,100$ e 150). A linha contínua representa a extrapolação dos pontos $Q_{c}$ no limite termodinâmico.

(em branco) e os demais sítios (em preto). As configurações lado a lado apresentam a mesma concentração $p$ de agentes persistentes. Em cada linha as configurações apresentam uma concentração $p$ diferente, e essa concentração aumenta da linha superior para a linha inferior de cada figura.

A figura 5.4 exibe configurações típicas quando se cruza a linha crítica $Q_{c}(p)$ com $Q$ fixo $(Q=21)$ e aumentando as concentrações $p=0.02$ (regime monocultural), $p=$ 0.03 (ponto de transição) e $p=0.24$ (regime multicultural) na primeira, na segunda e na terceira linha, respectivamente. Na ausência de agentes persistentes o cluster dominante se espalha por toda a rede. Para pequenos valores de $p$, a aderência (regiões em cinza na coluna da esquerda) aos agentes persistentes provoca um efeito barreira que tende a fragmentar os domínios culturais cada vez mais conforme $p$ aumenta, ocasionando um encolhimento do cluster dominante (regiões em branco na coluna da direita). Particularmente, no ponto crítico o cluster dominante percola a rede como se observa na figura $5.4(\mathrm{~d})$.

A figura 5.5 mostra configurações típicas quando a linha crítica é atravessada com $Q=21$ e aumentando as concentrações $p=0.44$ (ponto de transição) e $p=0.64$ 


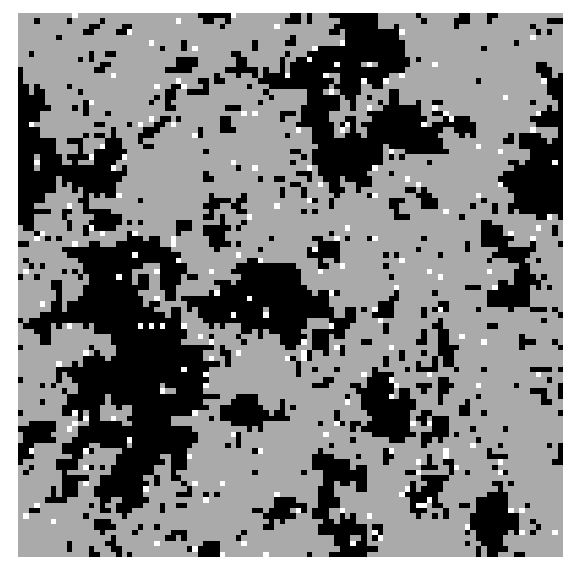

(a)

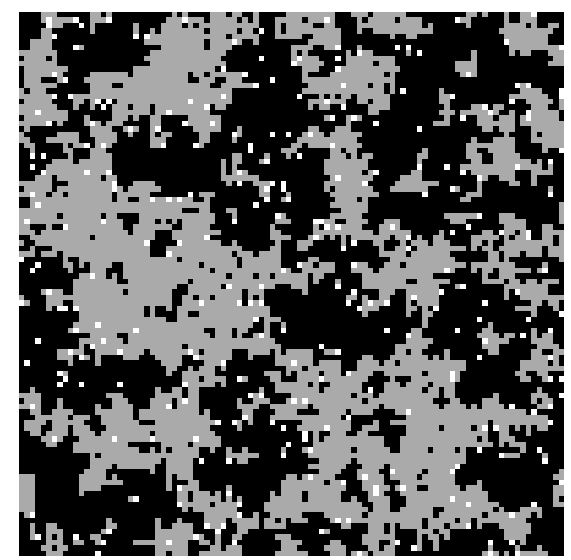

(c)

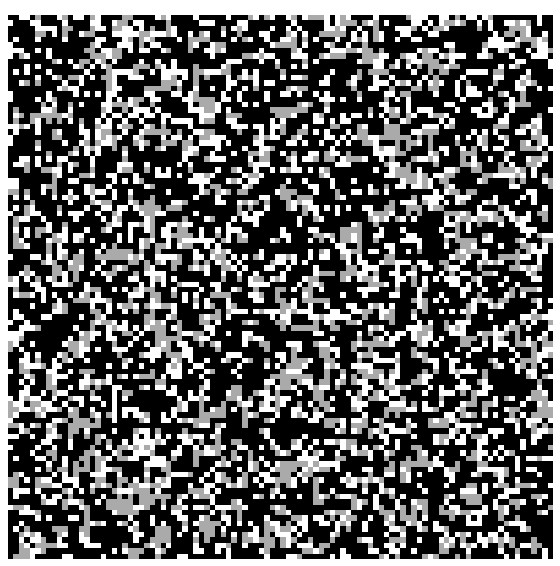

(e)

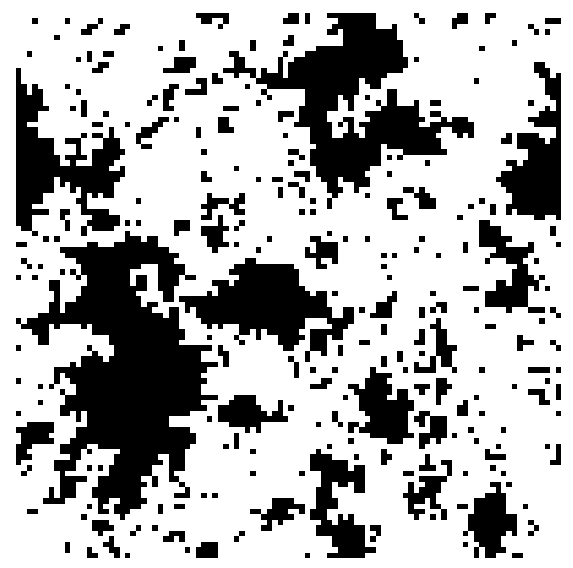

(b)

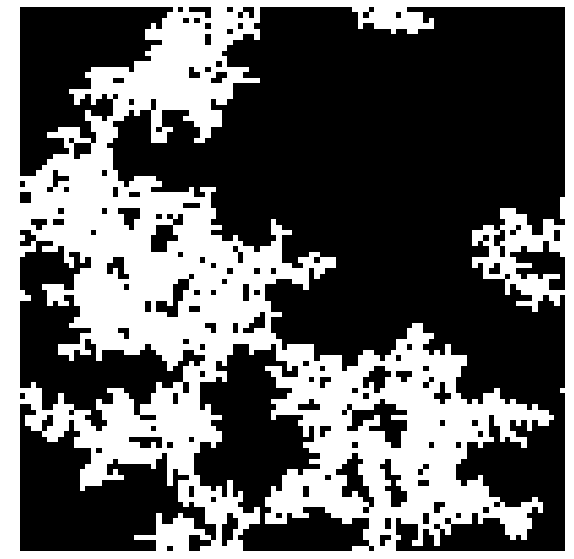

(d)

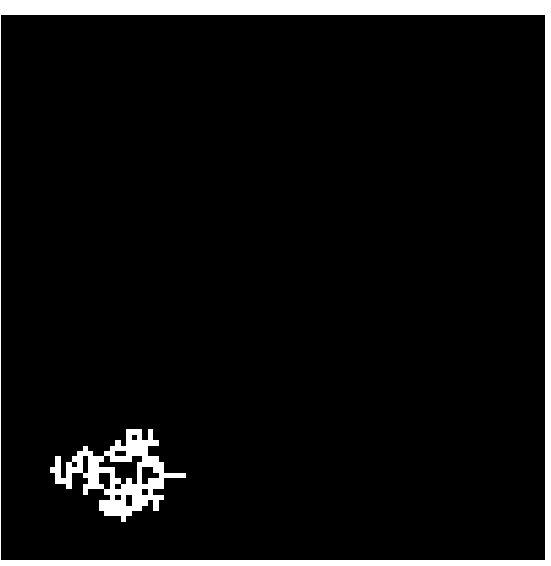

(f)

Figura 5.4: Configurações no estado estacionário para $F=5$ e $Q=21$ (com $L=100$ ) ilustrando o "efeito barreira". As configurações da coluna da esquerda são representadas por agentes persistentes (em branco), agentes aderentes (em cinza) e os demais agentes (em preto). Na coluna da direta, as configurações são representadas por agentes persistentes e aderentes que pertencem ao cluster dominante (em branco) e os demais agentes (em preto). A primeira, a segunda e a terceira linha correspondem aos valores $p=0.02,0.03$ e 0.24 , respectivamente. 


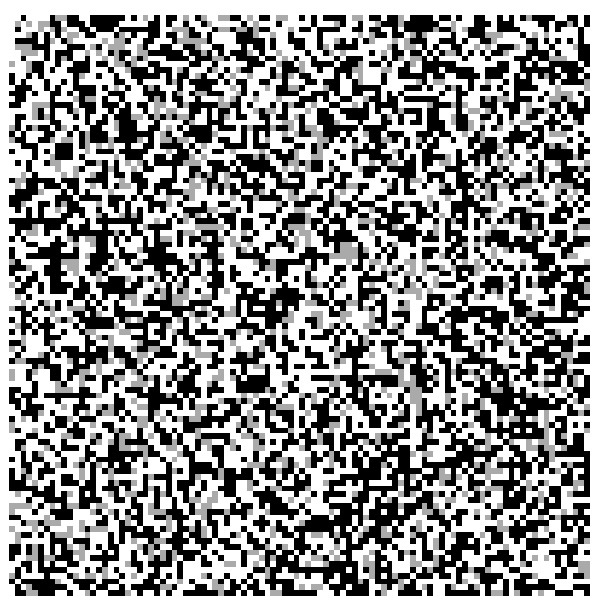

(a)

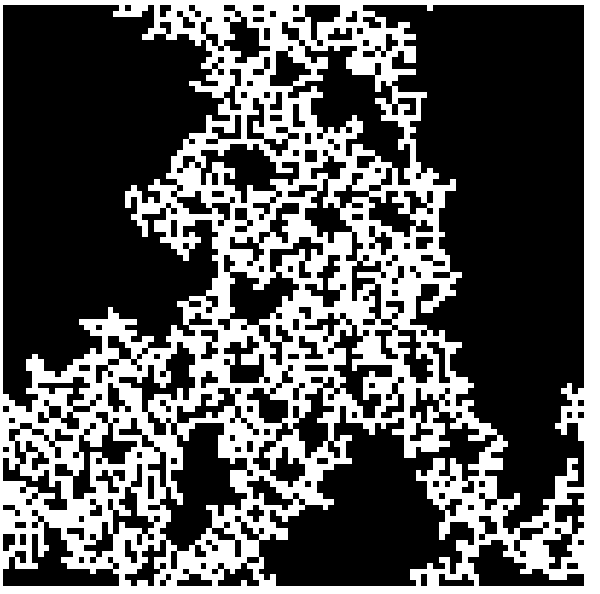

(b)

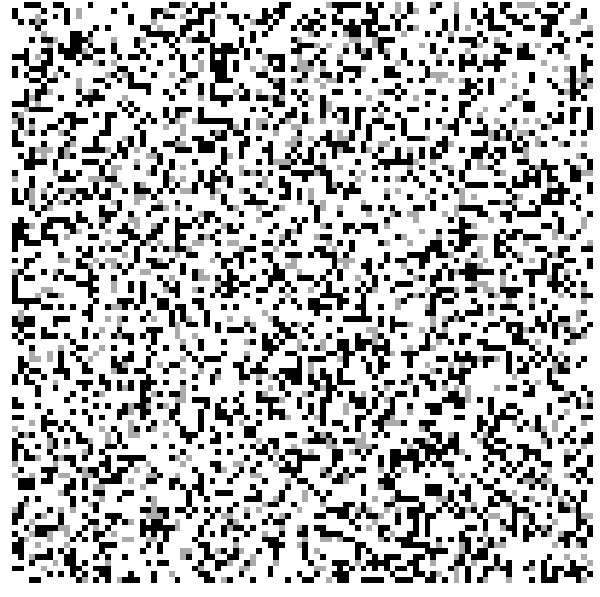

(c)

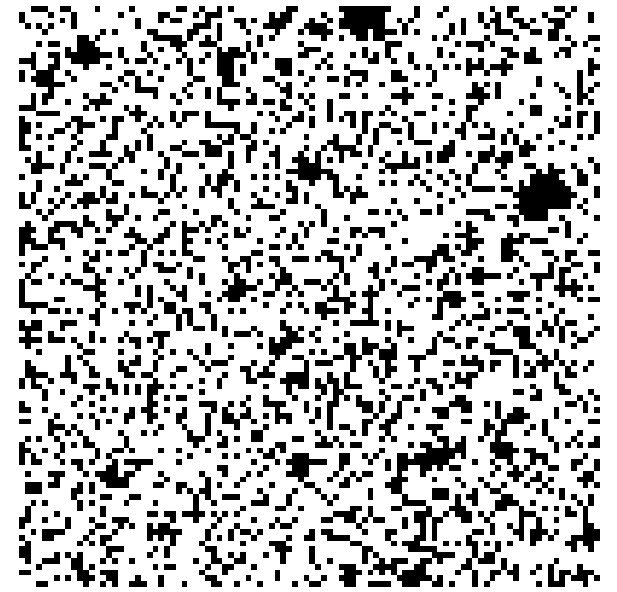

(d)

Figura 5.5: Configurações no estado estacionário para $F=5$ e $Q=21$ (com $L=100$ ) ilustrando o "efeito de ligação". As configurações da coluna da esquerda são representadas por agentes persistentes (em branco), agentes aderentes (em cinza) e os demais agentes (em preto). Na coluna da direta, as configurações são representadas por agentes persistentes e aderentes que pertencem ao cluster dominante (em branco) e os demais agentes (em preto). A primeira e a segunda linha correspondem aos valores $p=0.44$ and 0.64 , respectivamente. 
(regime monocultural) na primeira e na segunda linha, respectivamente. Para tais valores altos de $p$, os agentes aderentes (em cinza) são encontrados em menores concentrações e tendem a desempenhar um novo papel ao conectar os domínios de agentes persistentes e aderentes. Esse é um efeito de ligação que se opõe ao efeito barreira agregando agentes ao cluster dominante. Dessa forma, o cluster dominante tende a se expandir de um cluster percolante (figura 5.5(b)) para um maior ainda (figura $5.5(\mathrm{~d})$ ).

O papel da aderência da rede depende da concentração de agentes persistentes: o efeito barreira é suplantado pelo efeito de ligação conforme $p$ aumenta. O diagrama de fases é o resultado da persistência e da competição entre ambos os efeitos. A aderência da rede $\tilde{A}$ (triângulos) e a aderência do cluster dominante $\tilde{A}_{D}$ (círculos) em função de $p$ (para $M=100$ simulações com $F=5, Q=21$ e $L=100$ ) são exibidas na figura 5.6. Esse gráfico também apresenta o comportamento do tamanho médio do cluster dominante $\langle S\rangle$ em função de $p$. Para pequenos valores não-nulos de $p$ $(0<p<0.03)$ o sistema se encontra na fase monocultural $(\langle S\rangle \approx 1)$ e apresenta altas aderências. Nesse caso, o cluster dominante é predominantemente composto de agentes aderentes $\left(\left\langle\tilde{A}_{D}\right\rangle \approx 1\right)$. Conforme $p$ aumenta, o sistema entra na fase multicultural (em $p \approx 0.03$ ) e então retorna para a fase monocultural (em $p \approx 0.44$ ). Observamos que $\langle\tilde{A}\rangle$ e $\left\langle\tilde{A}_{D}\right\rangle$ sempre decaem. Para $p \geq 0.1,\langle\tilde{A}\rangle$ decai linearmente $(\langle\tilde{A}\rangle \approx 0.24(1-p))$. Quando o sistema entra na fase multicultural, $\langle S\rangle$ decai devido ao efeito barreira. Então, conforme $p$ continua aumentando, $\langle S\rangle$ se eleva devido ao efeito de ligação e o sistema retorna ao regime monocultural.

Para uma concentração constante $p$ (na região dominada pelo efeito de ligação), observamos que as aderências da rede e do cluster dominante decaem em função de $Q$ na forma de leis de potência:

$$
\begin{aligned}
\langle\tilde{A}\rangle & \propto Q^{-1.02}, \\
\left\langle\tilde{A}_{D}\right\rangle & \propto Q^{-0.98} .
\end{aligned}
$$

O gráfico log-log na figura 5.6(b) ilustra tal comportamento para $p=0.44$. Deveras, o aumento do valor de $Q$ torna mais improvável a troca de estados culturais provocando a diminuição das aderências e isolando domínios com o mesmo vetor cultural dos agentes persistentes. 


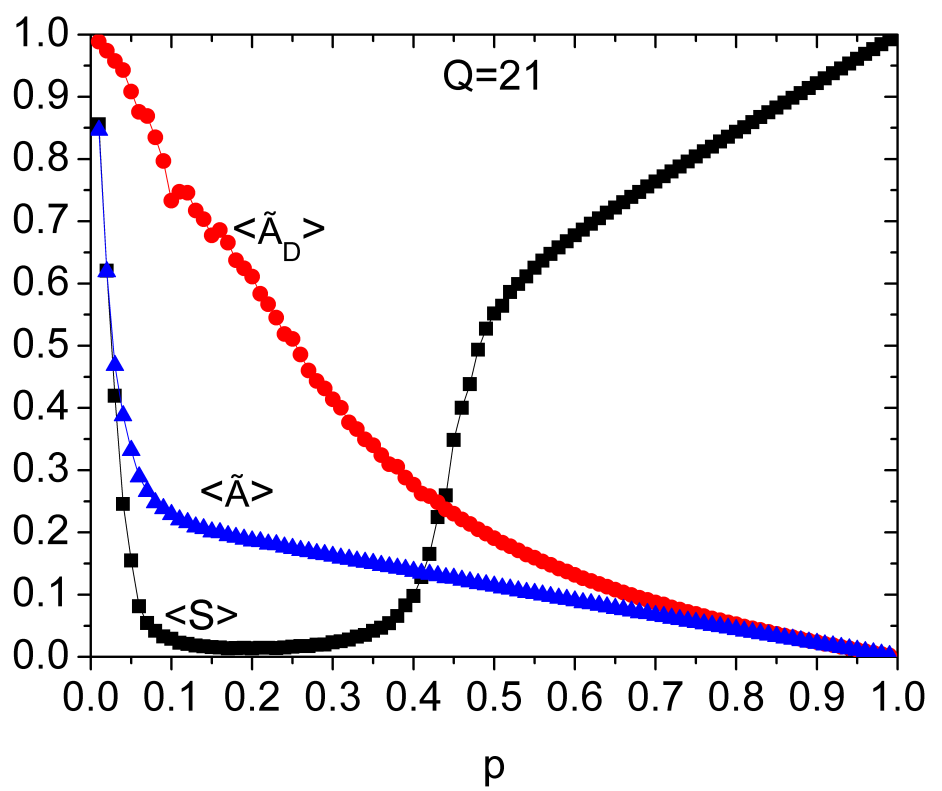

(a)

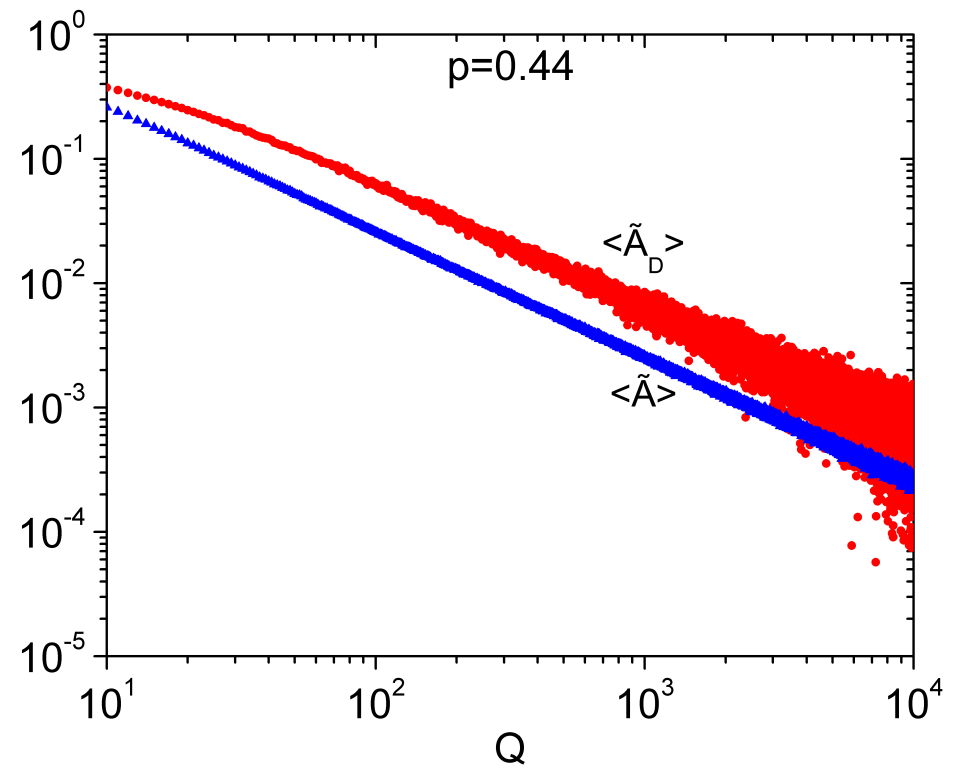

(b)

Figura 5.6: Em (a), $\langle\tilde{A}\rangle$ (triângulos), $\left\langle\tilde{A}_{D}\right\rangle$ (círculos) e $\langle S\rangle$ (quadrados) em função de $p$ para $Q=21$. Em (b), gráfico log-log de $\langle\tilde{A}\rangle$ (triângulos) e $\left\langle\tilde{A}_{D}\right\rangle$ (círculos) em função de $Q$ para $p=0.44$. Ambos os gráficos resultam de $M=100$ simulações com $F=5$ e $L=100$. 
O decaimento das aderências com o número de estados (para $Q$ grande) pode ser estimado analiticamente. Para isso, admitimos que a concentração de agentes aderentes $(\langle A\rangle)$ é proporcional à concentração $(p)$ de agentes persistentes e à probabilidade $\left(P_{k \geq 1}\right)$ de um par agente-vizinho compartilhar pelo menos um elemento cultural em comum (equação (4.5)), de modo que

$$
\langle\tilde{A}\rangle \propto p P_{k \geq 1} .
$$

Lembrando que $P_{k \geq 1}=1-P_{0}$, onde $P_{0}$ é a probabilidade de não interação entre um par agente-vizinho (equação (4.6)), podemos escrever a equação (5.4) como

$$
\langle\tilde{A}\rangle \propto p\left[1-P_{0}\right]=p\left[1-\left(1-\frac{1}{Q}\right)^{F}\right] .
$$

Expandindo $P_{0}=\left(1-\frac{1}{Q}\right)^{F}$ em série de Taylor, temos a expressão

$$
P_{0}=1-F\left(\frac{1}{Q}\right)+\frac{F(F-1)}{2 !}\left(\frac{1}{Q}\right)^{2}-\frac{F(F-1)(F-2)}{3 !}\left(\frac{1}{Q}\right)^{3}+\ldots
$$

Para valores altos de $Q$, a aproximação é dominada pelo termo de menor ordem:

$$
P_{0} \approx 1-F\left(\frac{1}{Q}\right)
$$

Substituindo esse resultado na equação (5.5), obtemos

$$
\langle\tilde{A}\rangle \propto p\left[1-P_{0}\right]=p\left[1-\left(1-F\left(\frac{1}{Q}\right)\right)\right]
$$

Assim:

$$
\langle\tilde{A}\rangle \propto\left(\frac{1}{Q}\right)
$$

que corresponde aos decaimentos observados na figura 5.6(b) (equações (5.2) e (5.3)). Nesta estimativa, assumimos que agentes se tornam aderentes ao interagir com agentes persistentes. Na rede, um agente pode se tornar aderente ao interagir com um agente persistente ou com um agente já aderente. Consequentemente, a aproximação apresentada na equação (5.9) é válida quando $\langle\tilde{A}\rangle \ll p$, pois nesse limite a influência 
dos próprios agentes aderentes nos demais agentes da rede é pequena. Deveras, as medidas das aderências $\left(\langle\tilde{A}\rangle\right.$ e $\left.\left\langle\tilde{A}_{D}\right\rangle\right)$ para $p=0.04, p=0.24$ e $p=0.64$ mostradas na figura 5.7 corroboram a validade da equação (5.9) e seus limites de aplicação. Note que para $p$ baixo ( $p=0.04$, figura 5.7(a)), a presença de agentes aderentes faz com que $\langle\tilde{A}\rangle$ se desvie do comportamento descrito por esta equação. No entanto, a curva da aderência da rede $(\langle\tilde{A}\rangle)$ começa a decair com $1 / Q$ quando $\langle\tilde{A}\rangle$ é muito baixo e $Q$ é alto. O aumento de $p$ (figuras $5.7(\mathrm{~b})$ e $5.7(\mathrm{c})$ ) faz com que a condição $\langle\tilde{A}\rangle \ll p$ seja atendida com mais facilidade. Logo, a manifestação do decaimento linear no gráfico log-log se torna mais evidente.

Em geral, modelos usados em física estatística podem apresentar comportamentos específicos na linha crítica. Para o presente modelo, as aderências da rede e do maior cluster decaem linearmente com concentração $p$ conforme $p$ varia sobre a linha crítica $Q_{c}(p)$. A figura 5.8(a) apresenta $\langle\tilde{A}\rangle$ (triângulos) e $\left\langle\tilde{A}_{D}\right\rangle$ (círculos) em função de $p$ (variando sobre a linha crítica) para $F=5, M=100$ e $L=100$. Os ajustes lineares das aderências resultam em

$$
\begin{array}{rr}
\tilde{A} \sim-0.86 p, \quad(0.05 \leq p<0.6) \\
\tilde{A}_{D} \sim-1.75 p, \quad(0<p<0.6)
\end{array}
$$

Curiosamente, observamos que o tamanho médio do cluster dominante (percolante) é aproximadamente constante, com

$$
\langle S\rangle=0.31 \pm 0.06
$$

sobre o caminho crítico.

A figura 5.8(b) apresenta o gráfico log-log de $\langle\tilde{A}\rangle$ (triângulo) e $\left\langle\tilde{A}_{D}\right\rangle$ (círculo) em função de valores de $Q$ sobre o caminho crítico (na região dominada pelo efeito de ligação). Os ajustes lineares das curvas em $\log$-log (para $Q \geq 18$ ) resulta nas curvas em forma de lei de potência

$$
\begin{aligned}
\langle\tilde{A}\rangle & \propto Q^{-1.21} \\
\left\langle\tilde{A}_{D}\right\rangle & \propto Q^{-1.27}
\end{aligned}
$$




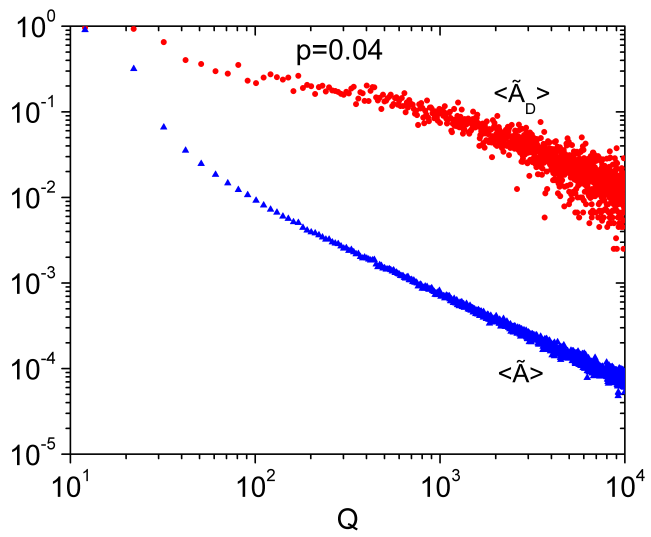

(a)

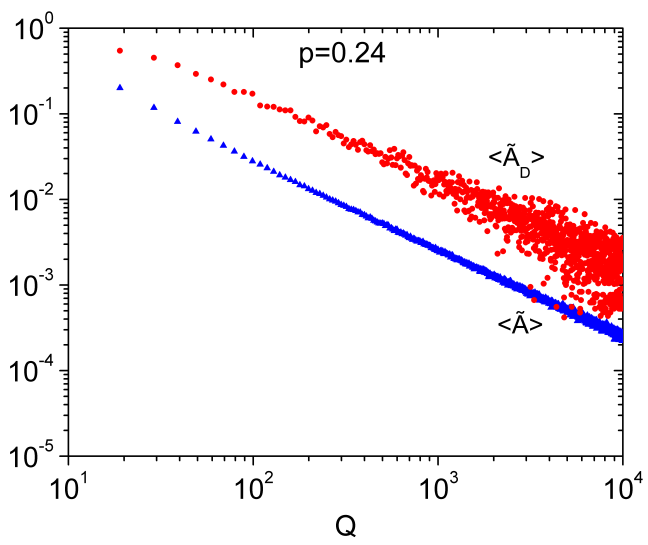

(b)

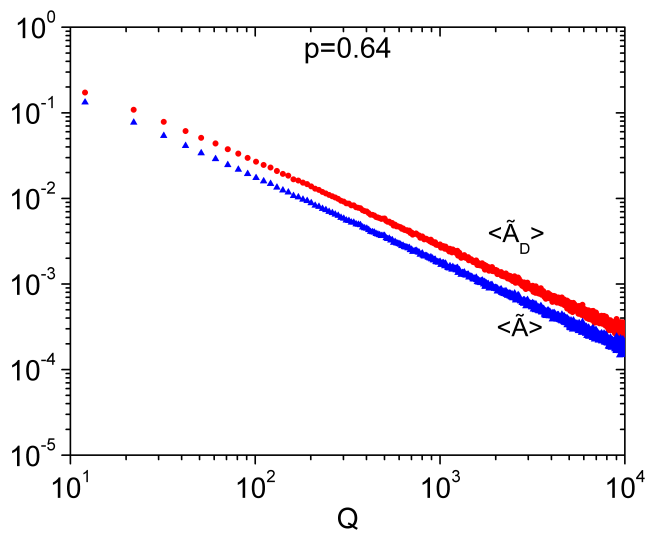

(c)

Figura 5.7: Gráfico log-log de $\langle\tilde{A}\rangle$ (triângulos) e $\left\langle\tilde{A}_{D}\right\rangle$ (círculos) versus $Q$ para um fixo $p=0.04 \mathrm{em}$ (a), $p=0.24 \mathrm{em}$ (b) e $p=0.64 \mathrm{em}$ (c). Os gráficos resultam de $M=100$ simulações com $F=5, Q=21$ e $L=100$. 


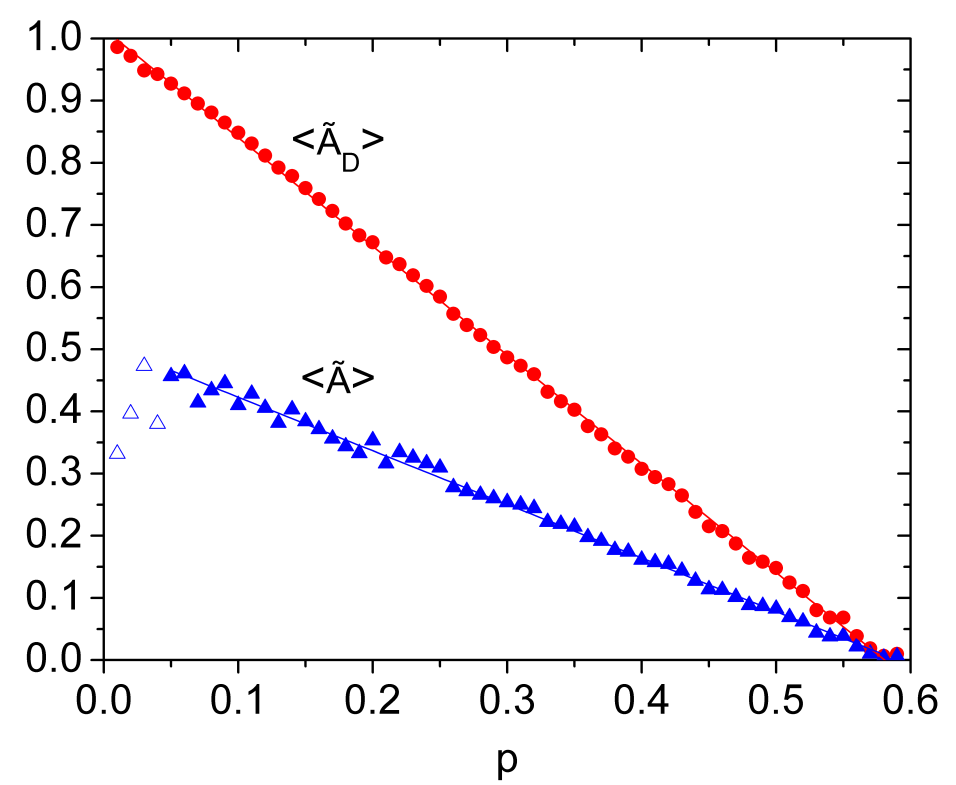

(a)

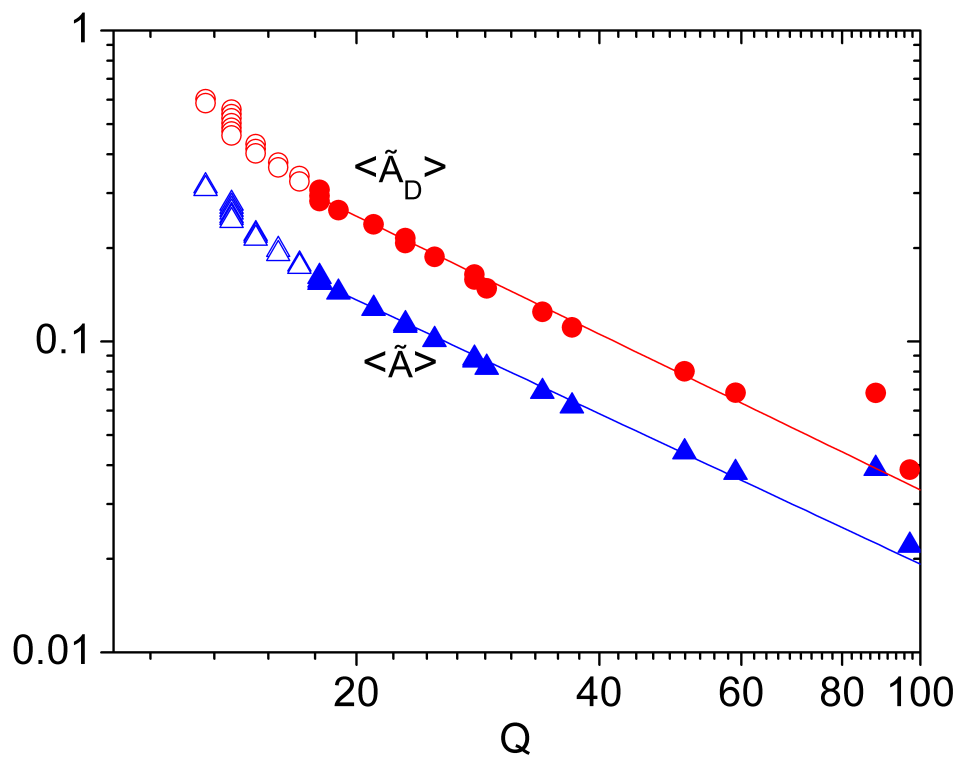

(b)

Figura 5.8: Em (a), $\langle\tilde{A}\rangle$ (triângulos) e $\left\langle\tilde{A}_{D}\right\rangle$ (círculos) versus $p$ sobre a linha crítica. Em (b), gráfico log-log de $\langle\tilde{A}\rangle$ (triângulos) e $\left\langle\tilde{A}_{D}\right\rangle$ (círculos) versus $Q$ sobre a linha crítica. Resultados obtidos de $M=100$ simulações com $F=5, M=100$ e $L=100$. 
Observe que as aderências médias em função de $Q$ obedecem leis de potência quando a concentração $p$ é fixa ou mesmo se $p$ varia sobre o caminho crítico (compare as figuras 5.6(b) e 5.8(b)). Esse resultado revela uma invariância de escala das médias das aderências em função do número de estados culturais quando o efeito de ligação suplanta o efeito barreira.

Para mostrar que os comportamentos descritos para $F=5$ são invariantes com $F$, apresentamos na figura 5.9 os diagramas de fases para $F=3,5,7$ (em redes $L=100$ e $M=100$ ). Como esperado (ver Capítulo 4), os pontos de transição $Q_{c}(p)$ aumentam com o aumento de $F$. Observamos também a queda e a elevação de $Q_{c}(p)$ (característicos dos efeitos barreira e de ligação) conforme se introduz agentes persistentes na rede. Logo, podemos inferir que as discussões realizadas para $F=5$ podem ser aplicadas em sistemas que consideram qualquer outro valor de $F$ tal que $F \geq 3$.

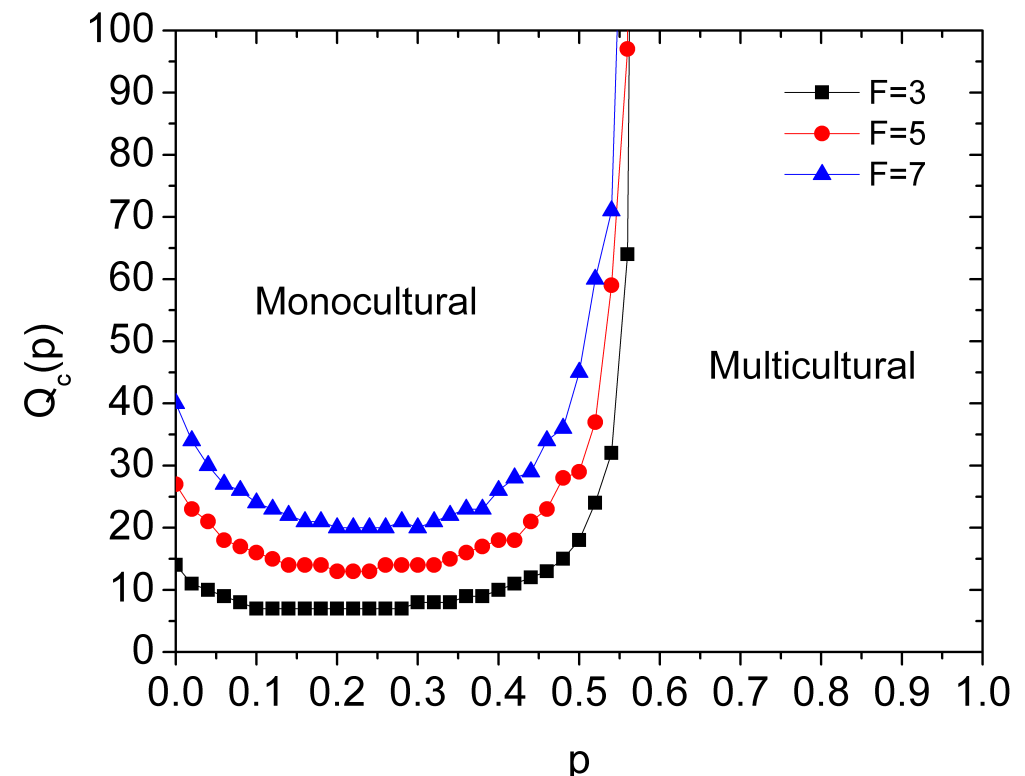

Figura 5.9: Diagrama de fases no plano $(p, Q)$ para $F=3,5,7(L=100$ e $M=100)$.

\subsection{Conclusão}

Neste capítulo estudamos o modelo de Axelrod sob influência de perturbações internas. Para esse propósito, agentes persistentes (caracterizados pelo mesmo vetor 
cultural $\psi_{P}$ ) foram introduzidos aleatoriamente em sítios da rede com probabilidade $p$. Sabe-se que, na ausência de agentes persistentes $(p=0)$, o sistema apresenta uma transição de um regime monocultural para um regime multicultural em um valor crítico $Q$ (número de estados). Os agentes persistentes interferem em interações culturais entre agentes não-persistentes porque eles não absorvem nenhum estado dos agentes vizinhos. Essa interferência pode ser reconhecida como uma restrição geográfica no contexto discutido por Parisi et al. [70]. Nessa perspectiva, a fragmentação de domínios encontradas para valores não nulos de $p$ se assemelha aos resultados do modelo de Parisi com obstáculos físicos. Além disso, os agentes persistentes também desempenham um papel similar à introdução de paredes ativas em modelos de percolação direcionadas [24].

A persistência revela uma dependência do valor crítico de $Q$ com a concentração $p$. Essa dependência nos permite obter o diagrama de fases no plano $(p, Q)$ para $F=5$. A linha crítica $Q_{c}(p)$ é explicada por duas forças opostas (denominadas efeito barreira e efeito de ligação) causadas por agentes aderentes (definidos como sendo agentes não-persistentes que apresentam o vetor cultural $\psi_{P}$ no estado final). Como discutido no texto, o efeito barreira tende a fragmentar os domínios encontrados na rede e a diminuir o tamanho do cluster dominante favorecendo, portanto, o regime multicultural. Notamos que tal fragmentação é similar à fragmentação também encontrada em estudos do modelo de Axelrod sob efeito de campos externo, local e global. Deveras, sabe-se que tais campos aumentam a diversidade de culturas no estado estacionário $[43,53,54,63,67,68,75]$. Por outro lado, a aderência pode desempenhar um papel diferente ao conectar pequenos domínios (efeito de ligação) para criar um cluster dominante. Logo, a competição entre o efeito barreira e o efeito de ligação conduzem a dinâmica para uma configuração final particular.

Os agentes persistentes podem ser considerados como mídia interna local difundindo uma ideia pela rede. Em um contexto mais amplo, nossos resultados sugerem que uma sociedade pode ter a tendência de atingir um consenso orientado (para o vetor cultural $\psi_{P}$ ) se agentes persistentes estiverem presentes. Na ausência de agentes persistentes, a sociedade pode evoluir para um regime monocultural qualquer. Como exemplo, os agentes persistentes podem desempenhar o papel de cabos eleitorais espalhando suas opiniões (ou orientações partidárias) em uma sociedade. 
Nesse sentido, nossos resultados sugerem que os cabos eleitorais podem não ser capazes de espalhar suas opiniões através de toda a rede mas, ao invés disso, podem induzir a formação de grupos de pessoas compartilhando a mesma visão política e até apoiando o mesmo partido. 


\section{Capítulo}

\section{Perspectivas e conclusões gerais}

"The important thing is to not stop questioning. Curiosity has its own reason for existence. One cannot help but be in awe when he contemplates the mysteries of eternity, of life, of the marvelous structure of reality. It is enough if one tries merely to comprehend a little of this mystery each day."

- Albert Einstein

\subsection{Perspectivas}

Nesta seção discorremos sobre algumas perspectivas de trabalhos futuros envolvendo o modelo de Axelrod e os estudos expostos nos capítulos anteriores desta tese. Cada subseção contém a descrição de uma proposta específica com o problema de interesse e a metodologia que deve ser adotada inicialmente para abordá-lo. Todos os resultados apresentados aqui são preliminares e têm como finalidade a ilustração e o direcionamento das atividades que se pretende desenvolver.

\subsubsection{Percolação}

Notamos no Capítulo 5 que para certos valores da probabilidade de ocupação $p$ de agentes persistentes há a formação de um aglomerado dominante que conecta a rede de um lado a outro. Esse resultado sugere que há um valor $p_{c}$ no qual o domínio formado por agentes persistentes e aderentes percola a rede. 
O problema original da percolação surgiu em 1957 com a pergunta feita por Broadbent e Hammersley [78]: "suponha que uma grande rocha porosa é submersa na água por um longo tempo, a aguá alcançará o centro da rocha ${ }^{1}$ "? De acordo com Grimmet [79], dois exemplos da aplicação da teoria de percolação seriam o problema de como distribuir as árvores na formação de uma floresta para minimizar os danos causados por um incêndio e o problema de quão infecciosa deve ser uma doença para virar uma epidemia.

Para o estudo da percolação ${ }^{2}$, considere uma rede regular bidimensional. Cada sítio dessa rede pode apresentar um de dois estados: ocupado ou vazio. Inicialmente todos os agentes da rede encontram-se no estado vazio. Então, cada sítio é ocupado com probabilidade $\tilde{p}$. O interesse do estudo da percolação está na formação dos domínios encontrados na rede em função da probabilidade de ocupação $(\tilde{p})$.

A figura 6.1 apresenta exemplos de percolação na rede $L=100$. Um sítio da rede é representado pela cor branca se estiver vazio, pela cor preta se estiver ocupado ou pela cor cinza se estiver ocupado e pertencer ao maior cluster de sítios ocupados. Observe que para baixos valores de $\tilde{p}(\tilde{p}=0.2)$, a maioria dos sítios ocupados estão isolados. O aumento de $\tilde{p}(\tilde{p}=0.4)$ faz com que os sítios ocupados passem a se aglomerar. Quando $\tilde{p}=0.6$, encontramos um cluster que se espalha através da rede (percola). Se elevamos ainda mais o valor de $\tilde{p}(\tilde{p}=0.8)$, quase todos os sítios ocupados estarão conectados. Grosso modo, esses resultados sugerem que, no limite termodinâmico, há um ponto crítico $\tilde{p}_{c}$ acima do qual existe um cluster infinito (que percola através da rede) e abaixo do qual não existe um cluster infinito. O ponto crítico $\tilde{p}_{c}$ indicaria, portanto, uma transição de fase no modelo de percolação.

Essa transição pode ser visualizada com a introdução da probabilidade $\tilde{P}$ como parâmetro de ordem, em que $\tilde{P}$ é a probabilidade de um sítio pertencer ao cluster infinito. A figura 6.2 mostra o comportamento de $\tilde{P}$ em função de $\tilde{p}$ para uma rede com $L=100$. De acordo com Neves em [80], a probabilidade crítica $\tilde{p}_{c}$ é definida como o maior valor de $\tilde{p}$ para o qual $\tilde{P}=0$ (na figura $6.2, \tilde{p}_{c}=0.55$ ).

No contexto do modelo de Axelrod, queremos determinar a probabilidade de ocu-

\footnotetext{
${ }^{1}$ Do original: Suppose a large porous rock is submerged under water for a long time, will the water reach the center of the stone?

${ }^{2}$ Há dois tipos de percolação: bond percolation e site percolation. Para nossos fins, consideramos a percolação por sítio (site percolation).
} 


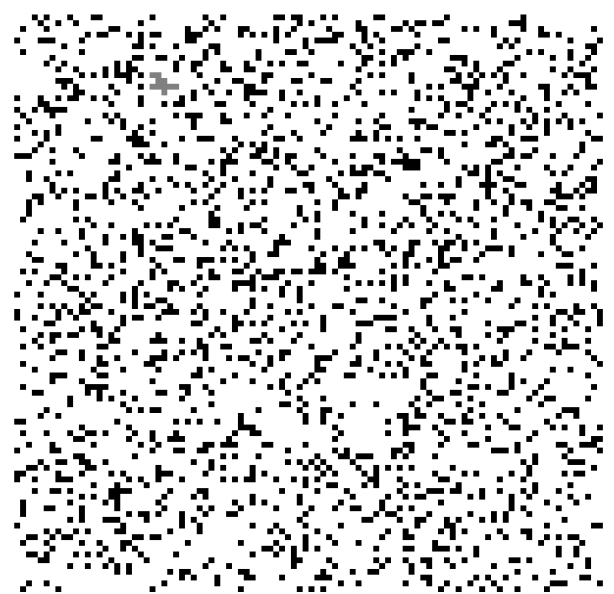

(a)

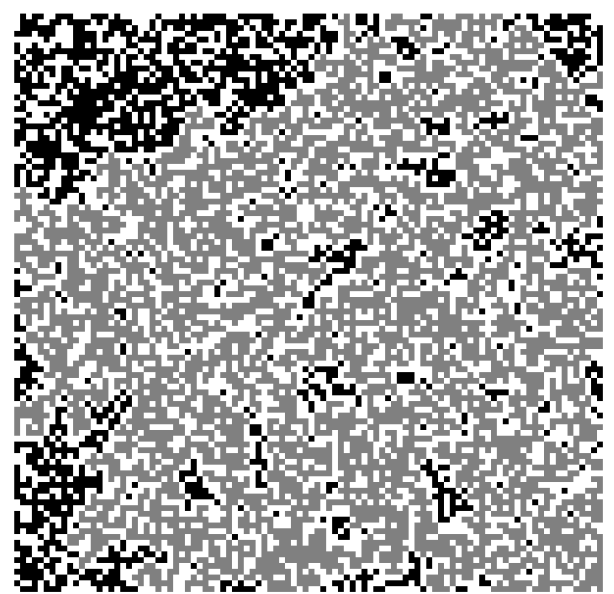

(c)

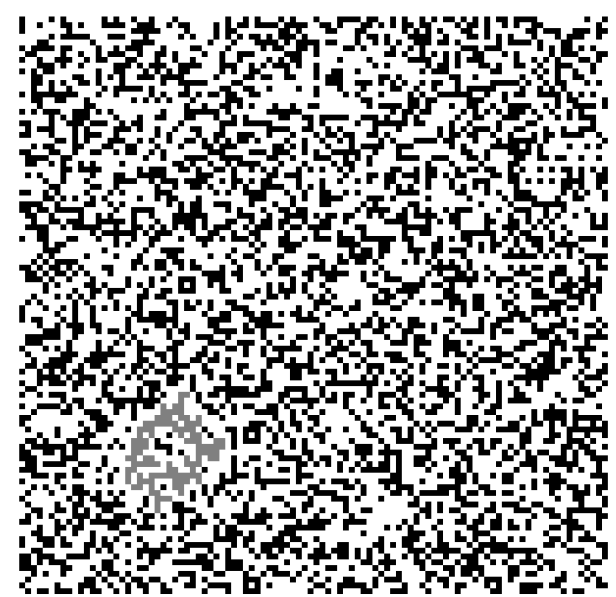

(b)

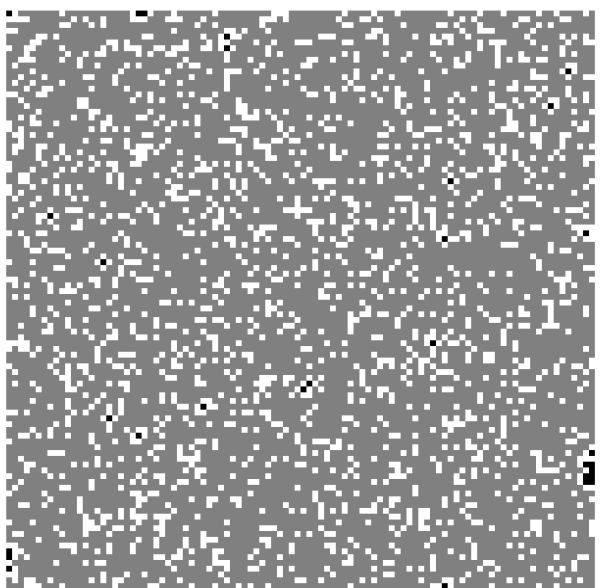

(d)

Figura 6.1: Figuras da rede quadrada de lado $L=100$ no modelo de percolação por sítio. Um sítio ocupado é representado pela cor preta, e um sítio vazio é representado pela cor branca. A cor cinza representa o maior aglomerado formado por sítios ocupados. As probabilidades de ocupação $\tilde{p}$ são: $\tilde{p}=0.2$ (a), $\tilde{p}=0.4$ (b), $\tilde{p}=0.6$ (c) e $\tilde{p}=0.8(\mathrm{~d})$. 


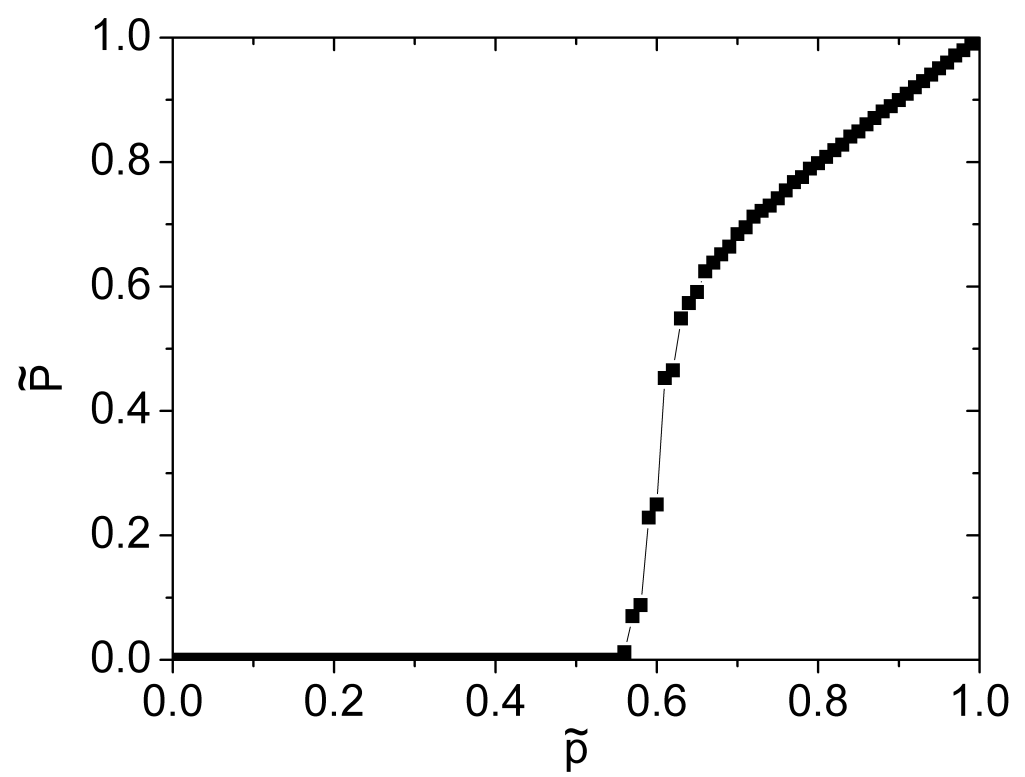

Figura 6.2: Probabilidade $\tilde{P}$ de um sítio pertencer ao cluster infinito em função da probabilidade de ocupação $\tilde{p}$ para uma rede quadrada com $L=100$ no modelo de percolação por sítio.

pação crítica $p_{c}$ de agentes persistentes (com vetor cultural fixo $\psi_{P}$ ) para que um aglomerado percolante formado por agentes persistentes e aderentes com a mesma cultura $\psi_{P}$ seja encontrado na rede. Também desejamos relacionar a probabilidade de ocupação crítica a posteriori $p^{\prime}$ (tal que $p^{\prime}=p+p_{a}$, onde $p_{a}$ é a fração de agentes aderentes encontrados na rede) com a probabilidade $\tilde{p}_{c}$. Considere, por exemplo, $F=5$. Nessa situação, o sistema pode apresentar uma configuração final monocultural (se $Q<Q_{c}$ ) ou multicultural (se $Q>Q_{c}$ ). Definindo a probabilidade de percolação $P(p)$ como sendo a probabilidade de se encontrar um agente (persistente ou aderente) pertencente ao cluster percolante, temos na figura 6.3 as curvas de $P(p)$ em função de $Q$ para $Q<Q_{c}$ (regime monocultural).

A figura 6.3 apresenta $P(p)$ em função de $p$ para $Q=5 \mathrm{em}$ (a), $Q=10 \mathrm{em}$ (b), $Q=15$ em (c) e $Q=20 \mathrm{em}$ (d) em uma rede de lado $L=100$ com condição de contorno aberta. Cada ponto corresponde a médias sobre $M=100$ simulações independentes. Os agentes persistentes são introduzidos com probabilidade $p$ no início da dinâmica e as medidas são realizadas na configuração final.

Observamos na figura 6.3(a) que $P(p) \approx 1$ quando $p \approx 0$. Isso acontece porque a 
rede apresenta um único aglomerado de sítios compartilhando o mesmo vetor cultural. Como já mencionamos no Capítulo 5, o aumento de $p$ causa uma fragmentação na rede (efeito barreira), resultando na diminuição do tamanho do maior cluster e na diminuição de $P(p)$. As quedas de $P(p)$ se tornam mais pronunciadas quando aumentamos o valor de $Q$ (figuras 6.3(b), 6.3(c) e 6.3(d)), sugerindo que o efeito barreira se torna mais influente quando $Q$ aumenta. Vemos, na figura 6.3(d), que a introdução de persistentes evita a formação de um cluster percolante para uma grande faixa de valores de $p$. Nesse caso, apenas para $p>0.8$ observamos evidências de um cluster percolante na rede.

A figura 6.4 apresenta curvas de $P(p)$ em função de $p$ para $F=5$ e vários valores de $Q(Q=30,40,50,100)$ em uma rede $L=100$ e $M=100$ quando $Q>Q_{c}$. Para os valores de $Q$ considerados, a configuração é multicultural para $p=0$ (ou seja, a rede apresenta vários domínios culturais pequenos). Quando $p$ aumenta, domínios compostos por agentes persistentes e aderentes são formados até que em $p=p_{c}$ seja encontrado um cluster percolante. Considerando a definição de $p_{c}$ como o maior valor de $p$ para o qual $P(p)=0$, temos $p_{c}=0.445$ para $Q=30, p_{c}=0.471$ para $Q=40, p_{c}=0.489$ para $Q=50$ e $p_{c}=0.522$ para $Q=100$.

As curvas de $P(p)$ em função de $p$ na figura 6.4 são diferentes das apresentadas na figura 6.3 (que correspondem ao mesmo modelo $\operatorname{com} Q<Q_{c}$ ) e são semelhantes à curva de transição característica do modelo de percolação (figura 6.2). Os valores $p_{c}$ aumentam com o valor de $Q$. A equação (4.6) nos mostra que, para dado $F$, o aumento de $Q$ aumenta a probabilidade de dois agentes vizinhos não compartilharem nenhuma característica em comum

$$
P_{0}=\left(1-\frac{1}{Q}\right)^{F}
$$

Em analogia com o modelo de percolação (em que não há interação entre os sítios vizinhos), a observação de $P_{0}$ nos permite afirmar que o valor $p_{c}$ (ocupação crítica de persistentes no modelo de Axelrod) converge para o mesmo valor $\tilde{p}_{c}$ do modelo de percolação $\left(\tilde{p}_{c}=0.55\right.$ para $L=100$ ) quando $Q \rightarrow \infty$ (pois $P_{0} \rightarrow 1$ ). A figura 6.5 mostra os valores de $p_{c}$ em função de $Q$ no eixo a esquerda e os valores de $P_{0}$ em função de $Q$ no eixo à direita. Os valores de $p_{c}$ (indicados pelos pontos 


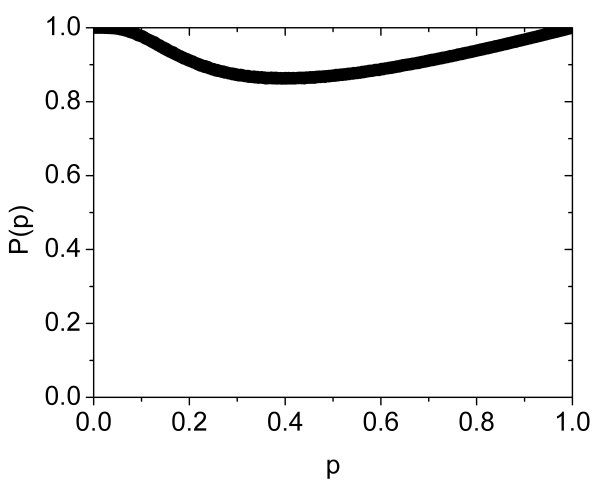

(a)

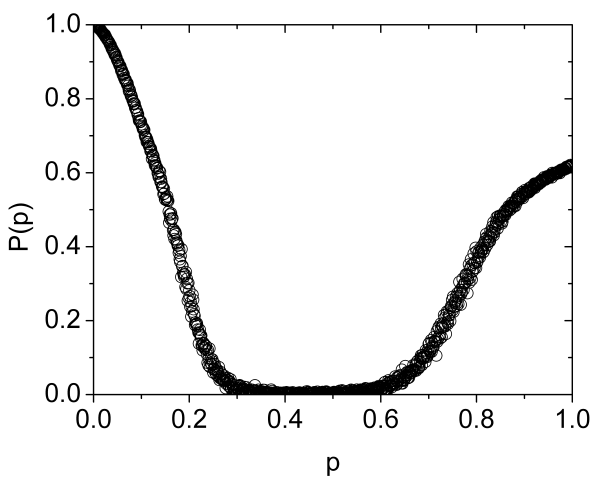

(c)

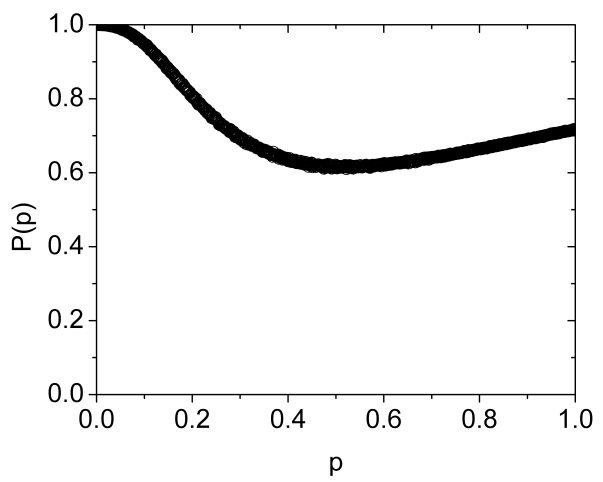

(b)

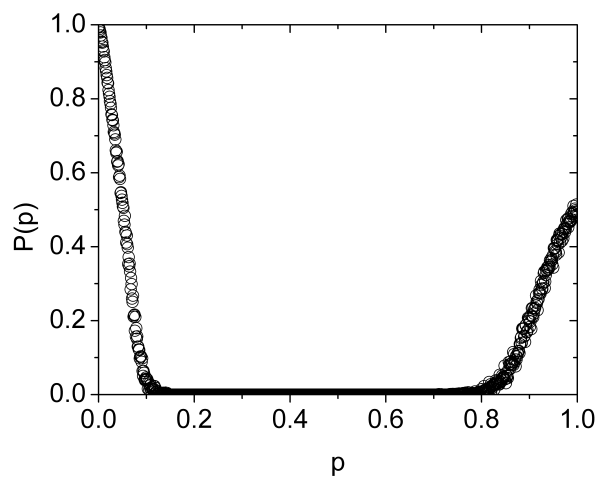

(d)

Figura 6.3: Relação entre $P(p)$ e $p$ para o modelo de Axelrod com $F=5$ (em uma rede $L=100$ e $M=100$ simulações). Os valores de $Q<Q_{c}$ (regime monocultural) são: $Q=5 \mathrm{em} \mathrm{(a),} Q=10 \mathrm{em}(\mathrm{b}), Q=15 \mathrm{em}(\mathrm{c})$ e $Q=20 \mathrm{em}(\mathrm{d})$. 


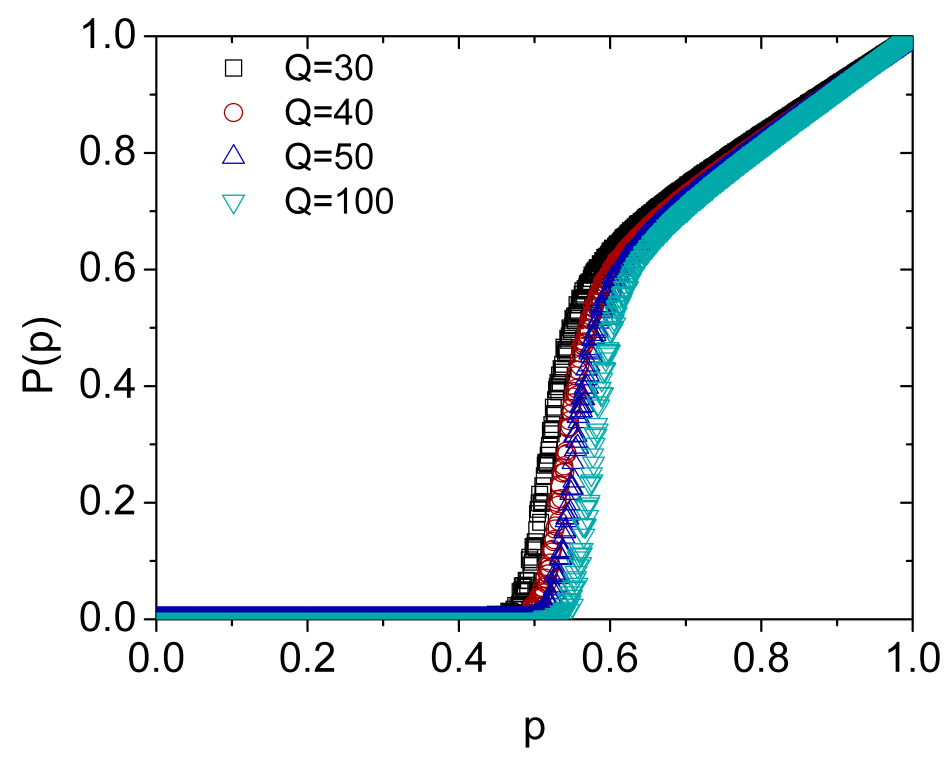

Figura 6.4: Relação entre $P(p)$ e $p$ para o modelo de Axelrod com $F=5$ (em uma rede $L=100$ e $M=100$ simulações). Os valores de $Q>Q_{c}$ (regime multicultural) são: $Q=30$ (quadrado), $Q=40$ (círculo), $Q=50$ (triângulo) e $Q=100$ (triângulo invertido).

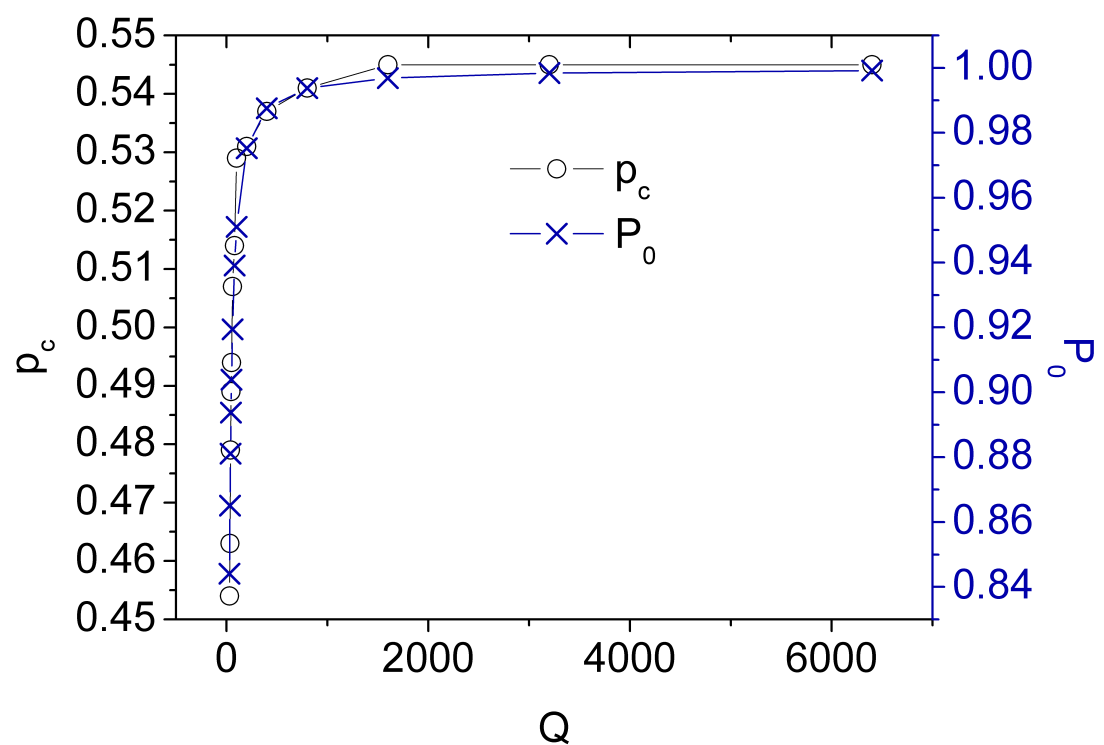

Figura 6.5: Probabilidade de ocupação de agentes persistentes $p_{c}$, representada pelos pontos circulares e com escala no eixo da esquerda, e $P_{0}$, representada pelos pontos $(\times)$ e com escala no eixo da direita, em função de $Q$ para $F=5$. Os resultados de $p_{c}$ foram obtidos em uma rede quadrada com $L=100$ e $M=100$. 
circulares) foram determinados a partir de simulações computacionais ( $L=100 \mathrm{e}$ $M=100)$ para $F=5$ e vários valores de $Q$. Os valores de $P_{0}$ foram obtidos a partir da substituição desses valores de $Q$ na equação acima (equação (4.6)). Note que $p_{c} \rightarrow 0.55$ e que $P_{0} \rightarrow 1$ quando $Q$ aumenta.

Nesse sentido, nosso objetivo é a determinação das probabilidades de ocupação crítica $p_{c}$ e da probabilidade efetiva $p^{\prime}\left(p^{\prime}=p+p_{a}\right)$ em função dos parâmetros $F$ e $Q$ do modelo de Axelrod.

\subsubsection{Diferenciação de espécies}

A teoria da seleção natural é a mais bem aceita no meio científico para explicar a evolução das espécies. Esta teoria, introduzida por Charles Darwin em 1859 [81], propõe que todas as espécies encontradas na natureza são descendentes de um ancestral comum. O modo como a seleção natural funciona foi elucidado mais tarde com o desenvolvimento da genética.

A genética, por sua vez, apresentou o conceito de DNA [82]. O DNA é o código genético de uma espécie e contém toda a informação necessária (genoma) para a construção de um ser vivo. Uma fita de DNA é agrupada em genes que, nos casos mais simples, desempenham uma função específica como a determinação da altura ou da cor dos olhos de uma pessoa. Os genes, então, são agrupados de forma ordenada em cromossomos dentro do núcleo celular.

A sistemática, ramo da biologia que estuda a classificação dos seres vivos e suas inter-relações, recentemente passou a incluir a análise do genoma como critério de classificação. Além disso, devemos destacar que há relação entre genótipo (código genético hereditário) e fenótipo (características observáveis tais como morfologia, fisiologia e comportamento) de um ser vivo, sendo possível determinar a espécie de um indivíduo analisando-se apenas o seu genoma. Esses novos conhecimentos permitiram identificar evidências da seleção natural apenas estudando-se o genoma de uma espécie (como a humana [83]).

O conhecimento do código genético e de sua importância permitiu elucidar o mecanismo de atuação da seleção natural:

1. Pais transferem código genético para os filhos; 
2. Durante a transferência, eventos como mutação podem alterar parte do código genético transferido;

3. A população de descendentes, então, não será uniforme - mas com diferenças sutis graças às alterações do código genético;

4. Nessa população não uniforme, os mais aptos em um ambiente são selecionados e sua prole recebe seu código genético;

5. Geração após geração, as diferenças nos códigos genéticos vão se acumulando, de modo que ocorra o surgimento de indivíduos especializados na sobrevivência em um ambiente bem específico.

O cenário descrito acima fornece o conjunto ideal de ocorrências para o surgimento de novas espécies. As alterações no código genético são inicialmente sutis, mas, com o tempo e com interações sucessivas, o acúmulo de mutações e diferenças genéticas eventualmente originam seres tão distintos que não podem mais ser considerados da mesma espécie.

Acredita-se que há o surgimento de espécies diferentes quando dois indivíduos de uma mesma população são isolados geograficamente [84]. Esse isolamento impede o intercruzamento de seus descendentes, fortalecendo e propagando as diferenças genéticas que existem entre eles. Consequentemente, o acúmulo sucessivo de diferenças genéticas resultará no surgimento de novas espécies em gerações posteriores.

No entanto, estudos recentes mostram que outros fatores podem influenciar o surgimento de novas espécies. Embora esses outros fatores ainda não estejam completamente determinados, observa-se que eles são responsáveis pela especiação (surgimento de novas espécies) mesmo quando indivíduos de uma mesma espécie não estão isolados geograficamente um do outro [85]. Em [85], os autores argumentam que trocas sucessivas de informação genética de um indivíduo com outros indivíduos diferentes pode culminar em um evento de especiação.

Nesse contexto, a geração de novas espécies pode ser abordada através da proposta de modelos computacionais. Em geral, modelos computacionais já são largamente utilizados em biologia no estudo de dinâmica de populações (e mesmo na simulação da evolução através da seleção natural), propagação de gripe e outras do- 
enças contagiosas, controle de probabilidade tumoral, entre outros. Em particular, utilizaremos o modelo sócio-cultural proposto por Axelrod em 1997 para oferecer insights sobre o processo de evolução e especiação biológicos.

A proposta da utilização do modelo de Axelrod baseia-se em uma analogia entre o vetor cultural $\psi_{i}=\left(\sigma_{i, 1}, \sigma_{i, 2}, \ldots, \sigma_{i, F}\right)$ de um indivíduo e o código genético de uma espécie. Cada elemento $\sigma_{i, k}$ (característica cultural) de $\psi_{i}$ corresponderia a um cromossomo específico ${ }^{3}$. O número $Q$ de estados diferentes permitidos para cada característica corresponderiam aos diferentes tipos de cromossomos encontrados na natureza. Cada sítio $i$ da rede do modelo de Axelrod abrigaria uma determinada subespécie $^{4}$ representada por um código genético $\psi_{i}$. A interação entre um par agente-vizinho seria encarada como mutação e/ou cruzamento interespecífico com troca de cromossomos entre duas subespécies distintas. A troca de material genético pode resultar na geração de novas subespécies. A cada passo da evolução, há propagação e extinção de código genético, e a situação final é caracterizada pela presença de aglomerados que representam as subespécies mais bem sucedidas.

Essa analogia também nos permitirá investigar se há a possibilidade de surgir, de ancestrais diferentes independentes, aglomerados distintos representados pelo mesmo código genético (mesma espécie ${ }^{5}$ ). Realizaremos essa investigação marcando geneticamente uma determinada subespécie e acompanhando como o marcador se espalha para as outras subespécies do meio. Em outras palavras, sorteamos aleatoriamente um sítio qualquer da rede e identificamos o vetor cultural $\left(\psi_{i}\right)$ correspondente à subespécie $(i)$ que ali se encontra. A subespécie $i$ tem então todos os seus cromossomos marcados com o índice 1 e os demais agentes da rede são marcados com o índice 0.

Promovemos a dinâmica inerente ao modelo de Axelrod descrito no Capítulo 2. A interação da subespécie $i$ com uma subespécie $j$ de sua vizinhança propaga a marcação genética 1 para a subespécie interagente $(j)$ ao transferir um cromossomo

\footnotetext{
${ }^{3} \mathrm{Em}$ alguns casos verifica-se que a transmissão de genes é mais frequente que a transmissão de cromossomos. A proposta que apresentamos pode ser adaptada para que $\sigma_{i, k}$ represente os genes envolvidos nessas transmissões.

${ }^{4}$ Aqui, entende-se por subespécie elementos da mesma espécie que possuem pequenas diferenças em seu código genético e que podem interagir/trocar informações genéticas entre si.

${ }^{5}$ Dois aglomerados $A$ e $B$ representados pelos vetores $\psi_{A}$ e $\psi_{B}$ têm mesmo código genético se $\psi_{A}=\psi_{B}$.
} 
marcado geneticamente. Considere agora que a subespécie $j$ interaja com uma outra subespécie vizinha $l$. A interação resulta na propagação de um cromossomo $\sigma_{j, k}$ de $j$ para $l$. A dinâmica do modelo de Axelrod evolui até o estado estacionário.

Após o estabelecimento do estado estacionário, comparamos o domínio que contém a subespécie $(i)$ originalmente marcada $\left(\psi_{i}\right)$ com os demais domínios da rede. A comparação entre os domínios de duas subespécies $i$ e $j$ é realizada com o cálculo do Grau de Separação $\left(G_{s}\right)$ entre o código genético $\left(\psi_{i}\right)$ da subespécie $i$ e o código $\left(\psi_{j}\right)$ da subespécie $j$. O $G_{s}$ é definido pela expressão

$$
G_{s}=F\left(1-P_{i, j}\right)
$$

Se $G_{s}=0$, o vetor de DNA de duas subespécies é o mesmo; se $G_{s}=F$, os vetores DNA de duas subespécies são completamente diferentes.

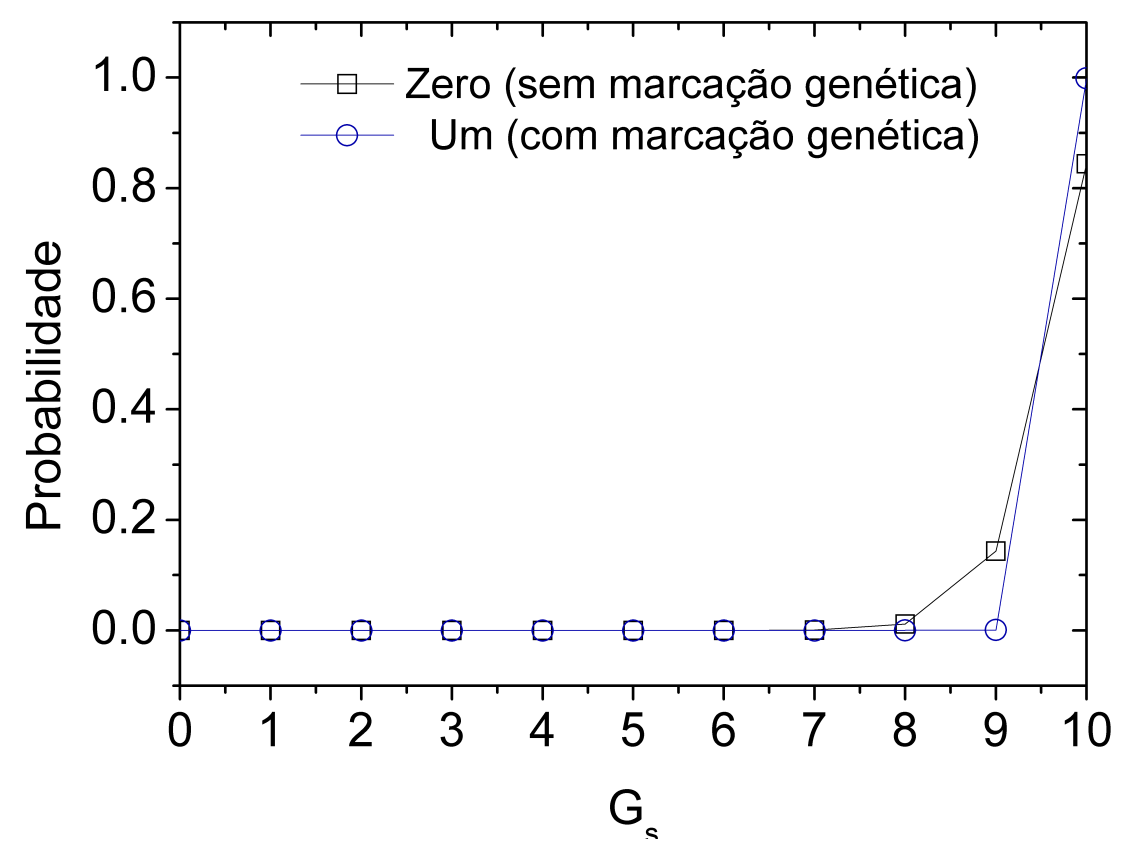

Figura 6.6: Relação entre o grau de separação $\left(G_{s}\right)$ entre duas subespécies e a probabilidade de se encontrar um par com dado $G_{s}$ nas $M=1000$ simulações realizadas. Os dados correspondem à situações sem (Zero) e com (Um) propagação de marcação genética.

Na figura 6.6 apresentamos a probabilidade de se obter um determinado $G_{s}$ da comparação de $i$ com os domínios sem marcação genética (quadrado) e da com- 
paração de $i$ com os domínios marcados geneticamente (círculo). Os dados foram extraídos de $M=1000$ simulações independentes para $F=10, Q=55$ e $L=100$ com condições periódicas de contorno. Observamos que os resultados revelam probabilidade não nula de encontrarmos domínios com marcação genética (pontos circulares) apenas se $G_{s}=10$. Por outro lado, observamos probabilidade não nula de encontrarmos domínios sem marcação genética (pontos quadrados) para $G_{s}=8,9$ e 10. Curiosamente, embora se possa esperar maior similaridade genética (baixo $G_{s}$ ) entre subespécies que trocaram material genético, os resultados indicam que a troca de informação ou faz com que dois indivíduos acabem por pertencer à mesma subespécie (e ao mesmo aglomerado) ou promove uma especiação com o surgimento de novas espécies (alto $G_{s}$ ).

Devemos lembrar que a interação do modelo de Axelrod é local: um agente interage com o seu vizinho mais próximo. Se esses agentes compartilham de um traço cultural comum, a probabilidade de interação $P_{i, j}$ é maior que zero e pode haver troca de informação entre eles. Como o estado final é caracterizado por domínios que fazem fronteiras um com os outros, há duas opções para um par agente-vizinho qualquer:

- ambos pertencem ao mesmo aglomerado (portanto, possuem o mesmo vetor cultural), fazendo parte da mesma espécie;

- ambos pertencem a aglomerados diferentes (portanto, possuem vetores culturais diferentes). Nessa situação, os indivíduos (do par agente-vizinho) estarão marcados geneticamente se houve troca de informação entre eles em algum instante da dinâmica. Sendo esse o caso, podemos inferir que tais agentes passaram por um processo de especiação.

Através dos resultados mostrados na figura 6.6 vimos que é improvável o surgimento de duas espécies iguais a partir de indivíduos diferentes, o que corresponderia a um $G_{s}=0$ na curva Zero (sem marcação genética). Vimos também que o processo de especiação pode ser pautado por troca de informações genéticas entre seres de espécies diferentes, o que corresponde a um $G_{s}=1$ na curva $\mathbf{U m}$ (com marcação genética). Na verdade, observa-se fato semelhante em algumas subespécies diferentes de orquídea que, embora não estejam isoladas das demais, interagiram entre si e 
tornaram-se híbridas em relação às outras. Este é primeiro passo para a formação de uma nova espécie [85] e concorda com os resultados preliminares que apresentamos.

\subsubsection{Evolução dinâmica da atividade}

A definição apresentada na equação (3.1) permite o cálculo da atividade da rede em qualquer instante de tempo. Desse modo, podemos estudar a atividade do sistema durante a dinâmica que conduz ao estado estacionário. Para ilustrar essa dependência temporal e como curiosidade, nós apresentamos na figura 6.7 alguns resultados preliminares sobre o comportamento da atividade $\langle a(t)\rangle$ (média da atividade por agente $a_{i}(t)$ sobre todos os agentes $i$ da rede e sobre $M=30$ simulações) em função de $Q$ (para $L=100$ e $t=10,10^{2}, 10^{3}, 10^{4}, 10^{5}$ ). Podemos observar que os resultados de $\langle a(t)\rangle$ tendem a revelar uma separação entre duas fases conforme $t$ aumenta. Para $t \sim T$, o comportamento da atividade média tende a ser similar ao comportamento do parâmetro de ordem $\langle A\rangle$ em função de $Q$ apresentado na figura 3.1.

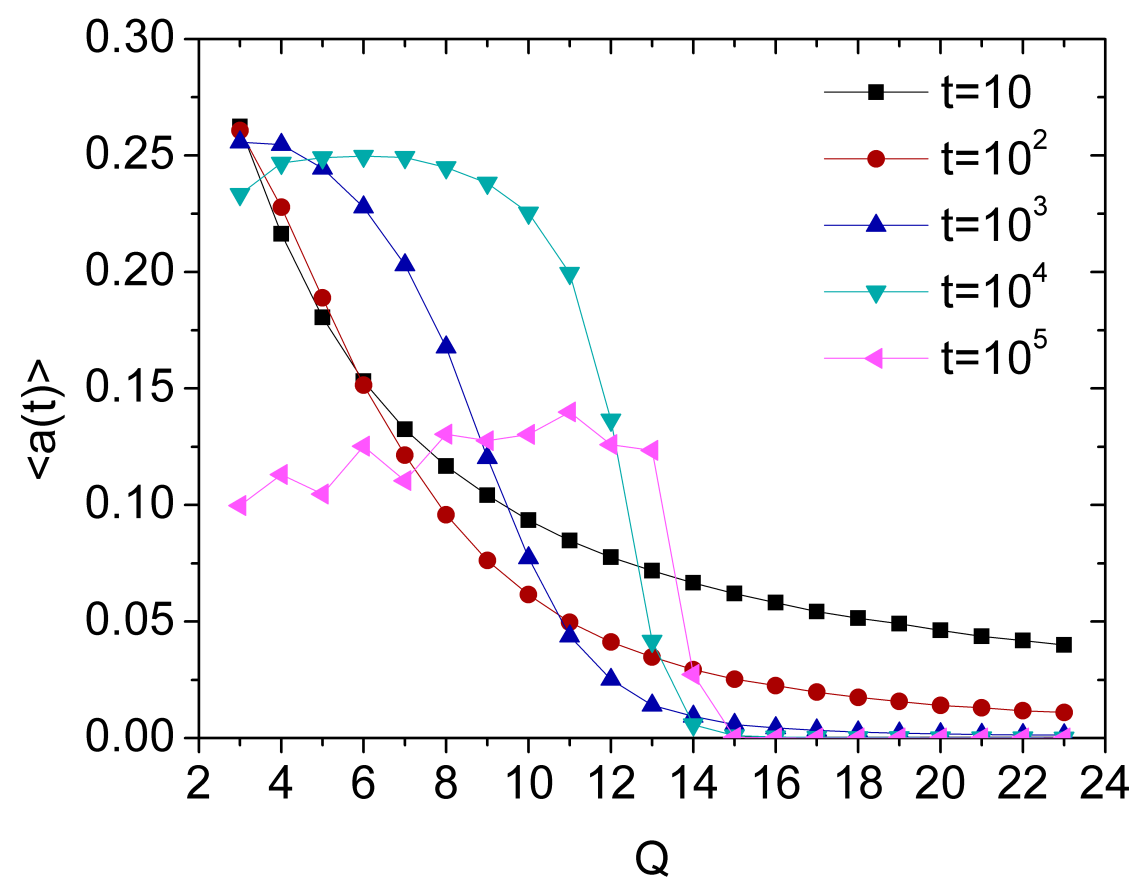

Figura 6.7: Atividade média $\langle a(t)\rangle$ em função de $Q$ para cinco instantes de tempo $t$ diferentes. Os resultados foram obtidos em uma rede quadrada com $L=100 \mathrm{e}$ $M=30$. 
Esses resultados são interessantes e uma investigação detalhada do comportamento dinâmico da atividade, tal como a dependência $a(t)$ em função de $t$ para $Q<Q_{c}, Q=Q_{c}$ e $Q>Q_{c}$, podem nos conduzir a um outro estudo.

\subsection{Conclusões gerais}

Nesta tese, estudamos a formação de grupos culturais através da utilização do modelo de Axelrod. Para isso, propusemos a atividade como parâmetro de ordem, estimamos o diagrama de fases para o modelo em uma rede quadrada e introduzimos agentes persistentes para mimetizar efeitos de mídia interna. A despeito da simplicidade do modelo, vimos que a modelagem vetorial baseada em agentes proposta por Axelrod exibe propriedades não-triviais que oferecem insights sobre fenômenos encontrados em uma sociedade de indivíduos interagentes. A caráter de exemplo, citamos a fragmentação cultural observada na configuração final quando $Q>Q_{c}$. Esse resultado sugere que nunca haverá um pensamento uníssono em uma sociedade cujos indivíduos possuem uma grande opção de escolha comportamental. Também merece destaque o efeito que a mídia exerce nos indivíduos de uma sociedade. Curiosamente, a exposição à influência midiática resulta em um efeito desagregador de opiniões e de comunidades. Extrapolando para o contexto das mídias sociais, podemos então compreender as reações adversas (como as publicadas pelos haters) encontradas nos comentários de qualquer informação em websites e nas redes sociais.

É nesse sentido que a proposta do parâmetro atividade tem sua importância revelada. Os seres humanos são animais hiper-sociáveis. Em [86], Herrmann et al. propõem o conceito de inteligência cultural para explicar o sucesso evolutivo de nossa espécie. Através de experimentos com chimpanzés, orangotangos e crianças de 2,5 anos que não tiveram educação formal, os autores mostraram que as crianças e os chimpanzés possuem o mesmo nível de habilidades cognitivas para resolver problemas do mundo físico. A pequena diferença, e que faz toda a diferença, reside nas habilidades cognitivas das crianças e dos chimpanzés para lidar com o mundo social. De acordo com os autores, essa habilidade social é o principal fator que torna os seres humanos diferentes dos parentes primatas com quem compartilham até $99 \%$ do código genético [87]. 
Em nossa sociedade, as interações com outros da mesma espécie se dá através da identificação de características (ou objetivos) em comum. Esse comportamento fica mais evidente quando observamos a formação de "tribos urbanas". De acordo com [88], as tribos urbanas "são grupos formados nas cidades, mais comumente nas metrópoles, os quais compartilham hábitos, valores culturais, estilos musicais e/ou ideologias políticas semelhantes". Como exemplo, temos as tribos dos góticos, dos punks, dos rockeiros, dos emos, entre outros. Como um grupo social, as tribos esperam certos comportamentos típicos de seus membros. Os resultados referentes à utilização da atividade como ferramenta indica que grupos maiores demandam mais esforços de seus membros para serem mantidos. O mesmo raciocínio pode ser estendido para os mais diversos tipos de comunidades ou grupos sociais. Nesse sentido, uma reunião de condomínio que conta com a presença de muitos condôminos, por exemplo, pode se tornar um verdadeiro campo de batalha.

Como ressaltado por Stix em [89], o que nos diferencia dos demais animais é a nossa capacidade de compreender os sinais subjetivos dos companheiros e a possibilidade de interagir e trabalhar em grupo em busca de um bem maior (seja alimento, abrigo, ou qualquer outra coisa de interesse comum). $\mathrm{O}$ desenvolvimento do ser humano em sociedade favoreceu o surgimento de ferramentas simbólicas complexas como a linguagem e a matemática. Essas ferramentas permitiram uma melhor conexão entre os seres da nossa espécie e reforçou ainda mais a capacidade colaborativa. Como exemplo, temos construções complexas como a Torre Eiffel, o Large Hadron Collider (LHC) e muitos outros monumentos que só são encontrados ao nosso redor por causa das ações colaborativas entre membros de nossa espécie.

Por isso, o estudo do processo de formação (ou não) de um consenso é importante: apesar da nossa capacidade de cooperação e de trabalho em grupo, e das tentativas dos meios de comunicação de uniformizar o pensamento popular, sempre haverá dissenso na sociedade enquanto os indivíduos puderem (e esperamos que sempre possam!) escolher livremente suas opiniões. 


\section{Referências Bibliográficas}

[1] Lionel S. Penrose. The elementary statistics of majority voting. Journal of the Royal Statistical Society 109, 53 (1946).

[2] Gordon Tullock. Problems of majority voting. Journal of Political Economy 67, 571 (1959).

[3] James M. Buchanan. Simple majority voting, game theory, and resource use. The Canadian Journal of Economics and Political Science / Revue canadienne d'Economique et de Science politique 27, 337 (1961).

[4] Wolfgang Weidlich. The statistical description of polarization phenomena in society. British Journal of Mathematical and Statistical Psychology 24, 251 (1971).

[5] Richard A. Holley e Thomas M. Liggett. Ergodic theorems for weakly interacting infinite systems and the voter model. The Annals of Probability 3, 643 (1975).

[6] Ivan Dornic, Hugues Chaté, Jérôme Chave, e Haye Hinrichsen. Critical coarsening without surface tension: The universality class of the voter model. Physical Review Letters 87, 045701 (2001).

[7] Claudio Castellano, Santo Fortunato, e Vittorio Loreto. Statistical physics of social dynamics. Reviews of Modern Physics 81, 591 (2009).

[8] Ernest Ising. Beitrag zur theorie des ferromagnetismus. Zeitschrift für Physik 31, 253 (1925). 
[9] Tsung-Dao Lee e Chen N. Yang. Statistical theory of equations of state and phase transitions. ii. lattice gas and ising model. Physical Review 87, 410 (1952).

[10] Serge Galam e Serge Moscovici. Towards a theory of collective phenomena: Consensus and attitude changes in groups. European Journal of Social Psychology 21, 49 (1991).

[11] Thomas M. Liggett. Interacting Particle Systems. Springer-Verlag New York (1985).

[12] Tânia Tomé, Mário J. de Oliveira, e Maria A. Santos. Non-equilibrium ising model with competing glauber dynamics. Journal of Physics A: Mathematical and General 24, 3677 (1991).

[13] Sandro M. Reia. Transições de fase e processos de nucleação no espaço de regras de autômatos celulares. Dissertação de mestrado, Universidade de São Paulo (2011).

[14] Sandro M. Reia e Osame Kinouchi. Nonsynchronous updating in the multiverse of cellular automata. Physical Review E 91, 042110 (2015).

[15] Mário J. de Oliveira. Isotropic majority-vote model on a square lattice. Journal of Statistical Physics 66, 273 (1992).

[16] Kurt Binder. Finite Size Scaling and Numerical Simulation of Statistical Systems, chapter IV. Some Recent Progress In The Phenomenological Theory Of Finite Size Scaling And Application To Monte Carlo Studies Of Critical Phenomena, pages 173-224. World Scientific Publishing (1990).

[17] Peter Nightingale. Finite-size scaling and phenomenological renormalization (invited). Journal of Applied Physics 53, 7927 (1982).

[18] Michael E. Fisher e Michael N. Barber. Scaling theory for finite-size effects in the critical region. Physical Review Letters 28, 1516 (1972).

[19] Kurt Binder e David P. Landau. Finite-size scaling at first-order phase transitions. Physical Review B 30, 1477 (1984). 
[20] Ubiraci P. C. Neves. Processos de Polimerização e Transição de Colapso em Polímeros Ramificados. Tese de doutorado, Instituto de Física de São Carlos, Universidade de São Paulo (1997).

[21] Shan-Ho Tsai e Silvio R. Salinas. Fourth-order cumulants to characterize the phase transitions of a spin-1 ising model. Brazilian Journal of Physics 28, 58 (1998).

[22] David P. Landau. Finite Size Scaling and Numerical Simulation of Statistical Systems, chapter V. Monte Carlo Studies Of Finite Size Effects At First And Second Order Phase Transitions, pages 225 - 260. World Scientific Publishing (1990).

[23] James J. Binney, Nigel J. Dowrick, Andrew J. Fisher, e Mark E. J. Newman. The Theory of Critical Phenomena. Oxford University Press (1992).

[24] Géza Ódor. Universality classes in nonequilibrium lattice systems. Reviews of Modern Physics 76, 663 (2004).

[25] José F. F. Mendes e Maria A. Santos. Short-time dynamics of a two-dimensional majority vote model. Physical Review E 57, 108 (1998).

[26] Wagner Figueiredo e Bartira C. S. Grandi. Competing spin dynamics in ising systems. Brazilian Journal of Physics 30, 58 (2000).

[27] Abel G. da Silva Filho e Francisco G. Brady Moreira. Dynamical critical exponent for the majority-vote model. Journal of Statistical Physics 106, 391 (2002).

[28] Paulo R. A. Campos, Viviane M. de Oliveira, e Francisco G. Brady Moreira. Small-world effects in the majority-vote model. Physical Review E 67, 026104 (2003).

[29] Francisco W. S. Lima, Umberto L. Fulco, e Raimundo N. Costa Filho. Majorityvote model on a random lattice. Physical Review E 71, 036105 (2005).

[30] Harry E. Stanley. Scaling, universality, and renormalization: Three pillars of modern critical phenomena. Reviews of Modern Physics 71, S358 (1999). 
[31] Per Bak e Chao Tang. Earthquakes as a self-organized critical phenomenon. Journal of Geophysical Research 94, 15635 (1989).

[32] Per Bak, Kan Chen, e Michael Creutz. Self-organized criticality in the 'game of life". Nature 342, 780 (1989).

[33] Stephen Wolfram. Cellular automata as models of complexity. Nature 311, 419 (1984).

[34] Wentian Li, Norman H. Packard, e Chris G. Langton. Transition phenomena in cellular automata rule space. Physica D: Nonlinear Phenomena 45, 77 (1990).

[35] Sandro M. Reia e Osame Kinouchi. Conway's game of life is a near-critical metastable state in the multiverse of cellular automata. Physical Review E 89, 052123 (2014).

[36] Thomas A. Witten e Leonard M. Sander. Diffusion-limited aggregation, a kinetic critical phenomenon. Physical Review Letters 47, 1400 (1981).

[37] Per Bak, Chao Tang, e Kurt Wiesenfeld. Self-organized criticality: An explanation of the $1 / f$ noise. Physical Review Letters 59, 381 (1987).

[38] Per Bak, Chao Tang, e Kurt Wiesenfeld. Self-organized criticality. Physical Review A 38, 364 (1988).

[39] Iram Gleria e Raul Matsushita. Sistemas complexos, criticalidade e leis de potência. Revista Brasileira de Ensino de Física 26, 99 (2004).

[40] Claudio Castellano, Matteo Marsili, e Alessandro Vespignani. Nonequilibrium phase transition in a model for social influence. Physical Review Letters 85, 3536 (2000).

[41] Claudio Castellano, Daniele Vilone, e Alessandro Vespignani. Incomplete ordering of the voter model on small-world networks. EPL (Europhysics Letters) 63, 153 (2003).

[42] Quentin Michard e Jean-Philippe Bouchaud. Theory of collective opinion shifts: from smooth trends to abrupt swings. The European Physical Journal B Condensed Matter and Complex Systems 47, 151 (2005). 
[43] Juan C. González-Avella, Victor M. Eguíluz, Mario G. Cosenza, Konstantin Klemm, Jose L. Herrera, e Maxi San Miguel. Local versus global interactions in nonequilibrium transitions: A model of social dynamics. Physical Review E 73, 046119 (2006).

[44] Andrew Adamatzky. Game of Life Cellular Automata. Springer Publishing Company, Incorporated, 1st edition (2010).

[45] Bela Suki, Albert-Laszlo Barabasi, Zoltán Hantos, Ferenc Peták, e Harry E. Stanley. Avalanches and power-law behaviour in lung inflation. Nature 368, 615 (1994).

[46] Terry R. J. Bossomaier e David G. Green. Complex systems. Cambridge university press (2000).

[47] Petter Holme e Mark E. J. Newman. Nonequilibrium phase transition in the coevolution of networks and opinions. Physical Review E 74, 056108 (2006).

[48] Robert Axelrod. The dissemination of culture: A model with local convergence and global polarization. The Journal of Conflict Resolution 41, 203 (1997).

[49] Roland Bulirsch e Josef Stoer. Fehlerabschätzungen und extrapolation mit rationalen funktionen bei verfahren vom richardson-typus. Numerische Mathematik 6, 413 (1964).

[50] Malte Henkel e Gunter Schütz. Finite-lattice extrapolation algorithms. Journal of Physics A: Mathematical and General 21, 2617 (1988).

[51] Sandro M. Reia e Ubiraci P. C. Neves. Activity of a social dynamics model. Physica A: Statistical Mechanics and its Applications 435, 36 (2015).

[52] Hendrik J. Blok e Birger Bergersen. Effect of boundary conditions on scaling in the "game of life". Physical Review E 55, 6249 (1997).

[53] Lucas R. Peres e José F. Fontanari. Effect of external fields in axelrod's model of social dynamics. Physical Review E 86, 031131 (2012). 
[54] Juan C. González-Avella, Mario G. Cosenza, e Kay Tucci. Nonequilibrium transition induced by mass media in a model for social influence. Physical Review E 72, 065102 (2005).

[55] Yerali Gandica, Alejandro Charmell, Juan Villegas-Febres, e Ismardo Bonalde. Cluster-size entropy in the axelrod model of social influence: Small-world networks and mass media. Physical Review E 84, 046109 (2011).

[56] Dietrich Stauffer e Amnon Aharony. Introduction to Percolation Theory. Oxford University Press, New York (1971).

[57] Konstantin Klemm, Víctor M. Eguíluz, Raúl Toral, e Maxi San Miguel. Nonequilibrium transitions in complex networks: A model of social interaction. Physical Review E 67, 026120 (2003).

[58] Joaquin Marro e Ronald Dickman. Nonequilibrium Phase Transitions in Lattice Models. Cambridge University Press (1999).

[59] Michael Gastner. Percolation theory. Em: http://wwwf.imperial.ac.uk/ mgastner/percolation/percolation.html. (Acesso em: 04/10/2015).

[60] Krzysztof Malarz e Serge Galam. Square-lattice site percolation at increasing ranges of neighbor bonds. Physical Review E 71, 016125 (2005).

[61] Daniele Vilone, Alessandro Vespignani, e Claudio Castellano. Ordering phase transition in the one-dimensional axelrod model. The European Physical Journal B - Condensed Matter and Complex Systems 30, 399 (2002).

[62] Konstantin Klemm, Víctor M. Eguíluz, Raúl Toral, e Maxi San Miguel. Role of dimensionality in axelrod's model for the dissemination of culture. Physica A: Statistical Mechanics and its Applications 327, 1 (2003).

[63] Raúl Toral e Claudio J. Tessone. Finite size effects in the dynamics of opinion formation. Communications In Computational Physics 2, 177 (2007).

[64] Konstantin Klemm, Víctor M. Eguíluz, Raúl Toral, e Maxi San Miguel. Global culture: A noise-induced transition in finite systems. Physical Review E 67, 045101 (2003). 
[65] Maxi San Miguel, Victor M. Eguíluz, Raul Toral, e Konstantin Klemm. Binary and multivariate stochastic models of consensus formation. Computing in Science and Engineering 7, 67 (2005).

[66] Juan C. González-Avella, Mario G. Cosenza, e Kay Tucci. Nonequilibrium transition induced by mass media in a model for social influence. Physical Review E 72, 065102 (2005).

[67] Lucas R. Peres e José F. Fontanari. The mass media destabilizes the cultural homogeneous regime in axelrod's model. Journal of Physics A: Mathematical and General 43, 055003 (2010).

[68] Lucas R. Peres e José F. Fontanari. The media effect in axelrod's model explained. EPL (Europhysics Letters) 96, 38004 (2011).

[69] Haye Hinrichsen e Hari M. Koduvely. Numerical study of local and global persistence in directed percolation. The European Physical Journal B - Condensed Matter and Complex Systems 5, 257 (1998).

[70] Domenico Parisi, Federico Cecconi, e Francesco Natale. Cultural change in spatial environments: The role of cultural assimilation and internal changes in cultures. The Journal of Conflict Resolution 47, 163 (2003).

[71] Joseph Hoshen e Raoul Kopelman. Percolation and cluster distribution. I. Cluster multiple labeling technique and critical concentration algorithm. Physical Review B 14, 3438 (1976).

[72] Lucas R. Peres e José F. Fontanari. Statistics of opinion domains of the majority-vote model on a square lattice. Physical Review E 82, 046103 (2010).

[73] Malte Henkel. Conformal Invariance and Critical Phenomena. Springer (1999).

[74] Yasufumi Shibanai, Satoko Yasuno, e Itaru Ishiguro. Effects of global information feedback on diversity: Extensions to axelrod's adaptive culture model. The Journal of Conflict Resolution 45, 80 (2001). 
[75] Karina I. Mazzitello, Julián Candia, e Víctor Dossetti. Effects of mass media and cultural drift in a model for social influence. International Journal of Modern Physics C 18, 1475 (2007).

[76] Vladimir Dobrosavljevic, Nandini Trivedi, e James M. Valles Jr.. Conductor Insulator Quantum Phase Transitions. Oxford University Press, Oxford (2012).

[77] Sandro M. Reia e Ubiraci P. C. Neves. Persistent agents in Axelrod's social dynamics model. EPL (Europhysics Letters) 113, 18003 (2016).

[78] Simon R. Broadbent e John M. Hammersley. Percolation processes. In Mathematical Proceedings of the Cambridge Philosophical Society, volume 53, page 629. Cambridge Univ Press (1957).

[79] Geoffrey Grimmet. Percolation. Springer-Verlag, 2 edition (1999).

[80] Ubiraci P. C. Neves. Percolação direcionada em redes regulares bidimensionais. Dissertação de mestrado, Universidade de São Paulo (1992).

[81] Charles Darwin. The origin of species. John Murry London (1929).

[82] James D. Watson, Francis H. C. Crick, et al.. Molecular structure of nucleic acids. Nature 171, 737 (1953).

[83] Michael Bamshad e Stephen P Wooding. Signatures of natural selection in the human genome. Nature Reviews Genetics 4, 99 (2003).

[84] John A Endler. Geographic variation, speciation, and clines. Number 10. Princeton University Press (1977).

[85] Carlos Fioravanti. Os primeiros passos de novas espécies. Pesquisa FAPESP 212, 18 (2013).

[86] Esther Herrmann, Josep Call, María Victoria Hernández-Lloreda, Brian Hare, e Michael Tomasello. Humans have evolved specialized skills of social cognition: The cultural intelligence hypothesis. Science 317, 136 (2007). 
[87] The Chimpanzee Sequencing, Analysis Consortium, et al. Initial sequence of the chimpanzee genome and comparison with the human genome. Nature 437, 69 (2005).

[88] Tribos urbanas. Em: http://www.todamateria.com.br/tribos-urbanas/. (Acesso em: 01/10/2015).

[89] Gary Stix. O fator x. Scientific American Brasil 149, 62 (2014). 